\title{
PASSIVE ACOUSTIC DETECTION OF A SMALL REMOTELY OPERATED VEHICLE
}

\author{
A THESIS SUBMITTED TO THE GRADUATE DIVISION OF \\ THE UNVERSITY OF HAWAI'I AT MĀNOA IN PARTIAL \\ FULFILLMENT OF THE REQUIREMENTS FOR THE \\ DEGREE OF
}

MASTER OF SCIENCE

IN

MECHANICAL ENGINEERING

AUGUST 2011

\author{
By \\ Meng Cai \\ Thesis Committee: \\ Brian Bingham, Chairperson \\ John S. Allen \\ Reza Ghorbani
}

Keywords: Acoustic Signature, Passive Detection, ROV, Hydrophone, Data Acquisition 


\section{ABSTRACT}

This project quantifies the feasibility of passive acoustic detection of a small commercial off-the-shelf (COTS) remotely operated vehicle (ROV) by experimentally characterizing the acoustic signature and hydrodynamic flow associated with the motion of ROV.

Three experiments are conducted as parts of this characterization in this project. These trials are conducted in a small laboratory test tank, a larger outdoor test tank and a shallow-water coastal ocean environment. The laboratory tank test consists of a stationary hydrophone to detect the acoustic emissions, while simultaneously measuring the flow field using particle image velocimetry (PIV) system. Based on a variety of maneuvers in the test tank, the experiments are quantified by the acoustic signatures of the ROV. Also, we predict the capabilities of acoustically detecting an ROV in typical ocean environments such as shallow-water, ports and harbors, and deep-ocean environment. In addition, this thesis reports the results of a series of underwater detection trials in the field to verify the laboratory demonstration and analytical moderns. The intention is to experimentally measure the signal-to-noise ratio (SNR) of the ROV acoustic signature, as a function of distance between the ROV and acoustic receivers in the shallow-water ocean environment.

On the basis of experimental analysis, we present that the most significant contribution for ROV acoustic detection is from electric motors with signal frequency range of around 400-500 $\mathrm{Hz}$. The detectable distance range with ambient noise at $116 \mathrm{~dB}$ re $1 \mathrm{uPa}$ is between $15 \mathrm{~m}$ and $22 \mathrm{~m}$ away in a noisy littoral environment. Combined with the experimental analysis, we state the comparison between the acoustic predicted levels of the ROV with the measured results.

Finally, this project demonstrates the feasibilities of acoustical detection of a small ROV in the port environment. As a result, we conclude the experimental studies with later highlights and future research. 


\section{DEDICATION}

To my dearest dad, mom and the whole family

Who love me and support me unconditionally 


\section{ACKNOWLEDGMENTS}

I own my deepest gratitude to my advisor, Dr. Brian Bingham. He provided me with support, encouragement and guidance during my M.S. study. His vision and insightful thoughts have always thrown me light when I went into a dark end. He is more than an excellent advisor, he is a good mentor and role model. Dr. Brian, I am honored to be your first Master student!

My special thanks go to Dr. John Allen and his two Post-doctors In-Mei Sou and Chris Layman, one graduate student Tyler Hee Wai. They gave me tremendous help during my experimental studies. They helped me to set up the experimental instruments and provided me insightful guidance and suggestion. Without them, I cannot touch that far. Thanks so much for their patience and attention all the time.

I would also like to show my great appreciation to Dr. Reza, thanks for serving on my committee and for his great "Renewable Energy" graduate course which I really enjoyed in my Spring 2010 semester. I want to thank Dr. Sanyal, I am happy to take his "Rigid Body dynamic and Control" course and work as a Teaching Assistant for his "dynamic systems laboratory" course. I believe I have a great improvement after those trainings. I want to thank Dr. Bruce and Dr. Eva for their graduate courses in the department of Ocean and Resources Engineering (ORE). They are quite significant and useful to guide me through unknown oceanography fields.

I want to express my great appreciation to the Field Robotics Laboratory. Thanks a lot for every member in the laboratory: Tony, Nick, Vincent, Jon, Matt and Amanda. Thanks for all spending time with me in the lab and making our life more vibrant as parts of hard work.

Last but not least, I want to express my best sincerely and honorable thankful to my best friends, Dr. Tom Humphreys, Daniel Fan, Xiaofeng Kang, Kyl Bikowski, Yang Lei, and Yong Shi, who cheered me up when I was sad and took care of me when I felt sick.

All of you made my life in Honolulu, Hawaii more exciting and colorful. 


\section{CONTENTS}

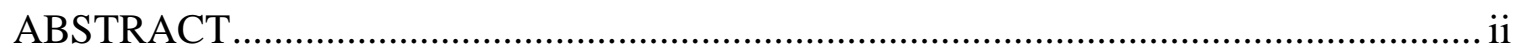

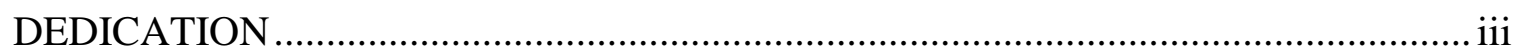

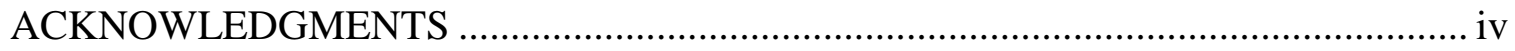

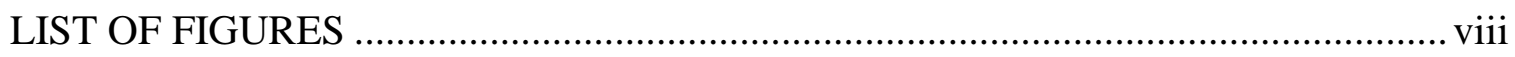

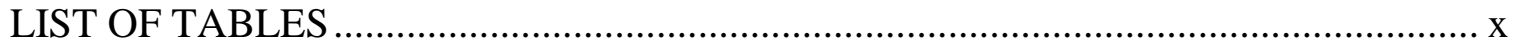

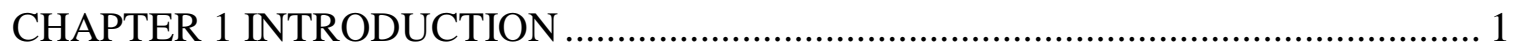

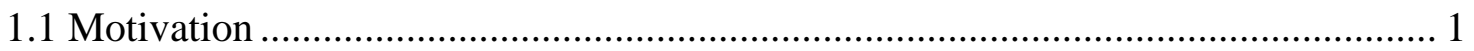

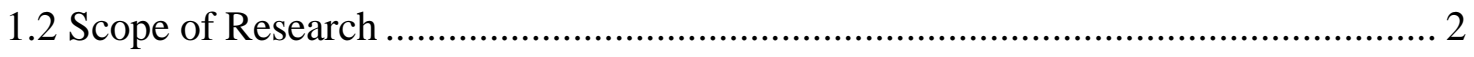

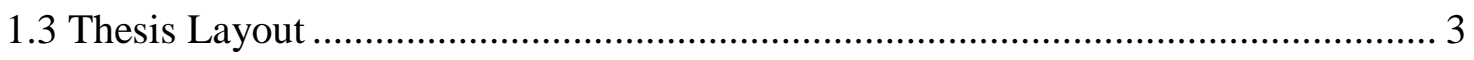

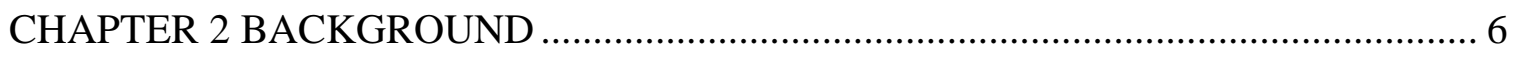

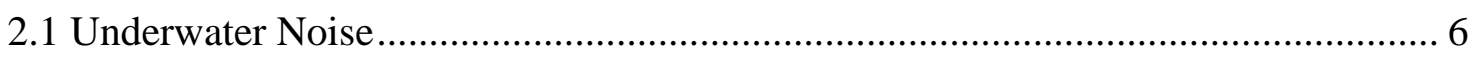

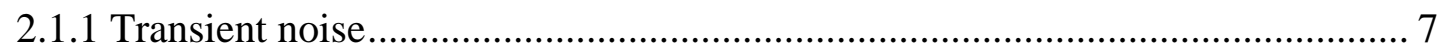

2.1.2 Ambient noise ................................................................................. 7

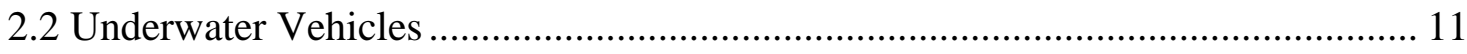

2.2.1 Autonomous Underwater Vehicle ......................................................... 11

2.2.2 Remotely Operated Vehicle................................................................. 12

2.3 Active and Passive Acoustic Detection............................................................... 13

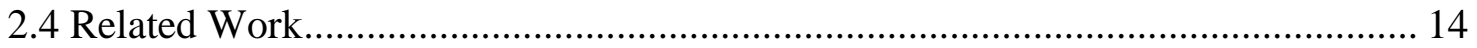

2.4.1 Divers and Underwater Animals Passive Detection..................................... 14 
2.4.2 Surface Vessels and Ships Passive Detection. 14

2.4.3 Completed Seaside Surveillance System.................................................. 15

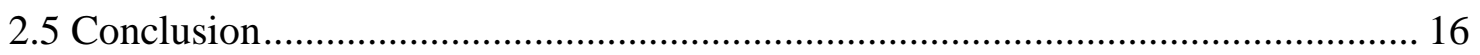

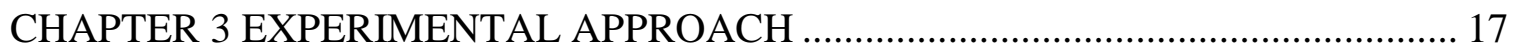

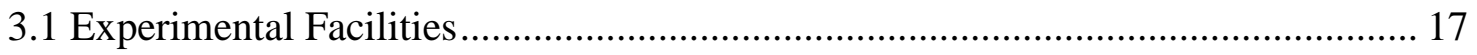

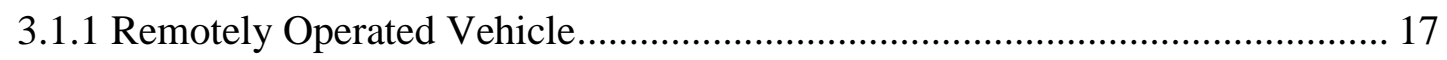

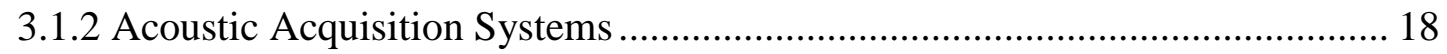

3.1.3 Particle Image Velocimetry System ….................................................. 22

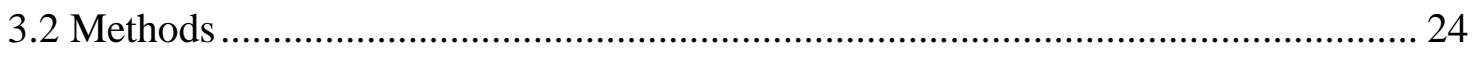

3.2.1 Model mathematical models to predict capabilities of passive detection ........ 24

3.2.2 Experimental evaluated the acoustic signature of the ROV in the tank .......... 30

3.2.3 Experimental evaluated the passive detection in shallow-water environment. 31

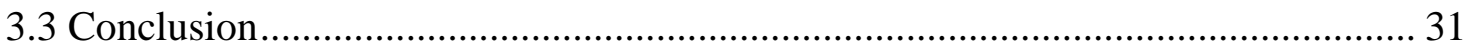

CHAPTER 4 ACOUSTIC DETECTION EXPERIMENTS ....................................... 32

4.1 LABORATORY TANK EXPERIMENT ........................................................ 32

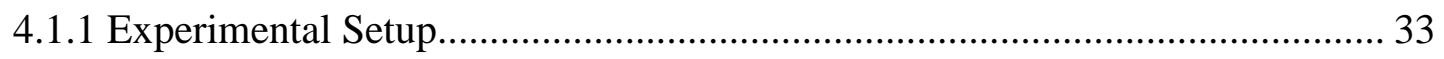

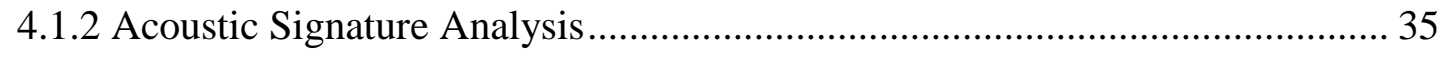

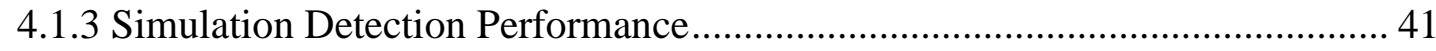

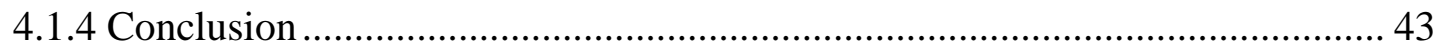

4.2 OUTDOOR TANK EXPERIMENT ............................................................ 44

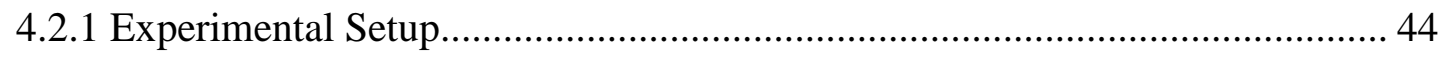




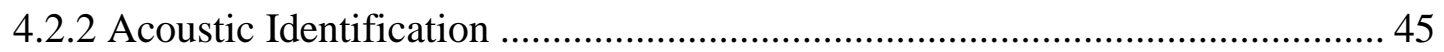

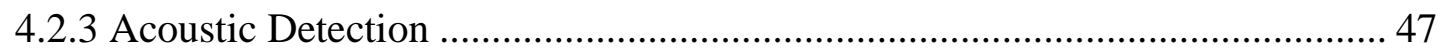

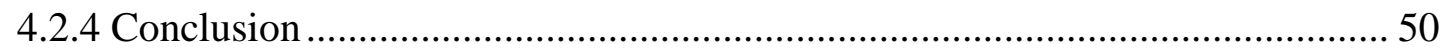

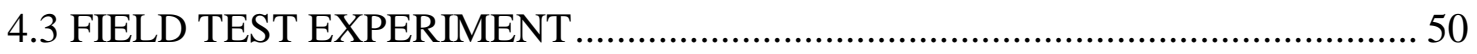

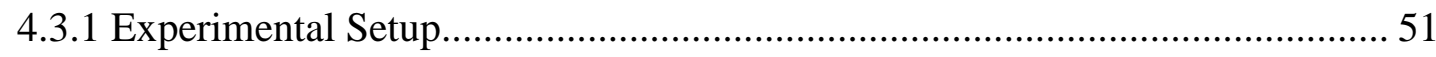

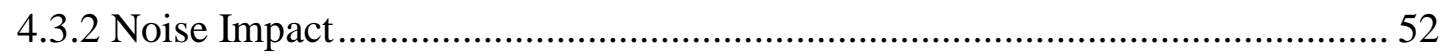

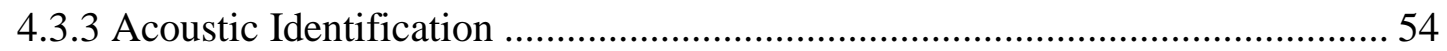

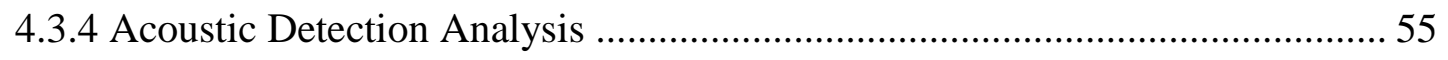

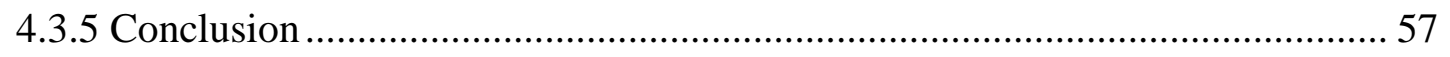

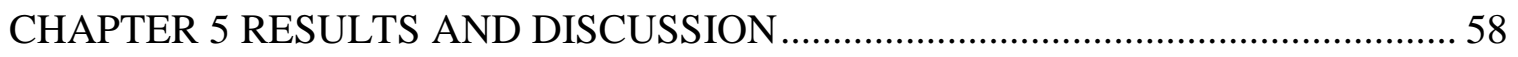

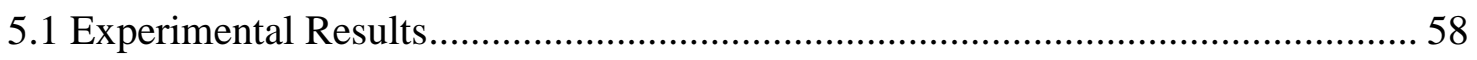

5.2 Prediction and Measurement of Acoustic Signals.................................................. 59

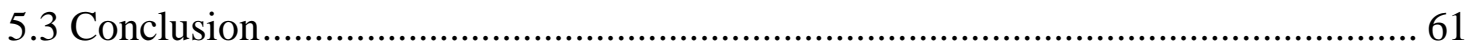

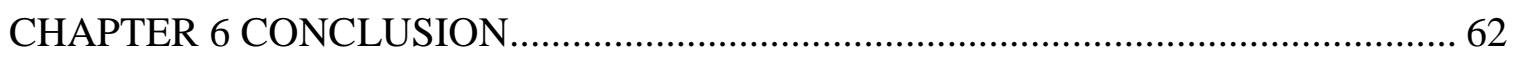

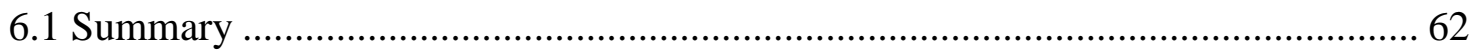

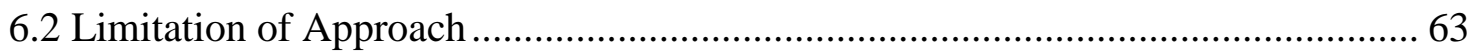

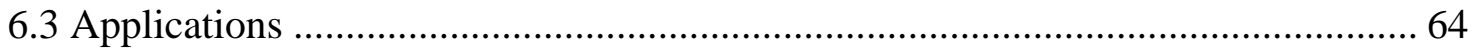

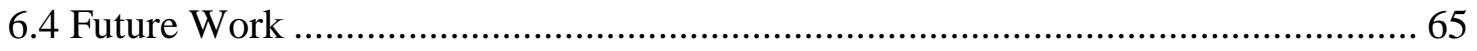

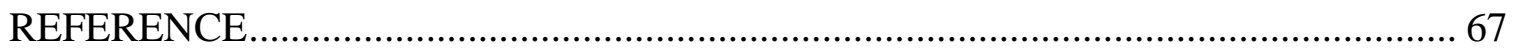

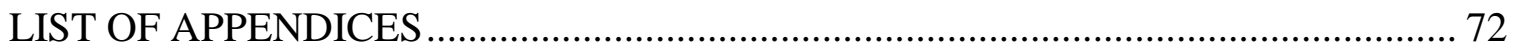




\section{LIST OF FIGURES}

Figure.2.1. Wenz Curves of ambient noise............................................................ 10

Figure 2.2. A summary of noise levels in bays and harbors ........................................... 11

Figure 2.3. Autonomous Underwater Vehicle (REMUS 100, Hydroid, Inc) ................... 12

Figure 2.4. Remotely Operated Vehicle (Jason II, WHOI) ............................................. 13

Figure 3.1. SeaBotix LBV 150 (San Diego, CA)......................................................... 18

Figure 3.2. The diagram of Hydrophone Type 8103 (Norcross, GA).............................. 19

Figure 3.3. Aquarian Audio Products H1a Hydrophone (Anacortes, WA) ...................... 19

Figure 3.4. The image of Voltage Preamplifier EC 6081/VP 2000 (Goleta, CA) ............ 21

Figure 3.5. Personal Daq/3000 Series (Cleveland, $\mathrm{OH}$ ) …............................................. 22

Figure 3.6. Fluorescent Particles-data Processing ............................................................ 23

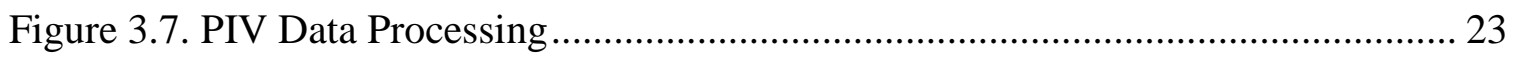

Figure 3.8. Schematic diagram of acoustic signature with ambient noise........................ 25

Figure 4.1. Acoustic and PIV flow measurements of ROV in a clear acrylic tank .......... 32

Figure 4.2. The ROV and aft hydrophone placement with laser irradiation..................... 33

Figure 4.3. A simplified diagram of the PIV systems.................................................... 34

Figure 4.4. PIV Image-based measurements ........................................................... 35

Figure 4.5. A comparison of the signature from moving and stationary ROVs when

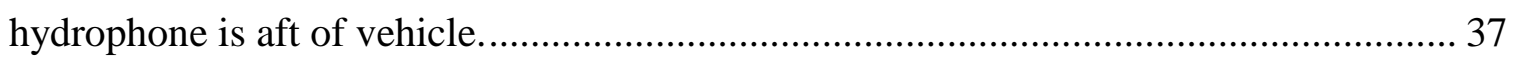

Figure 4.6. The instantaneous velocity field superimposes with the PIV raw image ....... 38 
Figure 4.7. Velocity field with the PIV raw image in 0.8 second lag. 38

Figure 4.8. The comparison of the acoustic signatures when hydrophone is in front and aft of a stationary ROV

Figure 4.9. The comparison of background noise and ROV signature with propellers.... 40

Figure 4.10. The comparison of background noise and ROV signature without propellers

Figure 4.11. Experiment setup in the circular tank at Univ. of Hawaii Marine Center... 45

Figure 4.12. The comparison of background noise and mechanical noise when ROV was

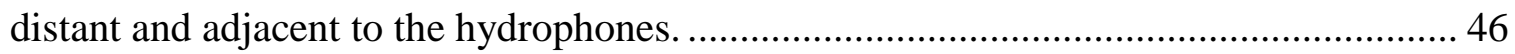

Figure 4.13. Time and frequency spectrogram of the comparison of acoustic signature when ROV was running in stationary condition close to left hydrophone ...................... 47

Figure 4.14. Time and frequency spectrogram of moving ROV across the circular tank 48

Figure 4.15. The field test conducted at Makai Pier, Oahu, Hawaii............................... 52

Figure 4.16. Ambient noise in field tests recorded for 60 seconds .............................. 53

Figure 4.17. ROV acoustic signature in field test 4 recorded for 120 seconds................ 55

Figure 4.18. Experimental data of four trial runs.................................................... 56

Figure 5.1. The comparison of different acoustic tests when stationary ROV was running 59

Figure 5.2. The comparison of acoustic signal prediction and measurement .................. 60 


\section{LIST OF TABLES}

TABLE I. The summary of ambient noise level versus frequency................................ 9

TABLE II. Description of the experimental trials and the corresponding acoustic

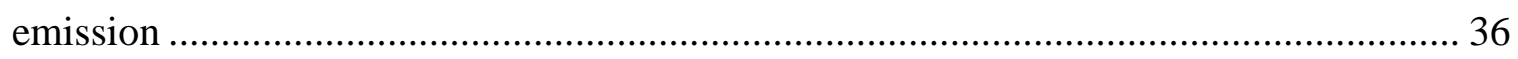

TABLE III. The summary of modeled signal propagation in three typical environments

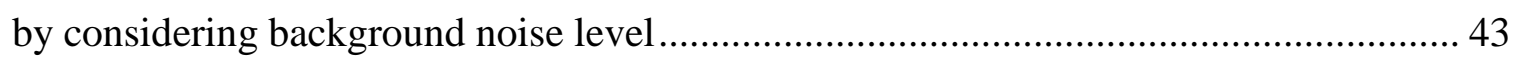

TABLE IV. Experimental ROV motion in the outdoor tank .................................... 48 


\section{CHAPTER 1}

\section{INTRODUCTION}

As terrorism threats become more technologically advanced and better funded, the security of ports and harbors continues to be of increasing interests to defense agencies. Such advanced processes lead to a brand new problem: homeland security threats, which are imperative and meaningful to modern society securities [1]. A variety of commercial and military systems exist for active diver detection, but the emergence of low-cost, readily available underwater robotic platform for delivering explosives is a distinct potential threat to port facilities. The goal of this work is to assess the feasibility of passive acoustic detection of such robot-based threats to port and harbor security.

\subsection{Motivation}

For the Department of Homeland Security (DHS), the further exploration of new technologies related to maritime domain awareness (MDA) is an important and special area.

In the early 2007, the DHS issued a Broad Agency Announcement (BAA) soliciting proposals [2] to establish the Center of Excellence for Maritime Security, Island and Remote Environment Security (CIMES) and the National Center for Secure \& Resilient Maritime Commerce (CSR). DHS selects University of Hawaii and Stevens Institute of Technology to co-lead both centers. They are responsible for conducting research and developing new technologies to strengthen MDA, safeguard populations and properties unique to U.S. homeland security [2]. University of Hawaii at Manoa, Honolulu, Hawaii, conducts further research and education for maritime and island security. Stevens 
Institute of Technology, Hoboken, New Jersey, guides further research and education for port security.

One challenging aspect of MDA is underwater surveillance in maritime environments such as ports and harbors, and other maritime environments. The potential threats on the surface and underwater for ports and harbors include divers [3], small vessels [4], river boats [5], ships, underwater animals, submarine and also some new concerns such as Unmanned Surface Vehicle (USV), Autonomous Underwater Vehicle (AUV) and Remotely Operated Vehicles (ROV). These threats are exacerbated by the emergence of low cost and readily available underwater robotic platforms, which are capable of delivering explosives (or other hazards) within port facilities. Many existing technologies are effective in acoustically detecting surface and underwater vessels [6], [7]. Meanwhile, these issues are becoming a worldwide concern for developing marine security and operation systems.

Based on previous understanding [8], [9], the abilities to detect underwater threats, continue to be the issues of growing interest with the increasing concerns of detrimental

effects on the marine environment. The method of passive acoustic detection for security threats is still a significant topic for further research and development.

\subsection{Scope of Research}

In order to protect the security of ports and harbors, solve these potential and existing threats, this project addresses passive acoustic methods to explore and detect underwater targets such as a ROV. The feasibility of passive acoustic detection in a cluttered harbor and a coastal environment remains an outstanding question, a limited number of previous studies and projects [10], [11], have addressed these questions. For the overview of background and previous work, Chapter 2 will detail the development process. 
My contributions to this project include characterizing the hydrodynamic flow associated with the motion of a small ROV and addressing the acoustic signature emitted from the ROV in the laboratory test. We use passive acoustic detection as a complement of current active detection for maritime research. This method quantifies the aspects of radiated noise from a small ROV and separates them to different sound levels such as flow noise, propeller noise, motor noise and propeller wash noise. After the comparison, we confirm the electric motor noise is the most significant factor for underwater detection.

In addition, this paper reports the results of a series of underwater detection trials in the field to verify the laboratory demonstrations. The goal of this project is able to experimentally and analytically measure the signal-to-noise ratio (SNR) of the ROV acoustic signature, as a function of distance between the ROV and acoustic receivers in the shallow-water ocean environments.

The next part of this project is in collaboration with CIMES for predicting the capabilities of acoustically detecting an ROV in typical ocean port environments. Combining the acoustic predicted levels with the experimental measured levels, we assesse those predicted methods and finally demonstrates the feasibilities of underwater acoustic detection in the actual marine environment.

\subsection{Thesis Layout}

My thesis is readily organized to describe the experimental process. For the rough idea and approximate understanding of this project, a brief guidance on the general layout of the thesis is presented as follows:

a) Chapter 2: Background. First, this chapter introduces underwater acoustic noise and presents the basic knowledge of acoustics and detection. Also, this chapter shows the general underwater devices and detection methods, addresses a brief comparison between active and passive methods for the application of underwater 
detection and navigation. Then, the chapter presents literature reviews in those particular fields and related technologies.

b) Chapter 3: Experimental Approach. This chapter introduces all the experimental facilities and presents the methodology of mathematical calculation. In addition with that, this chapter attends a detail at each component of the passive SONAR equations. The mathematical principles and the specific calculation processes are analyzed, the available simulation models are also built in this chapter.

c) Chapter 4: Acoustic Detection Experiments. This chapter details three experimental setups and methods, addresses the experimental results in different sections. They have been completed in the laboratory tank, the outdoor tank and shallow-water port environment. In Section 1, the indoor laboratory tank results include the acoustic signature characterization and experimental results of detection performance in three typical simulated environments: shallow coastal water, ports and harbors, and deep-ocean environment. Section 2 shows the outdoor tank results include the acoustic identification and acoustic detection data, which are the significant improvement to the indoor tank. In Section 3, the field test results include the actual acoustic detection trial of underwater ROV, which considers the measurement of ambient noise and transmission loss as a significant factor related to the characterization of acoustic detection.

d) Chapter 5: Results and Discussion. This chapter presents the special spectrograms and comparisons among three different experimental acoustic signatures. Through the analysis, this chapter discusses the experimental results by the feasibility analysis and performance evaluation. In addition, this chapter presents the precise comparison between prediction and actual measurements of acoustic signatures in the field.

e) Chapter 6: Conclusion. This chapter is a brief overview of the practical impacts for this research project. It summarizes the whole project and addresses the 
application of the acoustic detection technology. Finally, this chapter presents the conclusion with the later highlights and future research. 


\section{CHAPTER 2}

\section{BACKGROUND}

Acoustic detection is usually based on the signal transmission in the medium, which means to quantify the abilities to discern between signal and noise, or filter a faint signal from other noise [12]. Based on that, this technology can be used to detect targets in the complex environments such as gases (such as the atmosphere), liquids (such as the water), and solids (such as the earth) [13]. The research by detection is mostly based on the signal frequencies with the filtration of ambient noise and unrelated sounds. The density of seawater makes the possibility for acoustics to propagate between surface and bottom boundaries. In addition, the special frequency ranges of the signals from targets such as divers and underwater vehicles are characteristic for the ocean detection [14], [15]. Therefore, this project selects acoustical detection systems to identify the dominant acoustic sources and realize the underwater detection.

This chapter is started to present the brief introduction to underwater acoustics and states the overview of previous research and development.

\subsection{Underwater Noise}

The ocean has natural sources of background noise at the frequencies of interests. They are considered as the noise in signal-to-noise ratio (SNR), and would affect acoustic detection by raising the lowest amplitude level of the detectable signals. Background noise is loosely categorized into two types: transient noise and ambient noise. 
2.1.1 Transient noise. Transient noise is caused in the open-water environment like harbor and ocean [16], transient background noises have typical and characteristic time durations. There are numerous sources of noise in the oceans, many sources of them are hard to quantify due to the transitory in nature. They may only affect sound environments for short periods of time. These potential sources include but certainly not limited to:

(1) Human industrial sources ashore, particularly in coastal areas and ships.

(2) Biological factors including:

Mammals: a variety of whales and dolphins, - echolocation and communication.

Crustacean: snapping shrimp, - mostly in warm and shallow coastal areas.

(3) Weather - rain.

The noise is from the sea surface mostly impacted by rain drops and the implosion of air bubbles.

2.1.2 Ambient noise. It is considered as background noise at a specific location, normally specified as a reference level to study a new intrusive sound source. Here are the expected major sources of ambient noise in the ocean referred from [16].

\section{(1) Tides}

One of the contributions to ambient noise is the water flows due to tides, which can create large changes in ambient pressure of the ocean. These changes will be most significant at very low frequencies $(<100 \mathrm{~Hz})$ [17] but will be decreased in the power with the depth increased.

\section{(2) Seismic}

Another noise source in low frequency is due to the earth's seismic activity which dominates the frequencies below $10 \mathrm{~Hz}$. However, both tides and seismic sources are considered as insignificant for the calculation of ambient noise levels [17]. 


\section{(3) Turbulence}

Oceanic turbulence dominates the noise spectrum in ambient noise levels below 10 Hz. In fact, the calculation in the actual environment, the effect of turbulence will not be considered due to the small range of frequencies [17].

\section{(4) Ship Traffic}

Shipping noise is collected and heard from most places of the ocean, even if vessels are not seen in the vicinity. This is due to the long attenuation lengths at these frequencies and the heavy ship traffic around the world. In the North Atlantic, there are more than 1000 ships underway at any time. The noise from this shipping traffic can travel up to distances of 1000 miles [16]. Most dominant parts by man-made noise lie in the frequency range depending on the operating area and shipping densities.

\section{(5) Sea State}

The main source of noise is wind and waves at the surface of the ocean correlate to an oceanographic term called sea state [17], which is the dominant factor in calculating ambient noise levels between $0.5 \mathrm{kHz}$ and $50 \mathrm{kHz}$. Less the $10 \mathrm{~Hz}$, wind-generated turbulence induces pressure variations similar to acoustic pressure variations. Greater

than $100 \mathrm{~Hz}$, wind generated micro bubbles in the shallow water layers could burst and cause pressure changes.

\section{(6) Thermal Noise}

Thermal Noise [17] contributes to electronic noise generated by the thermal agitation and originated from molecular motion. It dominates the very high frequencies (>100 kHz) which are used by radios and wireless signals.

The following TABLE I shows the summary for the ambient noise levels to declassify in detail. 
TABLE II. Ambient Noise Level versus Frequency referred by [17], [45]

\begin{tabular}{|c|l|}
\hline Frequency & \multicolumn{1}{c|}{ Description } \\
\hline$<10 \mathrm{~Hz}$ & Seismic activity noise and Oceanic turbulence dominate. \\
\hline $10-100 \mathrm{~Hz}$ & $\begin{array}{l}\text { Noise levels depend on shipping densities and industrial activities. } \\
\text { Levels are typically in the frequency range of } 60-90 \mathrm{~dB} . \\
\text { Tide is a small contribution, decreasing in strength against the depth. }\end{array}$ \\
\hline $100-1000 \mathrm{~Hz}$ & $\begin{array}{l}\text { Noise in this frequency range is dominated by shipping (the level is } \\
\text { decreasing with frequency increased). } \\
\text { A significant contribution is also found in the sea surface agitation. } \\
\text { Sea state is used for calculating ambient noise above 500 Hz. }\end{array}$ \\
\hline $1-100 \mathrm{kHz}$ & $\begin{array}{l}\text { Sea surface wave agitation is now the dominant factor, unless } \\
\text { marine mammals or rain is present. }\end{array}$ \\
\hline$>100 \mathrm{kHz}$ or & Noise is dominated by electronic thermal noise. \\
higher frequency
\end{tabular}

For common calculation in science and technologies, shown in Fig.2.1 is the simplified and clear Wenz Curves, which are worked for different ships and wind speed conditions. In the infrasonic region below $20 \mathrm{~Hz}$, only a single line is drawn, which is due to the wind speed dependence is slight and uncertain. The ambient noise spectrum at any location or any time is approximated by selecting the appropriate shipping and wind curves, then fairing them together at intermediate frequencies. The "heavy-shipping" curve is used for the locations near the shipping lanes of the North Atlantic; the "lightshipping" curve is appropriate for the locations remote from ship traffic; and the "moderate-shipping" curve is valued between prior two conditions. This figure shows the noise spectrum level in different environments. 


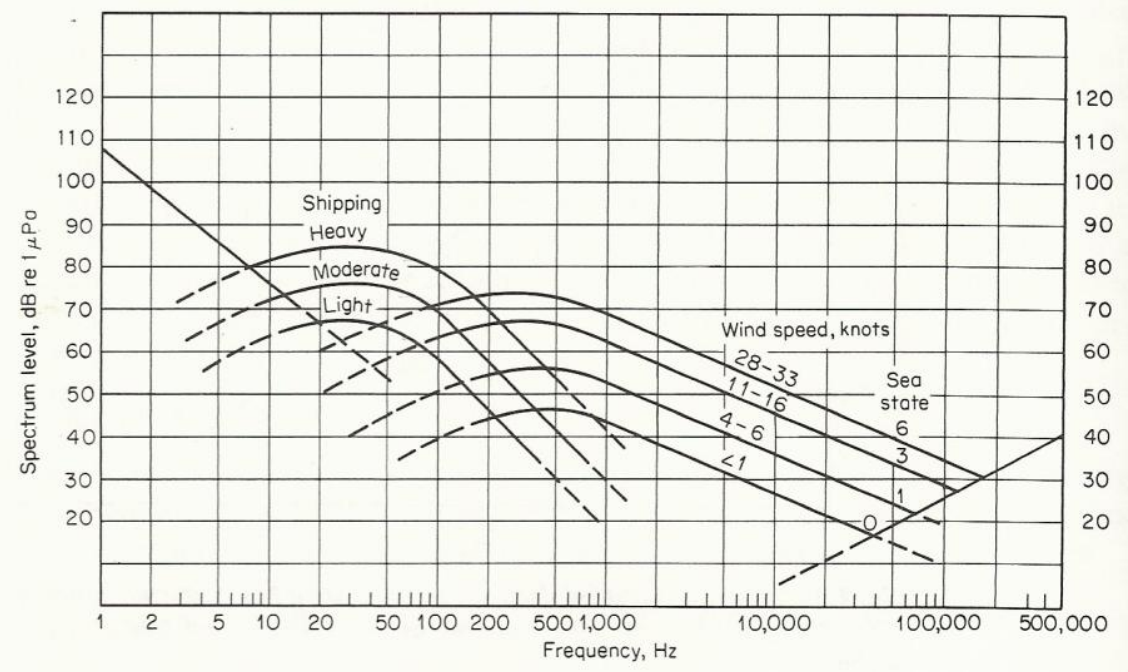

Figure.2.1. Wenz Curves are the average ambient noise spectra for different levels of shipping traffic, and sea state conditions (or wind speeds). Referred by Urick [17]

The locations in coastal water even in bays and harbors are subject to wide variations and have great ambient noise, because multiple noises are trapped and strengthened between shallow sea floor and the ocean surface.

At a given frequency in shallow water, the background noise is a mixture of four different types of noises: shipping and industrial noise; wind noise; biological noise; oceanic turbulence. At the particular time and place, the mix of these sources will determine the noise level, because the mix is variable with time, the existing noise levels will exhibit considerable variability from time to time and from place to place. Noise level generally decreases with increasing frequency. Also, noise level decreases at great depths because of most noise sources at the surface. As a consequence, only a rough indication given by levels might be found in bays, harbors and offshore coastal locations shown in Fig.2.2. 


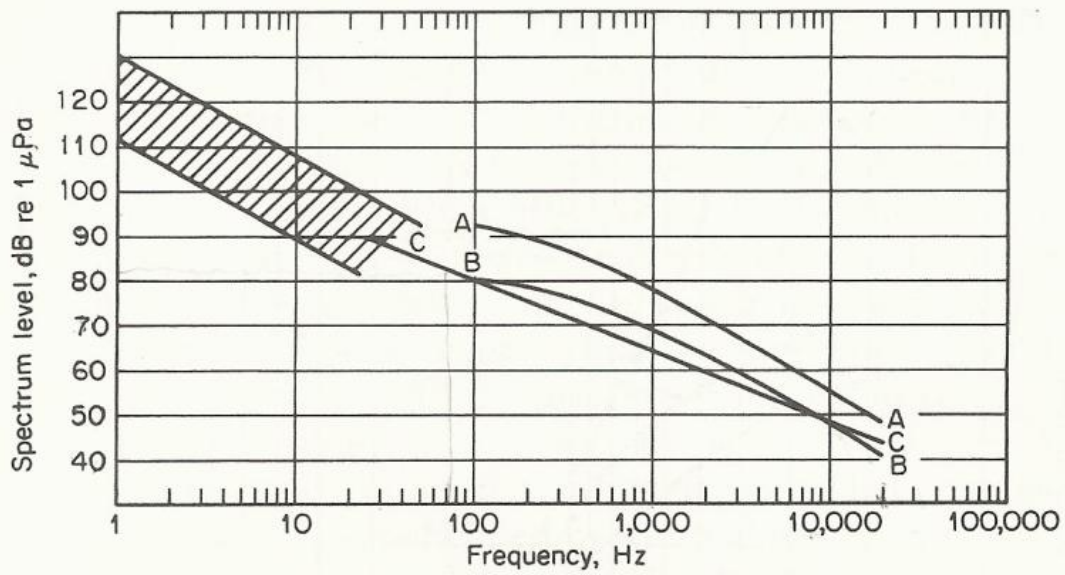

Figure 2.2. A summary of noise levels in bays and harbors. Referred by Urick [17]

\subsection{Underwater Vehicles}

\subsubsection{Autonomous Underwater Vehicle}

Autonomous underwater vehicle (AUV) [18] is an underwater robot which has been achieved in a variety of marine explorations. With the development of advanced capabilities and high-yield power supplies, AUVs are recently used for the tasks with many roles and missions. The following research about the applications of AUV is generally described in the aspects of commercial, military, research and hobby:

(1) Commercial. The oil and gas industries, and shipping companies use AUVs to sketch the maps of the seafloor and ensure safe operations, before they start subsea infrastructure and undersea exploration. As Fig.2.3 shown, the commercial surface AUV REMUS 1000 from Hydroid, Inc, provides a persistent ocean presence for scientific and defense customers [19]. 


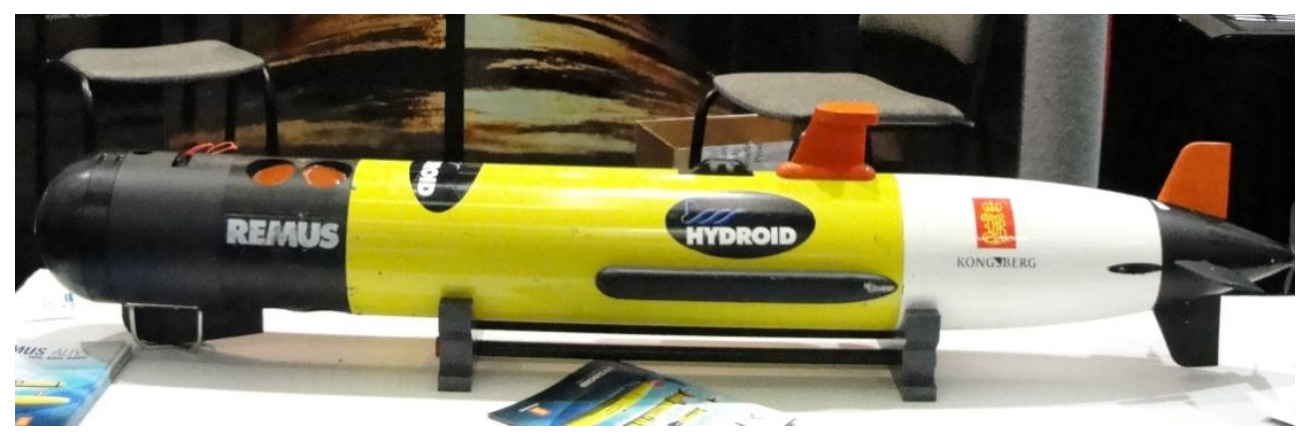

Figure 2.3. Autonomous Underwater Vehicle (REMUS 100, Hydroid, Inc)

(2) Military. A military mission for a typical AUV is to make the vision detection to monitor a protected area (such as a port or harbor) for new unidentified targets. AUVs are also applied in anti-submarine defensive warfare, to aid in the detection of manned submarines.

(3) Research. Scientists and researchers use AUVs to study lakes, oceans, and deepocean floors. A variety of sensors and electronic facilities [20] have been affixed to AUVs to measure the marine parameters like concentration, depth, temperature, absorption and reflection of lights, and the presence of the microscopic life. In addition, archaeologists can conduct undersea excavation work with the use of AUVs.

(4) Hobby. Several AUV competitions exist in colleges and research institutes. A simple AUV consists of a pipe body and waterproof motors with model airplane propellers. The camera, light tube and sonar can be also added in the AUV body. So a hobby AUV with a low cost can be completely operated in pools or lakes.

\subsubsection{Remotely Operated Vehicle}

In contrast to AUV, another typical underwater vehicle is a Remotely Operated Vehicle (ROV), typically tethered to the surface facilities. It is operated and powered by the surface staff in a vessel or on land. The vehicle is linked to the base location by a tether and cables, which could carry electrical power, video and data signals constantly between the operator and the vehicle. Fig.2.4 shows the well-known ROV (Jason II) from Wood Hole Oceanography Institute (WHOI) [21]. 


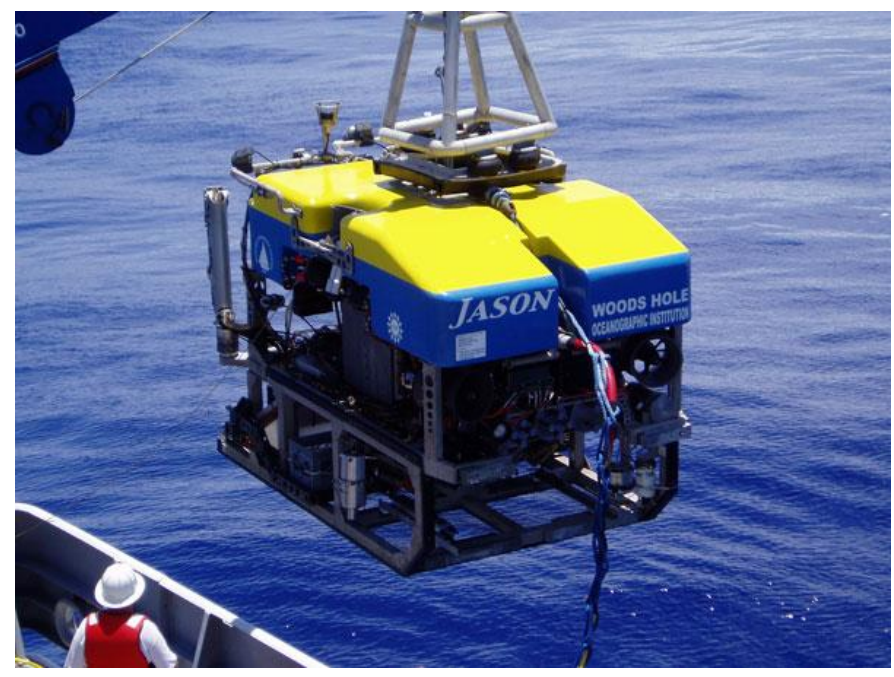

Figure 2.4. Remotely Operated Vehicle (Jason II, WHOI) [21]

\subsection{Active and Passive Acoustic Detection}

The main principle for active SONAR systems is to measure the time differences through collecting the pulses of produced sound, and calculate the range of underwater targets. At present, the widely used system for the detection is active sonar system. However, the application of active system is mostly limited by many factors, such as the requirement of the transmitter with the high cost, transmission by consistent sequence of data points [22], anti-detection measured by enemies if an active sonar system is in use before dispatching a diver. In addition, loud active sonar systems are dangerous and harmful to marine animals, such as middle-frequency sonar can cause tissue damage for sea animals [23].

These motivate the research on passive detection systems as a complement to active sonar detection systems, which is possible to make the surveillance robust, because passive acoustic detection involves the detection of sound or vibration created by the targets, and then those acoustic signatures are analyzed to determine the presence of underwater targets. In this case, passive detection methods can resolve the existing problems which the active systems have. 


\subsection{Related Work}

In retrospect, a number of completed technologies and research projects have regarded underwater threat detection. Most of the operational systems are relevant to military and commercial applications.

\subsubsection{Divers and Underwater Animals Passive Detection}

The Maritime Security Laboratory (MSL) at SIT conducted a series of experiments to measure the acoustic signals radiated by a diver in the Hudson River and the Stevens towing tank [24]. Borowski B. and Sutin A. [25], measured the main parameters by defining the detection distance of an underwater threat. The source level of the diver was measured by dividing the diver's sound from a reference signal by a calibrated emitter placed on the diver's path. Transmission loss, was measured by collecting noise levels of passing ships through their direction at various conditions. The ambient noise was recorded under variable environmental conditions and amounts of varying shipping traffic [26].

Lennartsson R. et al. [27] from the Swedish Defense Research Agency conducted one sea trial in the busy port of Gothenburg, Sweden. They measured divers with open circuit breathing systems using the algorithms of matched filters, non-coherent and quadrature detectors. They succeeded to find that the local shipping noise was an important acoustic source and higher electric field noise, other than the influence of winds.

Stolkin R. et al. [10], measured soniferous fishes and a diver's breathing sound, discriminate threat presence by the threshold value. Morrissey $\mathrm{R}$ et al. [34], used spectrogram analysis, matched filters and neural networks methods to accomplish realtime detection and localization of vocalizing marine animals.

\subsubsection{Surface Vessels and Ships Passive Detection}

Sorensen E. et al. [4] from Portland State University, used passive acoustic sensing for the detection of small vessels. They developed a surveillance system to provide wide 
area coverage, automatic detection and real-time communication alerts information. In addition, they built up the simulation tools to study the acoustic signature from boats in different environmental conditions.

Averbuch A. et al. [5] presented a robust algorithm to detect the acoustic emissions from the arrival of river boats. The work was done through acoustic signature analysis against an existing record and database of current acoustic signature.

\subsubsection{Completed Seaside Surveillance System}

The project in the Naval Research Laboratory (NRL) conducted a theoretical and experimental program, which addressed basic ocean acoustics, system performance prediction and enhancement, and underwater acoustic communication (ACCOM) [28].

Passive hydro-acoustic surveillance system is the U.S. Navy's SOund SUrveillance System (SOSUS) [29], which used bottom mounted hydrophone arrays and capable of detecting both surface vessels and submarines. Later, SOSUS has been used by civilian researches in various scientific projects.

NURC (NATO Undersea Research Center), Italy, conducted research on a wide-area of maritime surveillance application. Automatic identification system, which was an anomaly based detection [30]. The Center's work in this area currently focused on independent testing and evaluation of nonlethal response technologies. NURC also had underwater intruder detection projects Anti-submarine warfare (ASW) for military and civilian areas.

Many other systems were developed in [31], [32]. QinetiQ's anti-terrorist detection and protection system [33]; and Naval Undersea Warfare Center used wide-baseline passive acoustic system arrays for tracking marine mammals [34]; Northrop Grumman's Centrurion was also based on acoustic detection for commercial target detection and surveillance systems [35].

University of Hawaii is currently conducting research and education for island security in collaboration with Marine Security Laboratory. My work is part of the 
research project about harbor acoustic monitoring system [36] in CIMES, which proposes to use passive surveillance along with the help of passive acoustics and underwater navigation systems.

\subsection{Conclusion}

This chapter looks throughout underwater acoustics, addresses the background information and summarizes related scientific technologies. Based on all the significant knowledge of previous studies in underwater acoustic detection fields, we propose to conduct the individual research and continuing experiments to learn about the capabilities and methodologies of acoustic detection. 


\section{CHAPTER 3}

\section{EXPERIMENTAL APPROACH}

This chapter details the portable devices and experimental tools to evaluate the acoustic signature of a small ROV in typical environments. In addition to that, the theoretical analyses of SONAR equations and coefficients have been addressed. This chapter presents appropriate experimental approaches to implement the research proposals and destination. Simultaneously, this will provide stepping stones for advancing the own abilities to analyze problems and design technical structures.

\subsection{Experimental Facilities}

The project depended on the compromises of accuracy, features and cost, which contributed towards the selection of optimum hardware and software. We prepared an acoustic source, an acoustic receiver and a data acquisition system for the experiment of ROV detection in underwater environments. First, this chapter would detail each component of the facilities.

\subsubsection{Remotely Operated Vehicle}

This project used a SeaBotix LBV 150, a small available commercial off-the-shelf (COTS) ROV as the acoustic source. The added long tether and the integrated control console can provide simple operation methods for controlling this underwater ROV. The vehicle body is the heart of the whole system, which is designed to be rugged with four powerful motor driven thrusters, auto heading, auto depth, video overlay, a 270 degree 
field of vision, high-resolution color cameras, 150 meters of $7.6 \mathrm{~mm}$ diameter umbilical, an intuitive control console, a variable input power supply, transportation cases, spares and tools [37]. The LBV 150 is a small and multifunctional ROV, which is the main operated tool and sound source for the whole experiments.
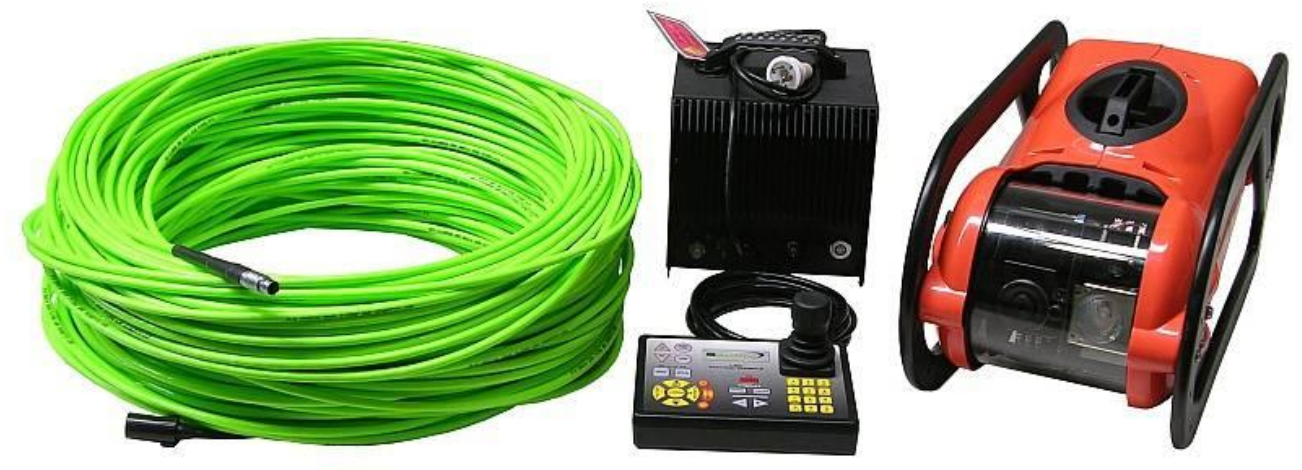

Figure 3.1. SeaBotix LBV 150. Left to right: Long tether, integrated control system, LBV vehicle (San Diego, CA) [37]

\subsubsection{Acoustic Acquisition Systems}

The Acoustic acquisition system includes a hydrophone, a preamplifier, a data acquisition and an output connection to the computer. The detailed explanations of each electronic device have been presented as follows.

\subsubsection{Bruel \& Kjaer Hydrophone Type 8103}

Type 8103 is "a small-size, high-sensitivity transducer for making absolute sound measurements" [38] over the frequency range $0.1 \mathrm{~Hz}$ to $180 \mathrm{KHz}$ with a receiving sensitivity of $-211 \mathrm{~dB}$ re $1 \mathrm{~V} / \mathrm{uPa}(-26.9 \mathrm{~dB} \mathrm{re} \mathrm{uV} / \mathrm{Pa})$. It has a high-receiving sensitivity relative to its size and respectful all-around characteristics, which make it generally applicable to laboratory, industrial and educational situations. Type 8103's frequency bandwidth is especially used to make acoustic investigations of underwater animals and the measurements of the pressure-level patterns. It is also useful for cavitations measurements. Fig. 3.2 indicates the major features of Type 8103. 


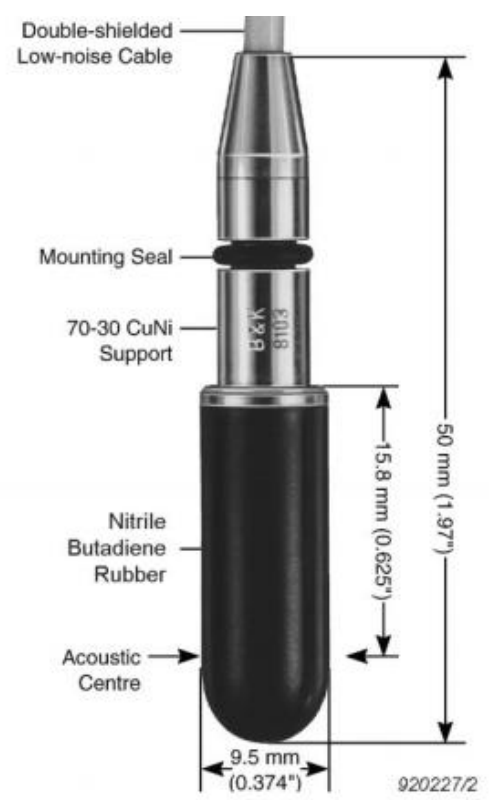

Figure 3.2. The diagram of hydrophone Type 8103 (Norcross, GA) [38]

\subsubsection{Aquarian Audio Products H1a Hydrophone}

The other hydrophone is Aquarian Audio Products H1a hydrophone [39], which also uses the low-noise, robust transducer assembly. It derives a high sensitivity of -190 dB re $1 \mathrm{~V} / \mathrm{uPa}(-31.6 \mathrm{~dB}$ re $\mathrm{uV} / \mathrm{Pa})$ and has useful range from $1 \mathrm{~Hz}$ to $100 \mathrm{KHz}$. There is no preamplifier or impedance buffer circuit within the hydrophone, which remains as simple use and low cost as possible. Meanwhile, it offers a very wide dynamic range without requiring any extra power. In addition, the system gain and input impedance should be considered by using one more preamplifier.

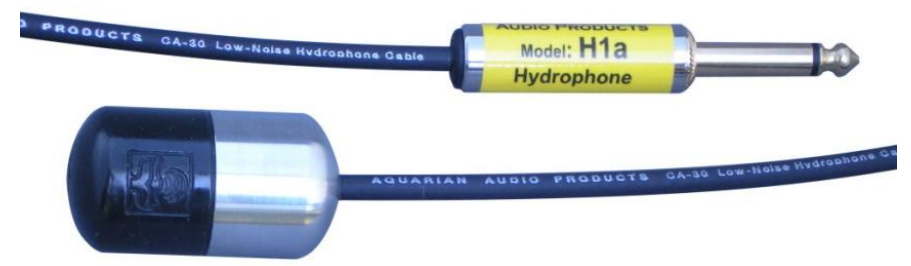

Figure 3.3. Aquarian Audio Products H1a Hydrophone (Anacortes, WA) [39] 


\subsubsection{Voltage preamplifier EC6081 (VP2000)}

The preamplifier is used to achieve three purposes for the experiment:

(1) Amplification. The signal received from the hydrophone must be amplified to achieve a suitable level for observation. The amplification of both voltages and currents needs to be undertaken to effectively strengthen the power.

(2) Impedance Matching. Preamplifier offers a very high-input impendence and matched output impedance. The former is to achieve maximum signal transfer from the hydrophone without distortions and the latter is to couple suitable output to the next stage.

(3) Gain Control. The next stage expects the signal at a specific level and the transducer input level may vary greatly. Most preamplifiers offer a continuously variable gain control and some preamplifiers additionally offer automatic level control to achieve close match with the signal level specifications.

For our experiments, the EC 6081/VP 2000 [40] is selected, which is a $1 \mathrm{MHz}$ bandwidth voltage preamplifier designed for uses in conjunction with piezoelectric hydrophones. VP 2000 offers an excellent low-noise performance over the entire frequency range and gain selections in 6 different levels varying from 0 to $50 \mathrm{~dB}$. A range of 12 high-pass and 12 low-pass filters are available, which allow ideal band-pass

filter settings. Also, the VP 2000 has a high-input impedance which allows the measurement at frequencies below $1 \mathrm{~Hz}$ with even extremely small hydrophone sensor capabilities. 


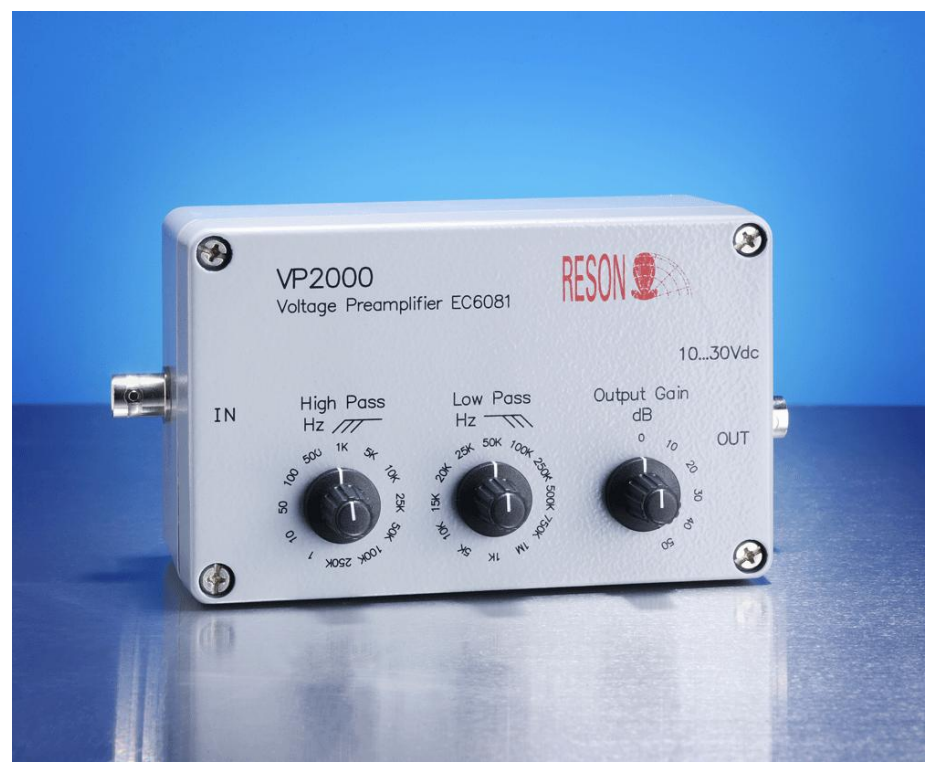

Figure 3.4. The image of Voltage Preamplifier EC 6081/VP 2000 (Goleta, CA) [40]

\subsubsection{Personal Daq/3000 Series}

The IOtech USB-based Personal Daq/3000 Series offer high-speed and multifunction data acquisition only in a low-cost and portable package. "The Personal Daq/3000 Series has 16-bit sample data, 1-MHz A/D converter with 8 differential analog inputs, 16 single-ended or 8 differential thermocouple inputs" [41]. Each channel in the series can be configured by software for different voltage and current ranges.

DaqView software is included with the Personal Daq/3000 Series, which is out of the box and a comprehensive application that enables software setups, data logs, and realtime data views without programming. This experiment uses the DaqView program to collect the experimental data. Then, MATLAB is used to plot the acoustic spectrogram, and further analyze the experimental data. 


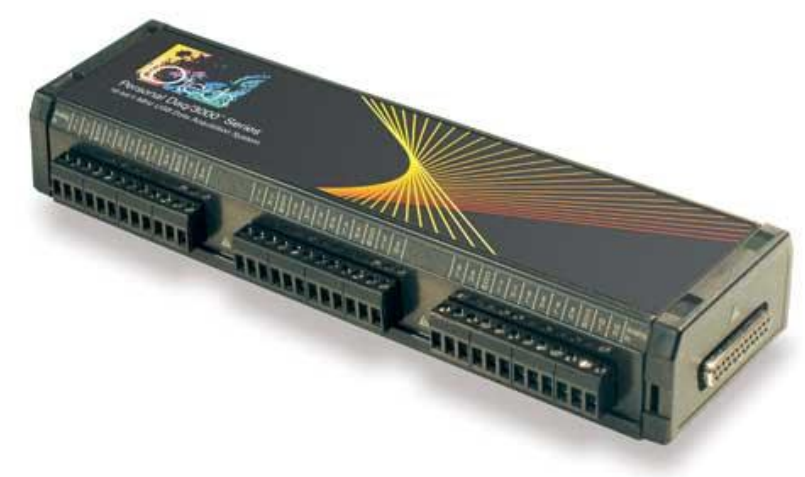

Figure 3.5. Personal Daq/3000 Series (Cleveland, $O H$ ) [41]

\subsubsection{Particle Image Velocimetry System}

Particle Image Velocimetry (PIV) is an optical method of fluid visualization used in education and research, as the technique for characterizing flows in the study of fluid dynamics [42] with the method of instantaneous velocity measurements and related properties in fluid field. It is a two (or three) -dimensional flow field measurement and non-intrusive. For the purpose of PIV, the fluid is seeded with neutrally buoyant tracer particles, which are assumed to follow the motion of flow dynamics. PIV apparatus consists of a camera, a high-power technical laser instrument, an optical installation for converting the laser output light to a thin laser sheet, the seeding particles and the fluid under investigation.

A sheet of laser light illuminates the flow particles, which is captured as digital images (image pair). From that, it is the motion of these seeding particles that is used to cross correlation to the two images, and obtain velocity information of the flows being studied. Fig.3.6 shows the diagram of the PIV system. It produces two-dimensional vector fields, while the special techniques measure the velocity at a point. 

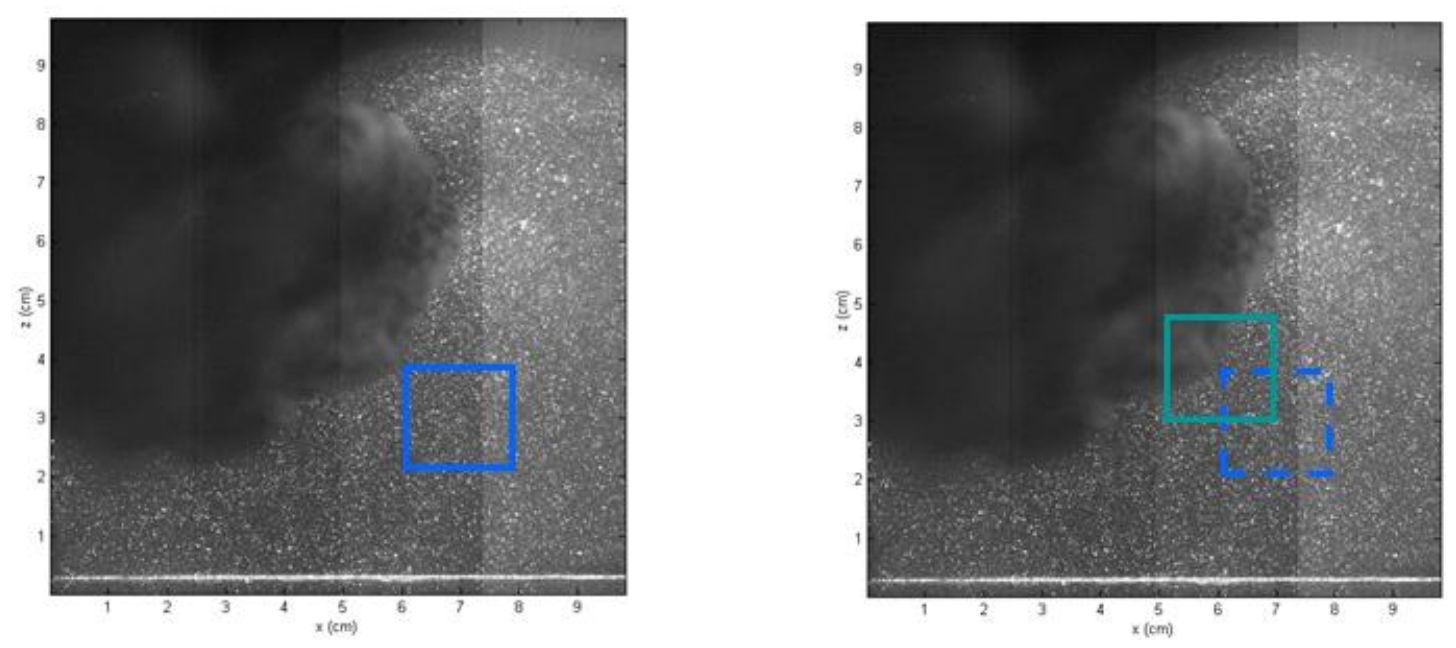

Figure 3.6. Fluorescent Particles-data Processing [43]

A large amount of interrogation areas are split in the frames, then it is possible to calculate displacement vectors for windows with the signal processing techniques. This could be converted to a velocity condition by the time between laser shots and the physical size of pixels on the high-speed camera. Then, the size of the interrogation window should be included at least 6 particles per window.

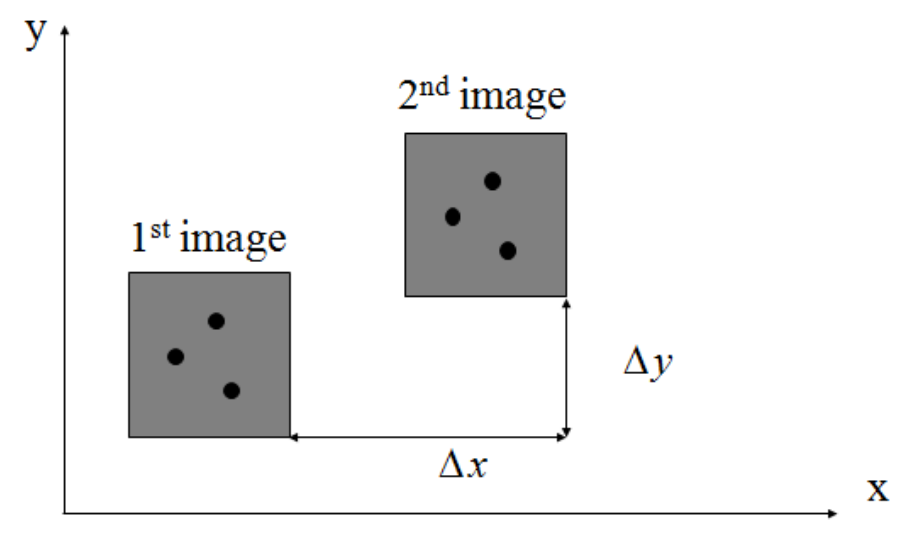

Figure 3.7. PIV Data Processing

Fig.3.7 shows the method for the velocity calculation. In two dimensional vector fields, the particle moves from $1^{\text {st }}$ image position to $2^{\text {nd }}$ image position, the changes of distance are $\Delta x$ in the $\mathrm{x}$-axis and $\Delta y$ in the $\mathrm{y}$-axis. So the axis velocities $u, v$, in each 
direction can be expressed with the division by $\Delta t$, the simple formula for velocity $V$ are shown as defined below.

$$
\begin{aligned}
& u=\frac{\Delta x}{\Delta t}, v=\frac{\Delta y}{\Delta t} \\
& V=\sqrt{u^{2}+v^{2}}
\end{aligned}
$$

\subsection{Methods}

\subsubsection{Model mathematical models to predict capabilities of passive detection}

\subsubsection{Passive Acoustic Detection}

The schematic diagram of the acoustic signature is shown in Fig.3.8. For the purpose

of this experiment, the stationary ROV is modeled as a sound source, which spreads the acoustic signals in all directions. This produces acoustic wave fronts that grow in size as the wave propagates away from the source like black dotted line. The yellow dotted lines show the special and asymmetrical acoustic wave fronts as the ROV moving, which would produce Doppler effects [17]. Because the ROV is running in a low speed, so we simplify to consider the symmetrical acoustic transmission. When the sound arrives at the surface and bottom of the water, the sound will stop further propagation and be reflected to the water again. Part of acoustic power will be lost by the absorption of seabed and open air. Meanwhile, there is also ambient noise around the environment marked in blue signs. 


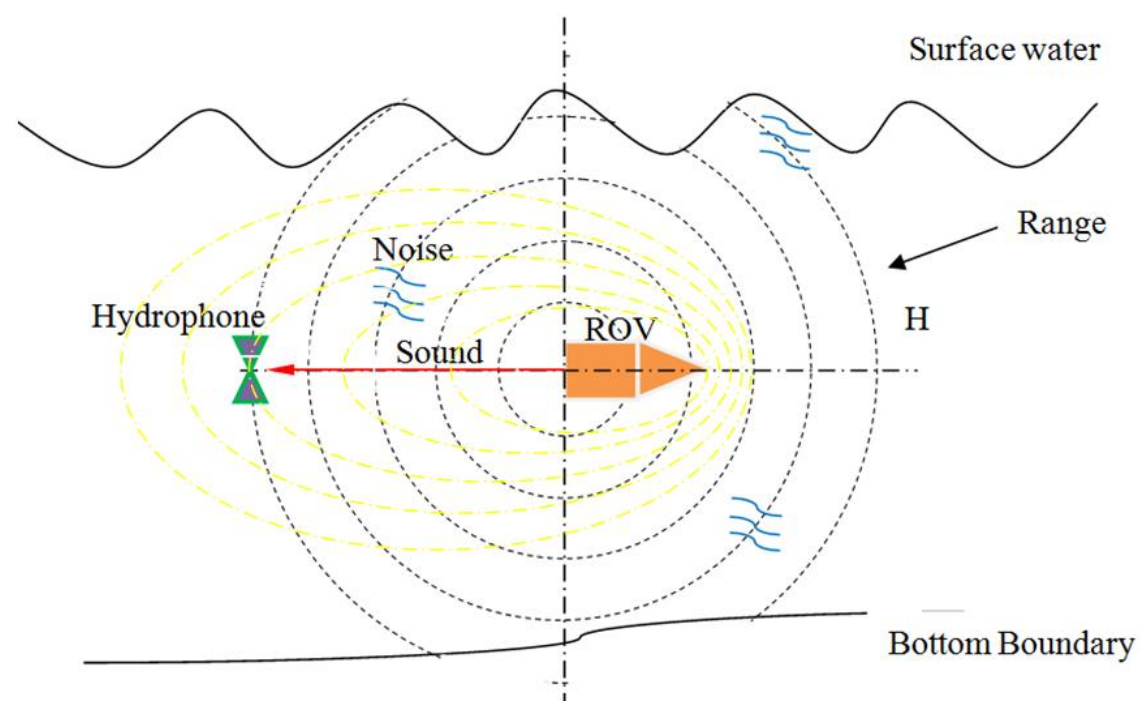

Figure 3.8. Schematic diagram of acoustic signature measurement with ambient noise.

Shown is that the hydrophone receives sound from the stationary ROV source.

\subsubsection{Acoustic Analysis}

The oceans create a complex medium. Sound can propagate in the medium but not followed by a straight path as expected. To this point, we need to explain the passive SONAR equations and provide mathematical analysis. In this session, the equations are broken into the individual terms and all the factors affecting the values for each term are discussed. The following development is an abbreviated version of the common SONAR equations as described by Urick [17].

\section{(1) Sound Pressure Level}

Sound Pressure Level (SPL) is defined as the sensor receiving intensity which decreases with transmission loss over the distance between the source and the hydrophone, measured in decibels. The equation is

$$
S P L=\text { Source }(S L)-\text { Transmission Loss }(T L)
$$




\section{(2) Sound Source Level}

Sound Level (SL) is the nature sound intensity from the acoustic sources without loss. In this project, most of which are from ROV mechanical noise including motors, thrusters and flow motion. This data was obtained through the actual experiments and could be used to detect the underwater vehicles based on the signals in different frequencies.

\section{(3) Transmission Loss}

Transmission Loss (TL), is a decrease in Power Special Density (PSD) as the pressure wave propagates out from the source and is an important factor to consider. There are many influencing factors, all of which can be grouped into two major categories: one is the geometric losses due to spreading; the other is the attenuation due to the absorption, scattering, viscosity and thermal losses.

TL is mainly due to spherical and cylindrical spreading. The spherical spreading is considered as the dominant factor in the transmission loss portion of the passive hydrodynamic equation other than the rest of factors.

$$
\begin{aligned}
& T L_{s p h}=10 \log \frac{I(1 y d)}{I(r)}=20 \log r \\
& \text { where } \\
& \frac{I(1 y d)}{I(r)}=\frac{4 \pi(r)^{2}}{4 \pi(1 y d)^{2}}=\frac{r^{2}}{(1 y d)^{2}}
\end{aligned}
$$

The equation above is for transmission loss only due to spherical spreading, which is the most dominant factor in the transmission loss portion of the passive SONAR equation, when the wave fronts hit the surface and the bottom, as in the case shown, the power in the wave fronts is reflected back into the ocean and continued for the transmission. Based on the same process as the spreading case, we can determine the transmission loss if also considering cylindrical spreading, so the equations are: 


$$
T L_{c y l}=10 \log \frac{I(1 y d)}{I(r)}=10 \log r
$$

where

$$
\frac{I(1 y d)}{I(r)}=\frac{2 \pi r H}{2 \pi(1 y d) H}=\frac{r}{(1 y d)}
$$

To derive the equation that takes both factors into account, one of the properties of logarithms is shown below:

$$
T L_{s}=10 \log \frac{I(1 y d)}{I(r)}=10 \log \frac{I(1 y d)}{I\left(r_{0}\right)}+10 \log \frac{I\left(r_{0}\right)}{I(r)}
$$

Where $r_{0}$ is the measured transition range. Assuming the first term accounts for the spherical spreading and the second term accounts for the cylindrical spreading, substituting in the previous equations for each. So the sum of equations becomes:

$$
T L_{s}=20 \log r_{0}+10 \log \frac{r}{r_{0}}
$$

Attenuation losses occur from both absorption and scattering. To account for attenuation in the equation of transmission loss measured in decibels, the term $\alpha$ is determined as the absorption coefficient. Using this new term, the equation of transmission loss can be expressed as follows [17]:

$$
T L=T L_{s}+T L_{a}=20 \log r_{0}+10 \log \frac{r}{r_{0}}+\alpha \times r \times 10^{-3} d B
$$

Where $r$ is transmission range from the source object to the hydrophone, measured in yards. For showing the results, the unit in yards could be transferred to standard unit in meters.

We can estimate a correct value for $\alpha$, which is influenced only by viscosity if considering that in freshwater. The viscosity losses in the water are due to two distinct effects: shear viscosity and volume viscosity, which are both dependent on the parameters, such as the frequency of the sound waves, the viscosity coefficient, the 
density and speed of sound. When both terms are combined, the parameters are set as normal values for parameters. So the value with frequency for the absorption coefficient [17] becomes:

$$
\alpha_{\text {viscosity }}=2.75 \times 10^{-4} \times f^{2} d B / k y d
$$

Where $f$ is the sound wave frequency in $\mathrm{kHz}$.

Seawater: If considering seawater as a dissipative medium, which absorbs the energies of the transmitted wave, the absorption coefficient $\alpha$ is also influenced by ionic relaxation and scattering as lists.

As sound waves pass through seawater, magnesium sulfate $\left(\mathrm{MgSO}_{4}\right)$ ions dissociate and re-associate to cause attenuation, the equation shown below for the absorption coefficient is

$$
\alpha_{\mathrm{MSO}_{4}}=\frac{40 f^{2}}{4100+f^{2}} d B / k y d
$$

Another factor in determining the absorption coefficient for frequencies below approximately $1 \mathrm{kHz}$ is the boron-borate relaxation process, the absorption coefficient is

$$
\alpha_{\text {boron-borate }}=\frac{0.1 f^{2}}{1+f^{2}} d B / k y d
$$

The last factor incorporated is the scattering of sound energy due to inhomogeneities in seawater. This factor is approximately constant, not dependant on frequency and would only be dominant below $100 \mathrm{~Hz}$. This can be expressed as

$$
\alpha_{\text {scattering }}=0.003 \mathrm{~dB} / \mathrm{kyd}
$$

When all these factors are combined, the equation for the absorption coefficient $\alpha$ will finally become 


$$
\alpha_{\text {seawater }}=\left[0.003+\frac{0.1 f^{2}}{1+f^{2}}+\frac{40 f^{2}}{4100+f^{2}}+2.75 \times 10^{-4} \times f^{2}\right] d B / k y d
$$

\section{(4) Signal to Noise Ratio}

The signal-to-noise-ratio (SNR) is a measuring factor used in science and engineering to quantify the signal corrupted by noise. It is a technical term used to characterize the quality of the signal detection of a measuring system [44]. It is technically defined as the ratio of signal power to the noise power corrupting the signal, or the power ratio between a meaningful detected signal and the unwanted background noise signature. A ratio higher than 1:1 indicates more signal than noise. SNR is quantified in decibel.

$$
S N R=\frac{P_{\text {signal }}}{P_{\text {noise }}}
$$

Where $P$ is the signal power. Both signal and noise level must be measured at equivalent conditions in the same systems. If the signal noise is measured across the same units, then the SNR can be obtained by calculating the square of the amplitude ratio:

$$
S N R=\left(\frac{A_{\text {signal }}}{A_{\text {noise }}}\right)^{2}
$$

Where $\mathrm{A}$ is the root mean square (RMS) amplitude. Because many signals have a very wide dynamic range, SNR is often expressed by the logarithmic decibel scale. The SNR is defined in decibels as

$$
S N R_{d B}=10 \log _{10}\left(\frac{P_{\text {signal }}}{P_{\text {noise }}}\right)=10 \log _{10}\left(\frac{A_{\text {signal }}}{A_{\text {noise }}}\right)^{2}=20 \log _{10}\left(\frac{A_{\text {signal }}}{A_{\text {noise }}}\right)
$$

SNR is usually measured to indicate an average Signal-to-Noise ratio, as it is possible that instantaneous signal-to-noise ratios will be considerably different. The following calculation and expression will be dependent on these equations.

(5) Self Noise 
Self-noise is the noise that the vehicle being studied produces and is detected by the sonar system, contributing to the overall noise interfering with the detection of other vessels. Some of the sources of self-noise [10], [45] include the following:

\section{(5.1) Propeller Noise}

Rotating propellers generate spectral lines in the frequency band, $f=0.1-10 \mathrm{~Hz}$. These frequencies depend on the rotation speed of the propellers and its geometry. Cavitation induced creates broadband noise at higher frequencies, which depends on: Rotation speed of propeller; Type of propeller (fixed or variable pitch); Depth of propeller (depths inhibit cavitations)

\section{(5.2) Flow Noise}

Turbulence generated by flow of water over ship's hull, depends on ship speed, shape and placement of transducers.

\section{(5.3) Machinery Noise}

Ships have numerous noisy machines - engines, reduction gears, generators and hydraulic machinery. This machinery causes vibrations in the hull by solid transmission through internal structures or through the air. These vibrations are then passed on to the water. Machinery noise is independent of ship speed [17]; therefore, it is the major component of self noise at low speeds and is masked at high speeds by flow noise. Both primary frequencies and harmonics are transmitted.

\subsubsection{Experimental evaluated the acoustic signature of the ROV in the tank}

For evaluating the acoustic signature, we held two tank tests: one was in the indoor laboratory tank, and the other was in the outside tank. Since the test tank is easy to set up, convenient to collect experimental data and adjust the methods. In both experiments, we have measured acoustic emission with maneuvering ROV. Simultaneously, we have measured the flow fields with PIV system. Section 1 and Section 2 in Chapter 3 will detail these experiments. 


\subsubsection{Experimental evaluated the passive detection in shallow-water environment}

Based on the previous experience, we have general ideas about acoustic signature, so it is time for us to move the experiment toward the open port environment, because the field test is more helpful for understanding the acoustic environment and offers the actual applications. During the experiment, we have collected multiple acoustic data stored in the hard driver, then we can compare the field test with prior laboratory and outdoor tank tests. In addition, we have compared the actual measurement with model prediction and observed the data precision. Section 3 in Chapter 3 will present this experiment.

\subsection{Conclusion}

This chapter states the experimental approach of this project and details each component of available experimental facilities, which are well-prepared to the further examination. In addition, this chapter presents the methods of passive acoustic detection, which are the fundamental knowledge to understand this project. Based on the prepreparation, the definite research object will be clarified during the following experiments. 


\section{CHAPTER 4}

\section{ACOUSTIC DETECTION EXPERIMENTS}

\subsection{LABORATORY TANK EXPERIMENT}

This section is started with attempts to move toward the implementation with experiments, and determines the performance of available technologies with respect to the actual application. The purpose of this laboratory tank test is to analyze the hydrodynamics flow of a moving ROV, present experimental results from collecting acoustic data using a hydrophone, simultaneously measuring the flow velocity fields with a PIV system. Fig. 4.1 shows the operation of the ROV in the laboratory tank.

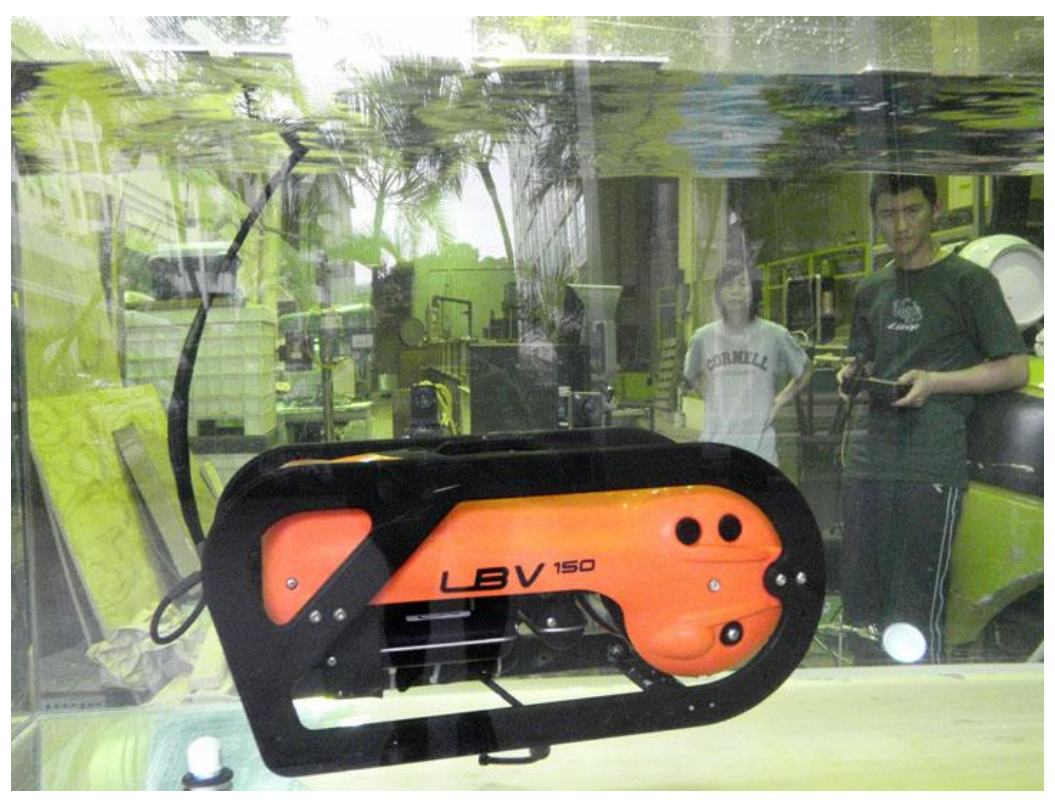

Figure 4.1. Acoustic and PIV flow measurements of the ROV were done in a clear acrylic tank 


\subsubsection{Experimental Setup}

The experiment was conducted in a clear test tank $(1.52 \mathrm{~m}$ long $\times 0.61 \mathrm{~m}$ wide $\times$ $0.76 \mathrm{~m}$ high). The ROV in the following experiments was a SeaBotix LBV 150, a commercially available off-the-shelf small ROV. Each vehicle maneuver was done with the ROV centered vertically in the tank as shown in Fig.4.2. The acoustic measurements were made by using a Bruel \& Kjaer hydrophone Type 8103. The hydrophone was secured to a metal post located $0.3 \mathrm{~m}$ from the bottom of the tank and $0.6 \mathrm{~m}$ from the water surface. Fig.4.2 shows that the laser light for the PIV system is from the right side of the image, the shadow of the ROV is on the left side. The particles are spread over the whole volume of the tank.

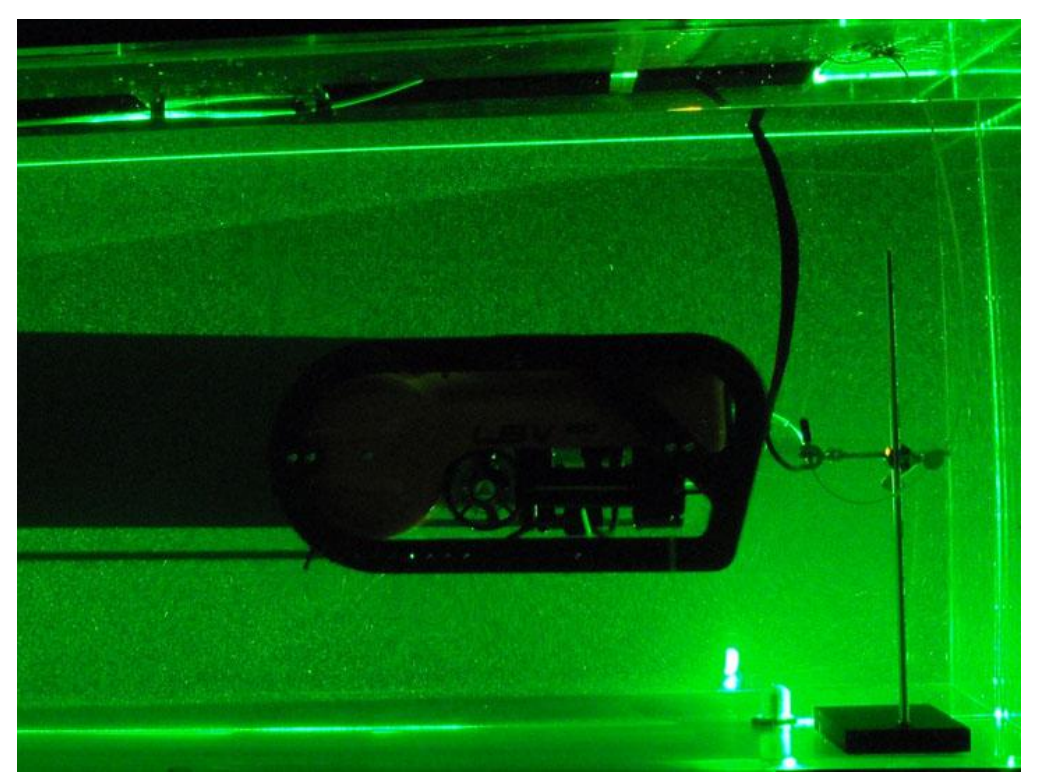

Figure 4.2. The ROV and aft hydrophone placement with laser irradiation.

The PIV experimental setup is shown in Fig.4.3, which includes the high-speed camera, high-power laser and experimental tank with inside ROV. 


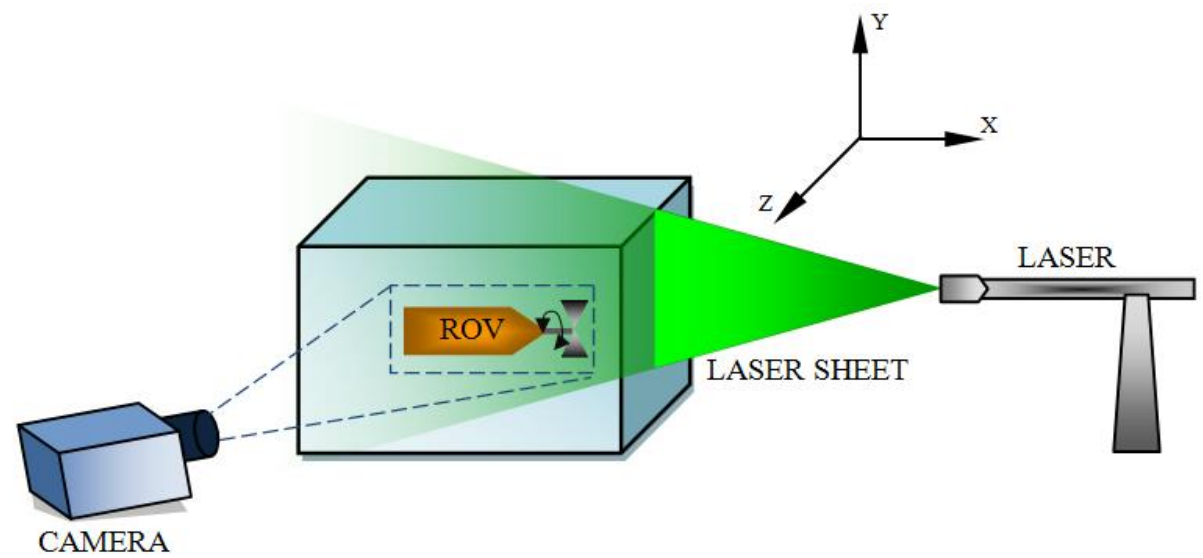

Figure 4.3. A simplified diagram of the PIV setup shows the laser sheet and the camera orientation relative to the $\mathrm{ROV}$.

The PIV measurements were made by using a TSI Incorporated (Shoreview, MN) PIV system shown in Fig.4.4 [42], which consisted of a pair of pulsed Nd: YAG lasers (30 Hz each), a 1024 by 1280 pixel complimentary metal-oxide semiconductor (CMOS) digital camera, a synchronizer, and a computer. An articulating laser arm was used to deliver the laser beam to the measurement location. The laser light sheet was formed using a cylindrical lens $(f=-25 \mathrm{~mm})$ and the beam was focused on a spherical lens $(f=$ $1.0 \mathrm{~mm}$ ) to control the thickness of the light sheet. The laser sheet was positioned in the tank from the side, forming a vertical plane $(x-y$ plane $)$. The fluid was seeded with tracer particles, which were assumed to follow the flow dynamics. Images were captured at a rate of $60 \mathrm{~Hz}$, yielding 30 instantaneous velocity fields per second. Cross-correlation was applied to the raw images to resolve the instantaneous velocity. Each raw image pair was initially interrogated with a 64 by 64 pixel subwindow followed by a 32 by 32 pixel subwindow with the displacement data obtained from the previous interrogation as initial estimates, resulting in 31 by 39 grids of velocity vectors for each instantaneous velocity field. 

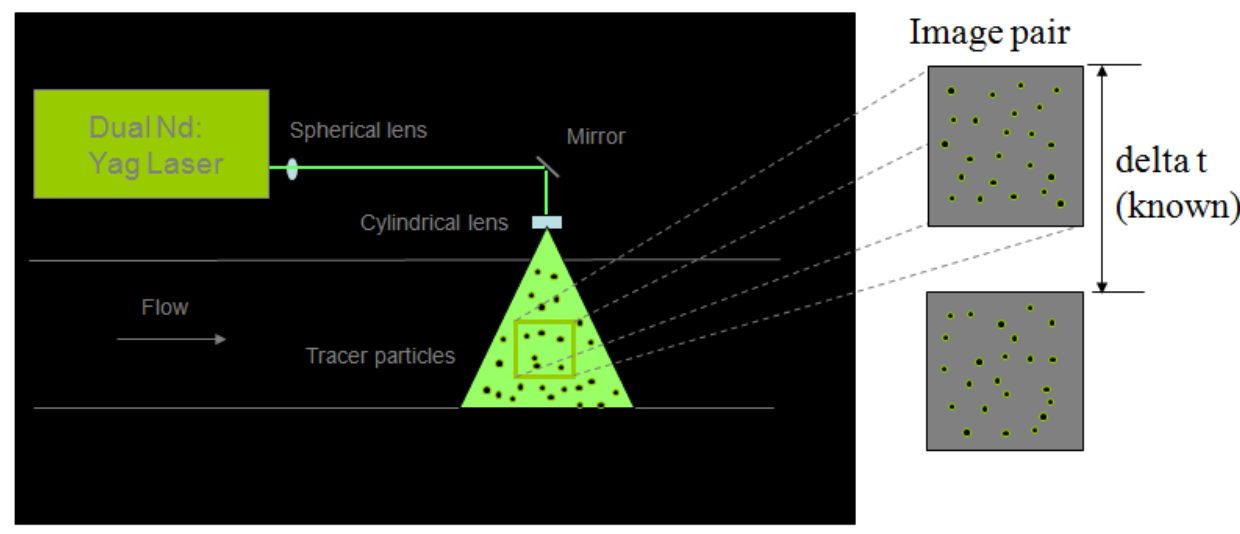

Figure 4.4. PIV Image-based measurements

\subsubsection{Acoustic Signature Analysis}

\subsubsection{Methods of Acoustic Characterization}

We collected the hydrophone data using a data acquisition system, with a sample rate of $44.1 \mathrm{kHz}$ and a resolution of 16 bits. The spectrogram was then completed by using a 16,384-points FFT, 8,192 overlap for each trial in the experiment to characterize the acoustic emission in a variety of scenarios. The trials were designed to determine the most dominant mechanism of the acoustic signature as outline in TABLE II. By comparing these individual trials, we were able to isolate each component of the ROV signature.

Fig.4.5 and Fig.4.8 through Fig.4.10 are the spectrograms for each of typical acoustic measurements from TABLE II. The horizontal axis is the time in seconds, the vertical axis is the frequency in $\mathrm{Hz}$ and the color bar to the right of the plot shows the sound pressure level (SPL) in decibels re 1 microPascal at 1 meter ( $\mu \mathrm{Pa}$ at $1 \mathrm{~m})$. 
TABLE III. Description of the experimental trials and the corresponding acoustic emission component

\begin{tabular}{|c|c|c|c|c|c|c|}
\hline \multirow[b]{2}{*}{ No. } & \multirow[b]{2}{*}{ Trial Description } & \multicolumn{5}{|c|}{ Acoustic Signature Components (Sources) } \\
\hline & & $\begin{array}{c}\text { Electric } \\
\text { motor }\end{array}$ & $\begin{array}{l}\text { Propeller } \\
\text { motion }\end{array}$ & $\begin{array}{l}\text { Propeller } \\
\text { wash }\end{array}$ & $\begin{array}{l}\text { Flow } \\
\text { over } \\
\text { ROV }\end{array}$ & $\begin{array}{c}\text { Ambient } \\
\text { noise }\end{array}$ \\
\hline Fig.4.5(a) & $\begin{array}{l}\text { ROV moving } \\
\text { forward } \\
\text { Hydrophone aft of } \\
\text { vehicle }\end{array}$ & $\mathrm{X}$ & $\mathrm{X}$ & $\mathrm{X}$ & $\mathrm{X}$ & $\mathrm{X}$ \\
\hline $\begin{array}{l}\text { Fig.4.5(b) } \\
\text { \&Fig.4.8(b) }\end{array}$ & $\begin{array}{l}\text { ROV stationary } \\
\text { Hydrophone aft of } \\
\text { vehicle }\end{array}$ & $\mathrm{X}$ & $\mathrm{X}$ & $\mathrm{X}$ & & $\mathrm{X}$ \\
\hline Fig.4.8(a) & $\begin{array}{l}\text { ROV moving } \\
\text { forward } \\
\text { Hydrophone in } \\
\text { front of vehicle }\end{array}$ & $\mathrm{X}$ & $\mathrm{X}$ & & $\mathrm{X}$ & $\mathrm{X}$ \\
\hline Fig.4.9(a) & $\begin{array}{l}\text { Single thruster } \\
\text { stationary with } \\
\text { propellers } \\
\text { Hydrophone aft of } \\
\text { thruster }\end{array}$ & $\mathrm{X}$ & $\mathrm{X}$ & $\mathrm{X}$ & & $\mathrm{X}$ \\
\hline $\begin{array}{l}\text { Fig.4.9(b) } \\
\text { \&Fig.4.10(b) }\end{array}$ & $\begin{array}{c}\text { Single thruster } \\
\text { stationary without } \\
\text { propellers } \\
\text { Hydrophone aft of } \\
\text { thruster } \\
\end{array}$ & $\mathrm{X}$ & & & & $\mathrm{X}$ \\
\hline Fig.4.10(a) & Background & & & & & $X$ \\
\hline
\end{tabular}

\subsubsection{Hydrodynamic Acoustic}

\section{a. Flow-induced signature}

Fig. 4.5(a) shows that the SNR for the ROV diminishes as the distance increases while the ROV is moved away from the hydrophone. Fig. 4.5(b) shows the acoustic signature of the ROV with the hydrophone fixed at a distance of $30 \mathrm{~cm}$ from the propellers. The locations of both the hydrophone and the ROV are fixed in this trial to 
eliminate the flow over the ROV body. Comparing the signature in low frequency (below $1 \mathrm{kHz}$ ) in Fig. 4.5(b) with Fig. 4.5(a), a small difference is shown due to the flow signal occurring only when the ROV is moving.

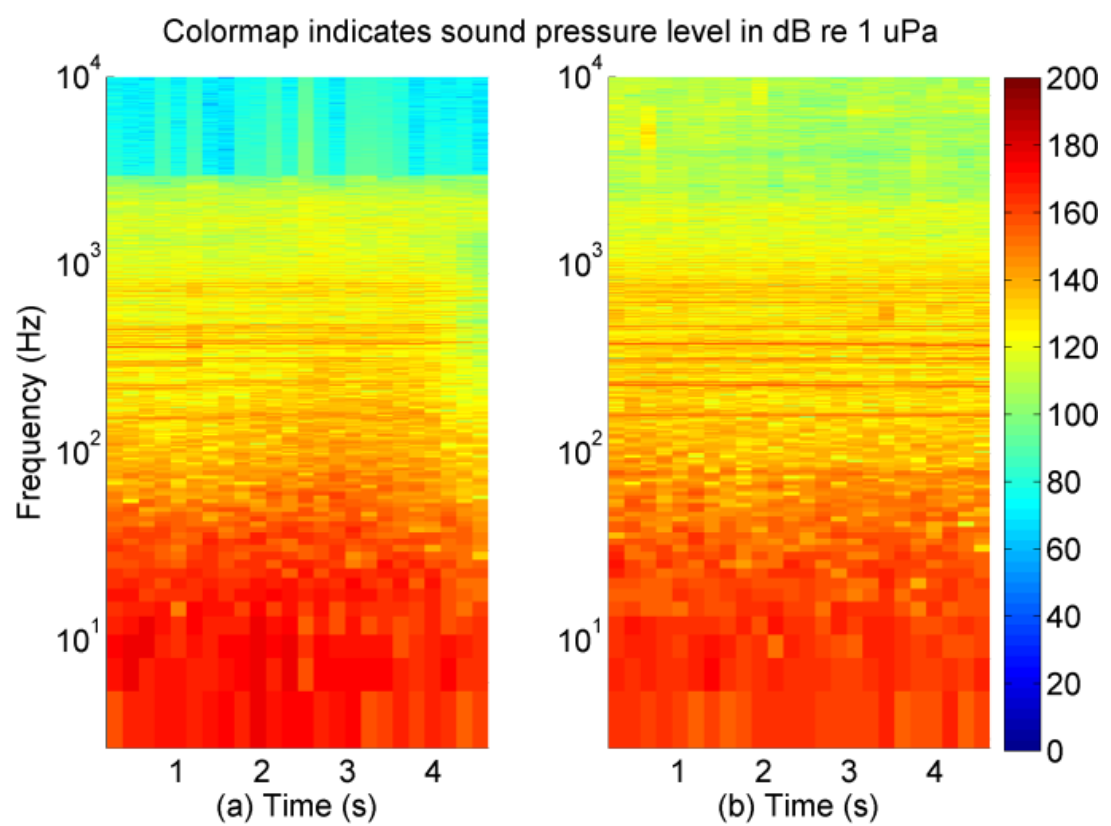

Figure 4.5. A comparison of the signature from moving ROV with stationary ROV when hydrophone is aft of vehicle. (a) ROV moving forward, hydrophone aft of vehicle; (b) ROV stationary, hydrophone aft of vehicle.

\section{b. Hydrodynamic flow by PIV}

A corresponding sequence of PIV measurements of the instantaneous velocity is shown in Fig. 4.6 and Fig. 4.7. The ROV is moving forward in the negative $x$ direction through stationary water. The two propellers located at both sides of the aft of ROV take in the fluid from the upper layer of the fluid body in Fig. 4.6. The fluid is ejected below and between the two propellers, generating a turbulent jet in the lower layer of the fluid body. Two dimensional results and the completed flow structure were presented. 


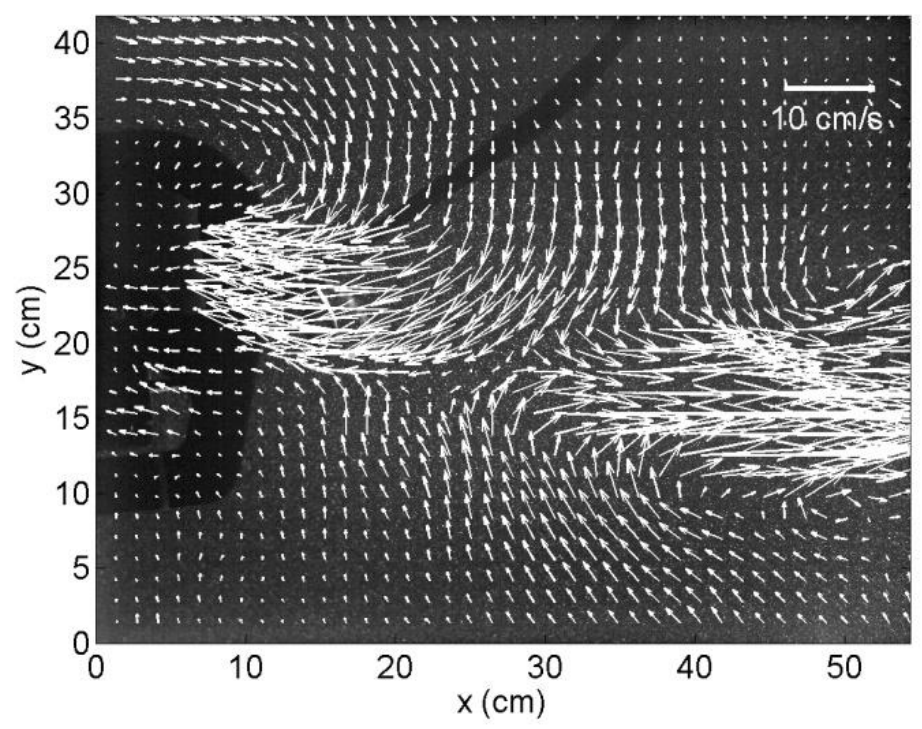

Figure 4.6. The instantaneous velocity field superimposed with the PIV raw image

The upper and lower layers of the fluid produce a shear layer between them in Fig. 4.7. The ROV is moving forward in 1 second, the distance change is about $9.3 \mathrm{~cm}$. So we can calculate the measured flow velocity is $9.3 \mathrm{~cm} / \mathrm{s}$.

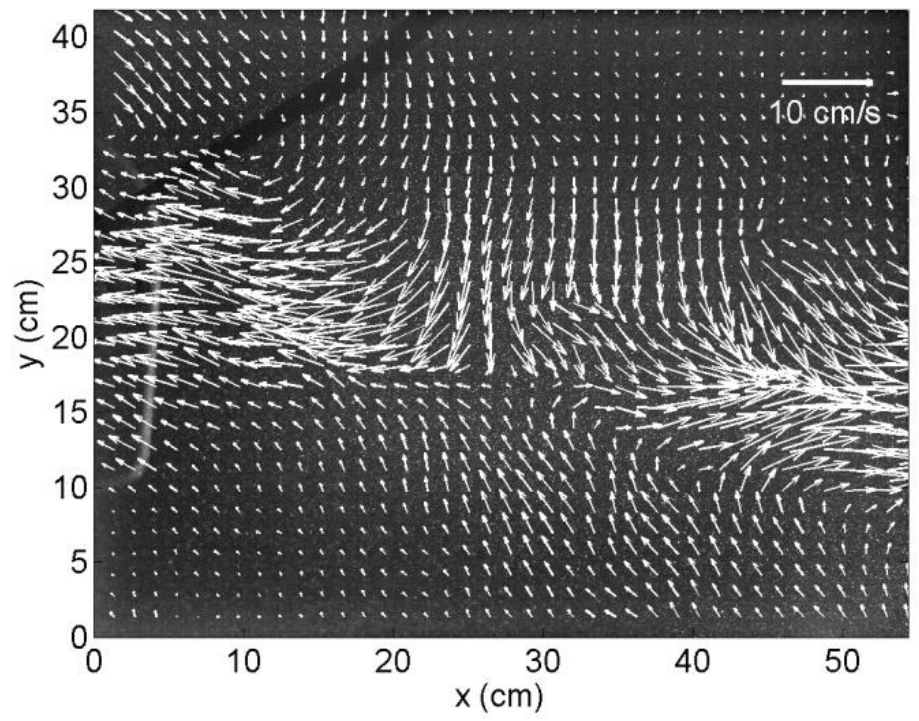

Figure 4.7. The instantaneous velocity field superimposed with the PIV raw image $(0.8$ second after the instant shown in Figure 4.6). The velocity is around $9.3 \mathrm{~cm} / \mathrm{s}$ 


\subsubsection{Propeller wash signature}

Fig. 4.8(a) shows the results of a trial where the hydrophone is located in front of the ROV as it moves forward. Comparing Fig. 4.8(a) with Fig. 4.8(b), it is apparent that the signals in low frequencies (below $50 \mathrm{~Hz}$ ) are more powerful. This comparison suggests that the acoustic signatures in the low frequency of Fig. 4.8(b) are due to water pressure fluctuations from propellers wash. The frequencies of pressure fluctuations are too low to be received by the hydrophone and this flow would diminish rapidly with distance from the ROV.

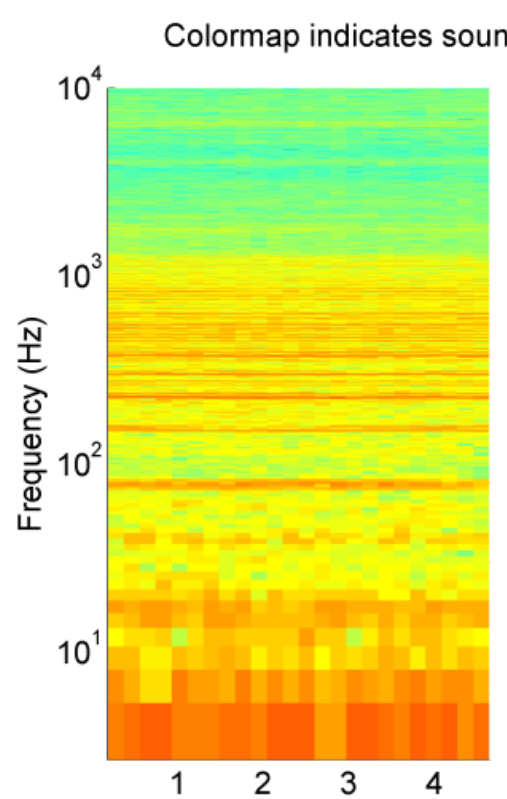

(a) Time (s)

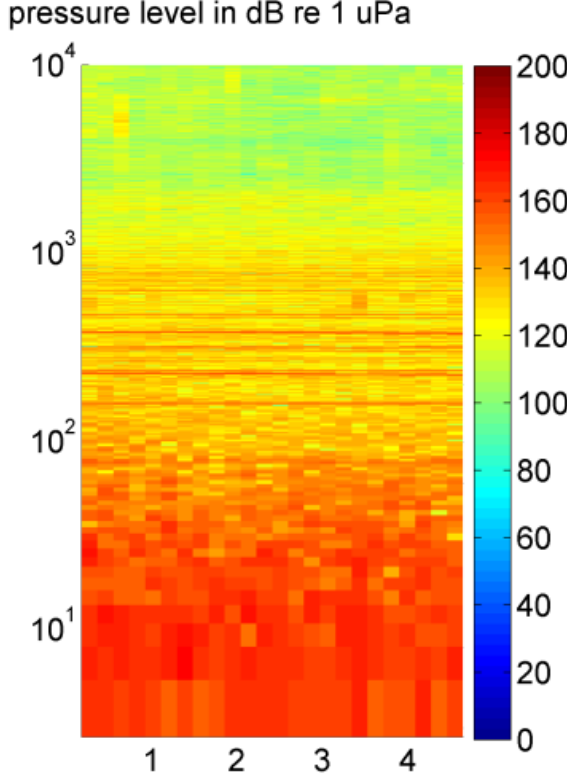

(b) Time (s)

Figure 4.8. The comparison of the acoustic signatures when hydrophone is in front and aft of stationary ROV. (a) ROV stationary, Hydrophone in front of vehicle; (b) ROV stationary, Hydrophone aft of vehicle

\subsubsection{Propeller-induced signature}

Shown are another group of tests for identifying the propeller noise. Fig. 4.9(a) is the acoustic signature of vehicles using propellers. Comparing with Fig. 4.9(b), which shows the signals from the ROV without propellers but with the motors still spinning, a visible difference is the missing of a wide range of signals in low frequency. We infer that these 
low-frequency signals are from the propellers-induced. The value of frequencies is between $40 \mathrm{~Hz}$ to $50 \mathrm{~Hz}$.

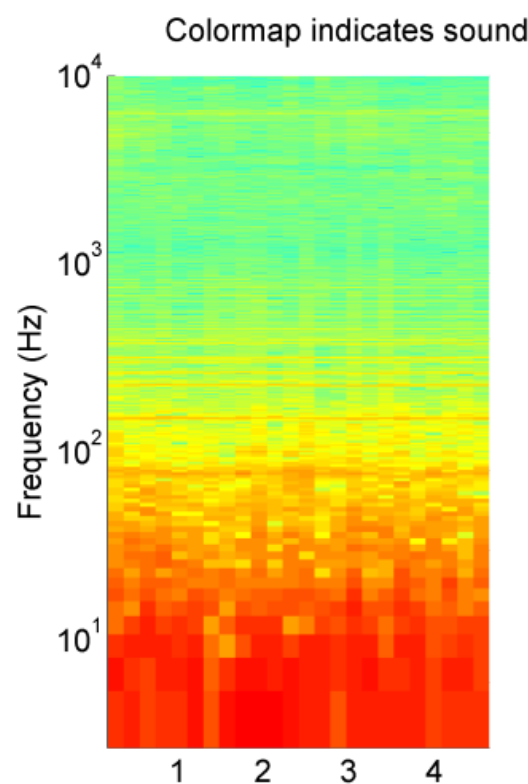

(a) Time (s)

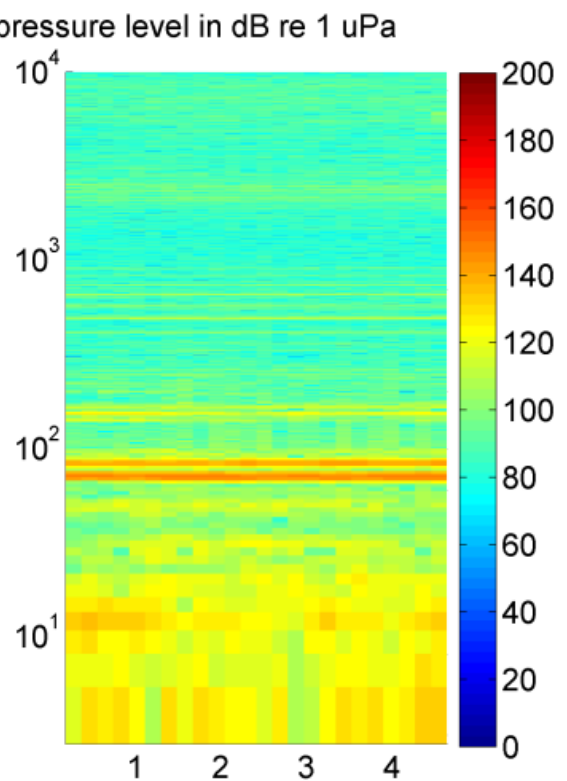

(b) Time (s)

Figure 4.9. The comparison of the signatures without the propellers from ROV. (a) Single thruster stationary with propellers, Hydrophone aft of thruster; (b) Single thruster stationary without propellers, Hydrophone is aft of thruster

\subsubsection{Electric motor signature}

In this experiment, all the electronic instruments were turned off to accurately record the background noise shown in Fig. 4.10(a). There are some noises at low frequencies from various ambient sources. Compared with Fig. 4.10(b), the noticeable signals between $70 \mathrm{~Hz}$ to $80 \mathrm{~Hz}$ and $400 \mathrm{~Hz}$ to $500 \mathrm{~Hz}$ remain. Since taking off the propellers, the only acoustic source is the stationary electric motor [46]. Compared with different frequency ranges, the signals of $70-80 \mathrm{~Hz}$ and $400-500 \mathrm{~Hz}$ are more strong and useful for underwater detection in the laboratory environment. So we can conclude that when the frequency is $70 \mathrm{~Hz}$, electric motor signal has the maximum sound pressure level of 146 $\mathrm{dB}$ re $1 \mu \mathrm{Pa}$ at $1 \mathrm{~m}$. Also, through the measurement, we can measure the signals of 400$500 \mathrm{~Hz}$ with the sound pressure level of $137 \mathrm{~dB}$ re $1 \mu \mathrm{Pa}$ at $1 \mathrm{~m}$. 


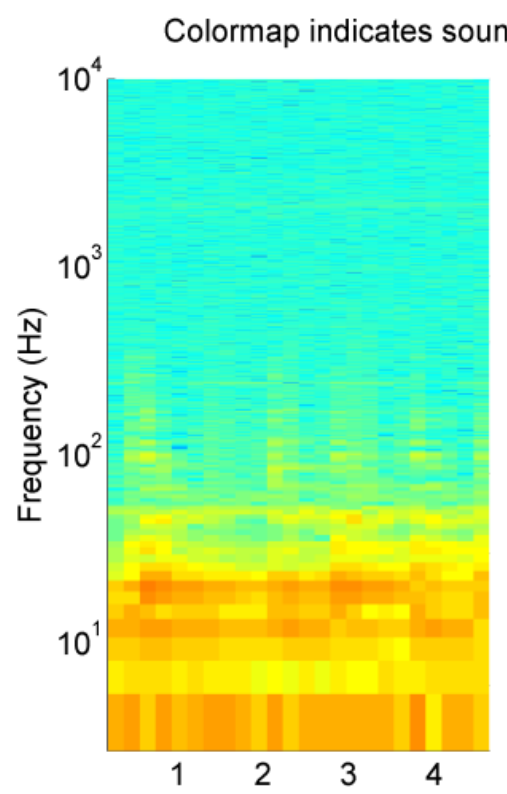

(a) Time (s)

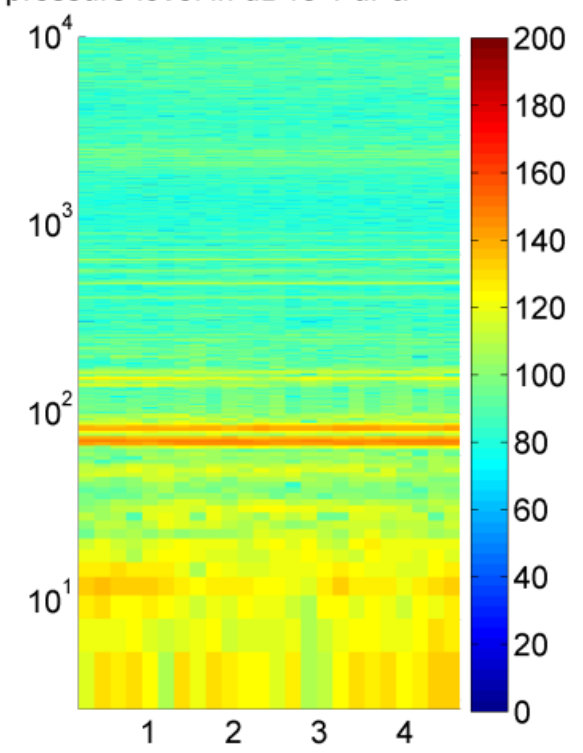

(b) Time (s)

Figure 4.10. The comparison of the background noise in the signature from ROV without propellers. (a) Background noise without any motion; (b) Single thruster stationary without propellers, Hydrophone aft of thruster

\subsubsection{Simulation Detection Performance}

Based on the results of the experiments described above, we estimated the ability to passively detect the acoustic signature of a small ROV. Fig. 4.10(b) shows the main component of the acoustic signature is a narrowband between $70 \mathrm{~Hz}$ to $80 \mathrm{~Hz}$ at a sound receiver level of $146 \mathrm{~dB}$ re $1 \mu \mathrm{Pa}$ at $1 \mathrm{~m}$. To accomplish this, the passive SONAR equation for the SNR at the receiver is

$$
L_{S / N}=S L-T L-N L
$$

Where $L_{S / N}$ is the SNR at the receiver and $N L$ is the ambient or background noise associated with the operating environment.

To capture the transmission loss associated with seawater, the equation followed the description and development in chapter three, which included the four pertinent contributions (boric acid, magnesium, viscosity, and scattering) to the acoustic absorption. 
The background noise levels also exhibit considerable variability with the maritime environment. For the current field experiment, the variability is not taken into account.

Signal propagation is modeled in three typical environments by considering background noise level, and the archetypical noise levels for three important operational environments are described as follows. Based on the noise threshold of these three environments, and assuming that the receiver can make the detection when the SNR is above $0 \mathrm{~dB}$, the conclusion should be:

In the shallow coastal water, wind speed is the dominant factor in the noise level, but additional factors complicating transmission loss are the proximity of the ocean bottom and self-noise. We find that in the spectra of ambient signal at a depth of $200 \mathrm{~m}$, the noise level is $73 \mathrm{~dB}$ re $1 \mu \mathrm{Pa}$, and the hydrophone can receive acoustic signals at the maximum detection distance of $36 \mathrm{~m}$.

In ports and harbors, these environments are at a particular interest for security considerations. The noise is mainly from shipping and industrial activity of human origins. In addition, noise is produced by marine life and turbulence of tidal currents, all these create a noisy ambient environment. We find the average of noise level is $82 \mathrm{~dB}$ re $1 \mu \mathrm{Pa}$, and the hydrophone can receive the signals from a maximum distance of $23 \mathrm{~m}$.

The noise in the deep-ocean areas is caused only slightly by winds and marine life, but the most probable source of noise appears to be the shipping noise and oceanic turbulence. From the Wenz curves, we find that the average noise of light shipping is 63 $\mathrm{dB}$ re $1 \mu \mathrm{Pa}$, the moderate shipping is $74 \mathrm{~dB}$ re $1 \mu \mathrm{Pa}$ and the heavy shipping is $82 \mathrm{~dB}$ re $1 \mu \mathrm{Pa}$. Assuming a simplified approximation at the point source, the hydrophone can be estimated to collect acoustic signals from the maximum distance of $60 \mathrm{~m}, 35 \mathrm{~m}$ and $23 \mathrm{~m}$. 
TABLE IV. The summary of modeled signal propagation in three typical environments by considering background noise level

\begin{tabular}{|c|c|c|c|c|}
\hline \multirow{2}{*}{ Types } & \multicolumn{2}{|c|}{ Noise Factors } & \multirow{2}{*}{$\begin{array}{c}\text { Noise Level } \\
\text { (dB re } 1 \mu \mathrm{Pa})\end{array}$} & \multirow{2}{*}{$\begin{array}{l}\text { Max detect } \\
\text { distance }(\mathbf{m})\end{array}$} \\
\hline & Dominant & Additional & & \\
\hline $\begin{array}{c}\text { Shallow } \\
\text { coastal water }\end{array}$ & Wind speed & $\begin{array}{c}\text { Proximity of } \\
\text { ocean bottom } \\
\text { Self-noise }\end{array}$ & 73 & 36 \\
\hline $\begin{array}{l}\text { Ports and } \\
\text { harbors }\end{array}$ & $\begin{array}{l}\text { Shipping } \\
\text { Industrial } \\
\text { activity }\end{array}$ & $\begin{array}{l}\text { Marine life } \\
\text { Turbulence of } \\
\text { tidal currents }\end{array}$ & 82 & 23 \\
\hline \multirow{3}{*}{$\begin{array}{c}\text { Deep-ocean } \\
\text { areas }\end{array}$} & \multirow{3}{*}{$\begin{array}{l}\text { Shipping } \\
\text { Oceanic } \\
\text { turbulence }\end{array}$} & \multirow{3}{*}{$\begin{array}{l}\text { Slight winds } \\
\text { Marine life }\end{array}$} & $\begin{array}{l}\text { 63(light } \\
\text { shipping) }\end{array}$ & 60 \\
\hline & & & $\begin{array}{c}74 \\
\text { (moderate } \\
\text { shipping) }\end{array}$ & 35 \\
\hline & & & $\begin{array}{l}82 \text { (heavy } \\
\text { shipping) }\end{array}$ & 23 \\
\hline
\end{tabular}

\subsubsection{Conclusion}

The experimental results show that the electric motor signal of an ROV is the dominant source of acoustic emission and the best candidate for detecting and classifying an ROV-delivered threat. The motor signature for this particular ROV is measured as 146 $\mathrm{dB}$ re $1 \mu \mathrm{Pa}$ at a frequency of around $70-80 \mathrm{~Hz}$ and $137 \mathrm{~dB}$ re $1 \mu \mathrm{Pa}$ at a frequency of around $400-500 \mathrm{~Hz}$. By simultaneously measuring the flow field using PIV, we are able to separate the flow-induced emission from the other acoustic sources and show that water-flow signals and propeller wash are low contributions for typical ROV operations.

Building on these results, we can potentially predict the range of possible detection in three typical ocean environments. This simple model, quantifying the transmission loss 
and ambient noise in operation environments, shows that the SNR would be above $0 \mathrm{~dB}$ for the detectable range in all directions between $23 \mathrm{~m}$ and $60 \mathrm{~m}$ depending on the level of noise in the environments.

\subsection{OUTDOOR TANK EXPERIMENT}

The laboratory tank has been clearly described in the previous Section 4.1. Based on a variety of maneuvers in the laboratory tank, we were able to quantify the acoustic signature of the ROV. However, due to freshwater and the limit space affected by reverberation in the laboratory conditions, we could not completely know about the acoustic transmission, so the further research is still full of constraints.

This section aims to extend the trial to the outdoor large tank by demonstrating passive acoustic detection of ROV [47], which is an improvement to the small laboratory tank with seawater and a larger room to conduct the ROV. The acoustic signature of the whole ROV running movement will be presented based on the revised experiments. In this section, we will introduce the experimental setup, analyze the experimental processes and the acoustic detection results. Summary is stated at the end of each section.

\subsubsection{Experimental Setup}

This outdoor tank is located at the University of Hawaii Marine Center, Honolulu, Hawaii. This test was done in Feb $1^{\text {st }}, 2011$. The location was made near the harbor with multiple industrial noise and shipping noise. However, the advantage includes the tank filled with seawater makes the experiments more applicable to harbor security than the freshwater in the laboratory tank. Also, this tank is larger than one in the laboratory and has more space for the ROV motion. This experiment set up two hydrophones in two ends of the circular tank, and the ROV was controlled along the diameter of the tank. Fig.4.11 shows the rough sketch of the experimental setup. 


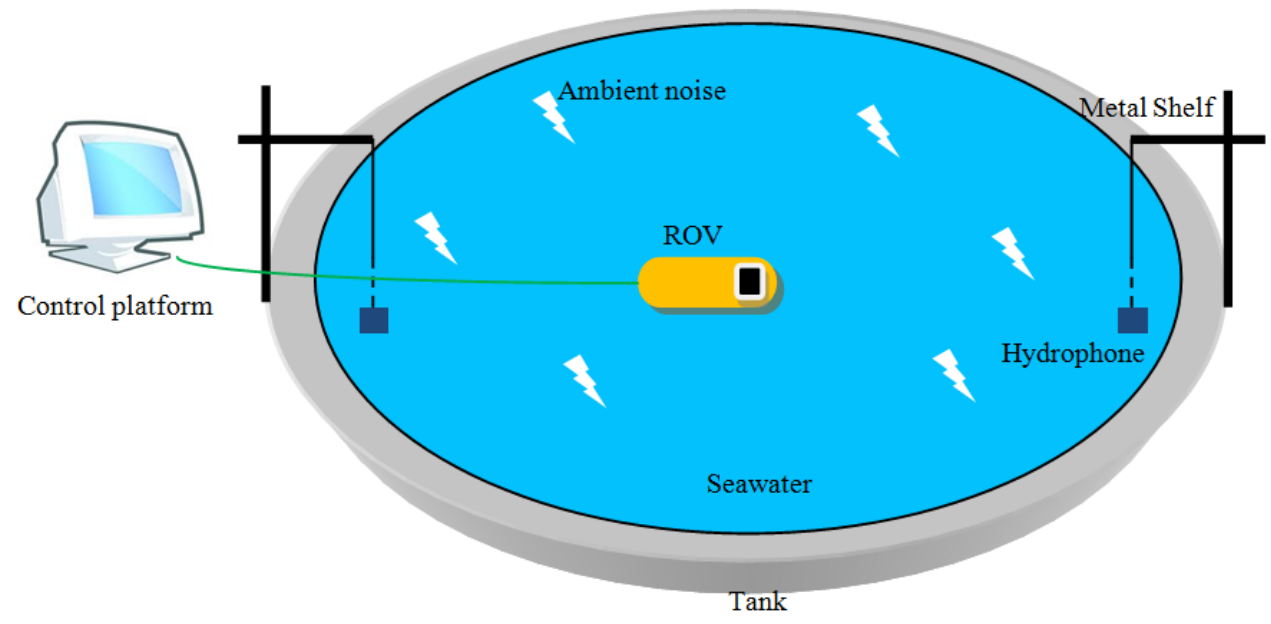

Figure 4.11. The diagram of experiment setup in the circular tank at University of Hawaii Marine Center

The diameter of circular tank is 6 meters and the depth of filled seawater is 1 meter. Two hydrophones were set about $60 \mathrm{~cm}$ below the surface of water, and attached to the metal posts extending into the water to make sure they were in a stationary condition. The hydrophones were Aquarian Audio Products H1a Hydrophones, which have been described in Chapter 3. The ROV was the same as used in the laboratory tank, LBV 150, which was operated via the tether to controllers out of the tank. Because the tank was near the industrial harbor, there was also considerable ambient noise inside the tank.

\subsubsection{Acoustic Identification}

Fig.4.12 and Fig.4.13 below compare the background noise with acoustic signals from moving ROV in a far distance (around 5.5 meters away) and near distance (0.5 meters away). They all clearly included the strong ambient noise in the low frequency (below $200 \mathrm{~Hz}$ ). That indicated the signals in this range of 70-80 Hz from ROV's mechanical noise, were hard to identify from the mixture with large ambient noise. Compared the signatures of trial (a) and trial (b), there were the differences between 400 $\mathrm{Hz}$ and $500 \mathrm{~Hz}$, which seemed to be from ROV mechanical noise, so another test (c) would be proposed to examine the signals in this range. Also, a very strong range of acoustic signals between $800 \mathrm{~Hz}$ and $2 \mathrm{kHz}$ was found during the whole period. We considered parts of these high-frequency acoustic signals would be from ROV 


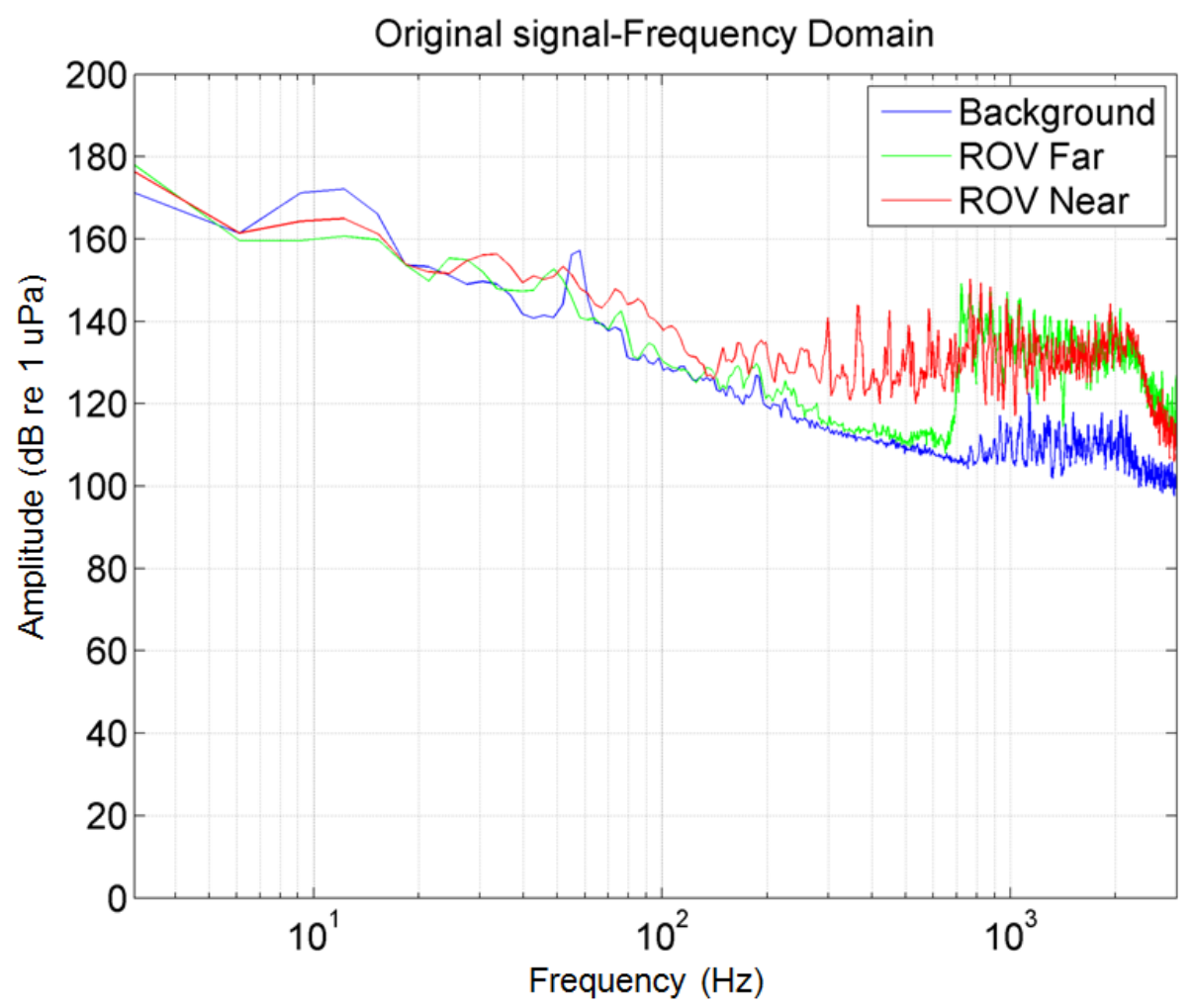

Figure 4.12. A comparison of the acoustic frequency domain recorded from the background noise and the ROV noise when it was distant from hydrophone and adjacent the hydrophone.

mechanical noise, but most signals between $800 \mathrm{~Hz}$ and $2 \mathrm{kHz}$ were from the reverberation by the tank walls. Then, comparing previous two trials with trial (c), the nearby hydrophone collected strong and steady acoustic signatures between $400 \mathrm{~Hz}$ and $500 \mathrm{~Hz}$ during the period of the ROV moving. Based on this experiment, the summary included that most signals in this range of $400-500 \mathrm{~Hz}$ were generated by $\mathrm{ROV}$ mechanisms. 


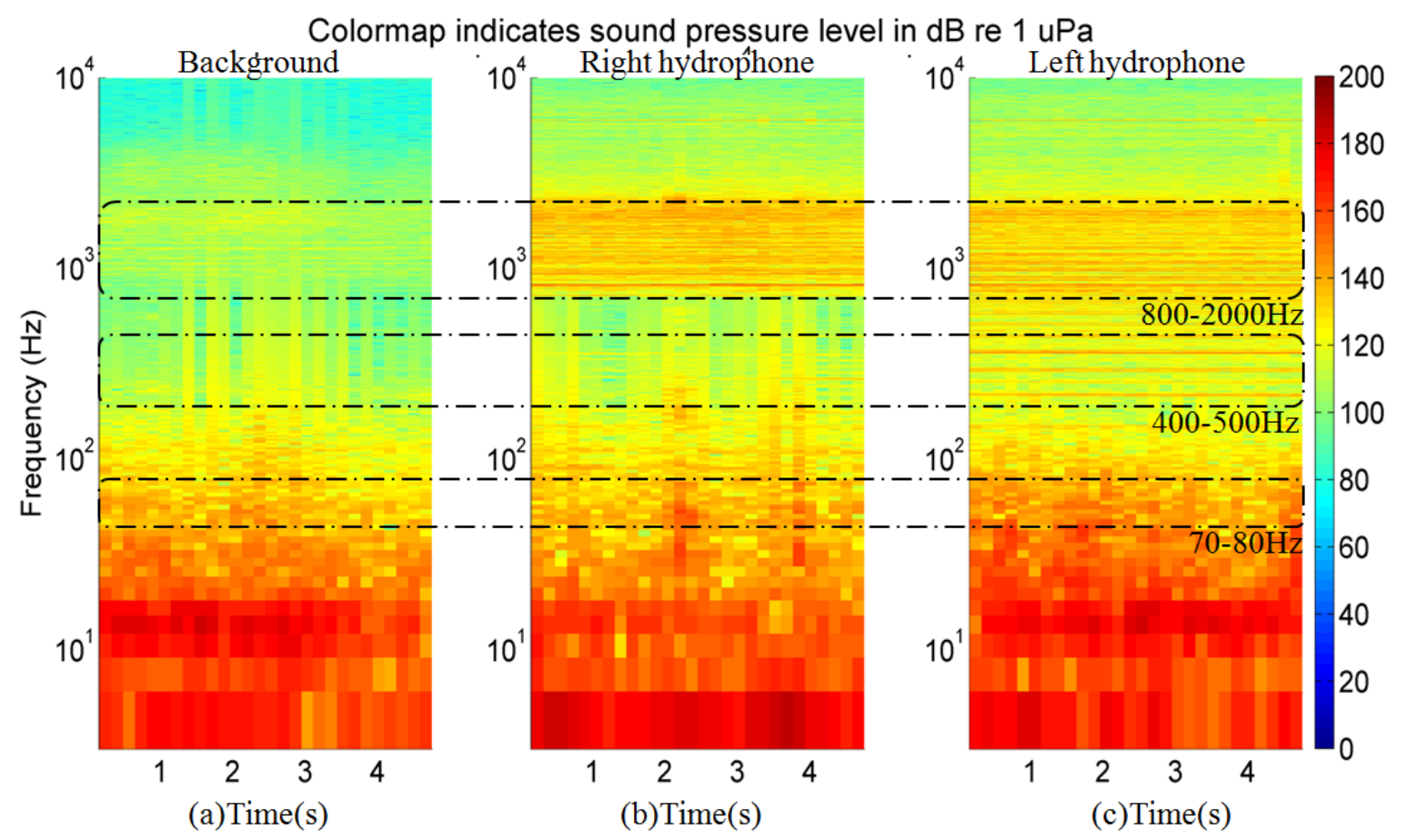

Figure 4.13. Time and frequency spectrogram of the comparison of acoustic signature when ROV was running in stationary condition close to left hydrophone. (a) is from the background noise; (b) is from right hydrophone with $5.5 \mathrm{~m}$ away from ROV; (c) is from left hydrophone with $0.5 \mathrm{~m}$ away from ROV.

\subsubsection{Acoustic Detection}

We had basic understanding of acoustic signals in different frequency ranges when the ROV was running in a stationary condition. Based on that, we tried to detect the ROV moving forward and backward in the big circular tank. The acoustic signals can be collected by two set-up hydrophones shown in Fig.4.14. 


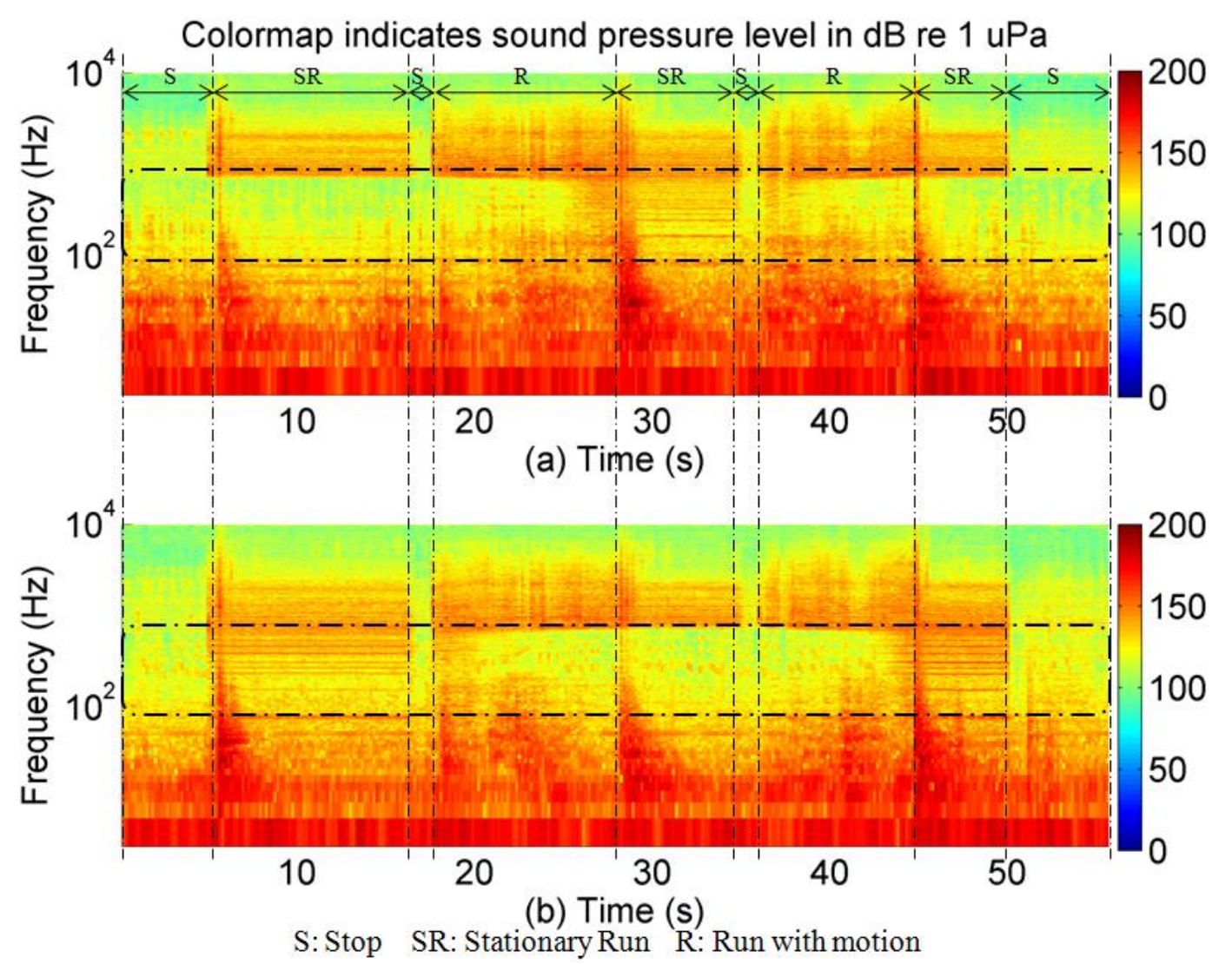

Figure 4.14. Time and frequency spectrogram of the ROV moving across the circular tank. (a) is from the near hydrophone, (b) is from the far hydrophone.

TABLE V. Experimental ROV motion in the outdoor tank

\begin{tabular}{|c|c|c|}
\hline ROV Condition & Time & Trial Description \\
\hline Stop (S) & $1-6 \mathrm{sec}$ & Ambient Noise only \\
& $35-36 \mathrm{sec}$ & \\
& $52-60 \mathrm{sec}$ & \\
\hline Stationary Run (SR) & $7-18 \mathrm{sec}$ & ROV run in stationary condition close \\
& $29-34 \mathrm{sec}$ & to one-side hydrophone. \\
& $47-51 \mathrm{sec}$ & \\
\hline Run with motion(R) & $19-28 \mathrm{sec}$ & ROV moved from one side to the other \\
& $37-46 \mathrm{sec}$ & side. ROV velocity is about $0.6 \mathrm{~m} / \mathrm{s}$. \\
\hline
\end{tabular}


The ROV was controlled at mid-depth of the water without contacting the surface water or the bottom of the tank. This test was started by background noise without any ROV motion. After 6 seconds, the ROV was running in a stationary condition close to the distant hydrophone. From the spectrogram, it was clear to see the pulse signal standing for ROV start-up. After 12 seconds continuous operation, the ROV was stopped for a short time period, and then the ROV started moving from the location with the distant hydrophone to the adjacent one. It took 10 seconds to bump into the tank wall (in 28 seconds). At this time, the ROV was running in a stationary condition near the adjacent hydrophone for 6 seconds. After 2 seconds break without any motion, the ROV started moving from the location of the adjacent hydrophone to the distant one, till bump into the tank wall again (in 46 seconds-time). It also took about 10 seconds to travel from one side to the other of the tank. Then, the ROV kept running for 5 seconds and stopped immediately at 51 seconds-time. The background noise was recorded by 9 seconds at the end for comparison.

From Fig.4.14, sound pressure levels from ROV in high frequency between $1 \mathrm{kHz}$ and $2 \mathrm{kHz}$ were found very strong all the time, which was due to the tank had relative limited space and distances, many reflection signals were added to make the original signals hard to separate. However, we could still clearly observe that the sound pressure level in this range of $200 \mathrm{~Hz}$ to $800 \mathrm{~Hz}$ was changed with the distance. When the ROV was running in a stationary condition, the acoustic signals recorded by the adjacent hydrophone had a big difference compared with the hydrophone in the other side. The experiment showed that when the ROV was moving forward or backward, the pressure levels in the range of $200 \mathrm{~Hz}$ to $800 \mathrm{~Hz}$ generally decreased or increased. Specially, the noise in the frequencies between around $400 \mathrm{~Hz}$ and $500 \mathrm{~Hz}$ seemed to be from the ROV motors and propellers, because sound source level in these two frequency ranges remained a high level, no matter whether the ROV was moving in a distant or adjacent distance to the hydrophones. 


\subsubsection{Conclusion}

This outdoor tank test is an improvement and compensation for the laboratory tank test because of the seawater instead and larger space. Based on the repeated trails, this experiment succeeded to identify the water flow noise and ambient noise. Although the influence of reverberation acoustic level and ambient noise still remained, we figured out that the water flow signals between $200 \mathrm{~Hz}$ and $800 \mathrm{~Hz}$ had a clear variation trend, while the signals from $800 \mathrm{~Hz}$ to $2000 \mathrm{~Hz}$ were considered from reverberated noise. In addition, this experiment addressed the frequency ranges of $400 \mathrm{~Hz}$ to $500 \mathrm{~Hz}$ were from $\mathrm{ROV}$ motors and they can be used as signal sources for passive detection. The measured distance of the path was around 6 meters, so the velocity of ROV in the tank could be calculated around $0.6 \mathrm{~m} / \mathrm{s}$.

This section makes a vital transition from laboratory tank test to the field test. It is helpful to further understand the acoustic signatures from the ROV. Next section will focus on the field test and assess the feasibility of acoustic detection in an open-ocean environment.

\subsection{FIELD TEST EXPERIMENT}

The experimental analysis of the data from the tests in the laboratory and outdoor tanks has been shown in previous sections, which presented the capability of the underwater acoustics involved in this study. The results suggest that it is feasible to detect the underwater acoustics from the ROV. The experiments in the tanks are both under relatively ideal and controllable environments. However, most current applications for acoustic detection should occur in ports and harbors, and other shallow water environments. The true field implementation (ports and harbors) are different than any tank environment, because the various weather conditions and underwater ocean creatures would bring more difficult progress. Therefore, this section extended the research work to a shallow-water coastal environment with considerable ambient noise. The field tests required significant changes in the hardware platform which created its 
own set of problems and issues. This also calls for additional software components to make the hardware work and achieve the final results.

This section describes a field test, which was located at Makai Pier, Oahu, Hawaii. Since the experiments occurred in the winter time with sea state from the coastal water, a significant amount of acoustic interferences were encountered. The field tests were

conducted at Makai Pier on Nov. $3^{\text {rd }}$ and Dec. $5^{\text {th }}, 2010$, large ambient noise could mix the experimental results with significant signal disturbances from the ocean and winds.

This session will also include the experimental setup, analyze the ambient noise from the port environment, consider the passive acoustic signals for detection, and then summarize the experiments results.

\subsubsection{Experimental Setup}

Fig.4.15 illustrates the experimental locations for four acoustic detection tests. The Environmental conditions, such as the ocean waves and marine animal noise, disturbed controls of ROV, so the paths of ROV were not followed as expected. The remote GPS was fixed on a surface float, which was tethered to the top of underwater ROV, to track the positions of the ROV. Four tests were plotted by the different color tracks in Fig.4.15. Two hydrophones were placed by the yellow marks as Hydrophone (\#1) and (\#2), separately by $58 \mathrm{~m}$ apart at a depth of $2.3 \mathrm{~m}$. The ROV was operated in the trial area between two hydrophones. The experiment measured the signal-to-noise ratio (SNR) of the ROV acoustic signature as a function of distance from both hydrophones. From the tests, the ROV position was measured by a GPS-enabled surface float to provide the ground truth for comparison to the acoustic tracking. 


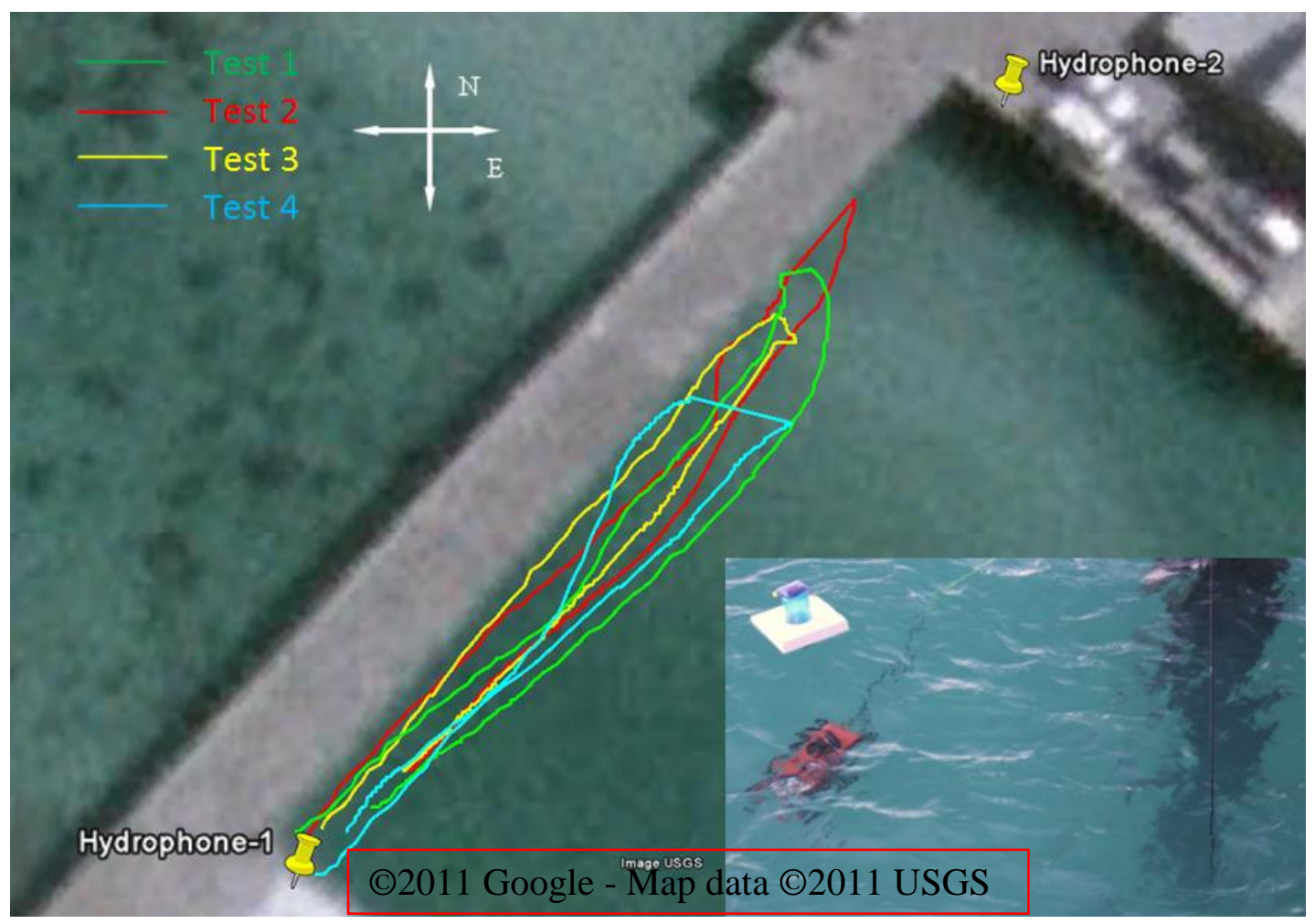

Figure 4.15. The field test was conducted at Makai Pier, Oahu, Hawaii. Shown as its image is from Google Earth with an insert of a camera shot of the ROV, the GPS float and a hydrophone. The GPS was used to track the ROV movements in the four tests and imposed on the Google Earth image. Two hydrophone locations are shown as yellow pins.

\subsubsection{Noise Impact}

Fig.4.16 shows one data sample of ambient noise for 60 seconds from data (a) by hydrophone (\#1) set in the adjacent position, and data (b) shows hydrophone (\#2) set in the distant position. From the spectrogram of ambient noise, we could find a large amount of continuous ambient noise in the high frequencies of $2 \mathrm{kHz}-3 \mathrm{kHz}$. Also, there was some ambient noise in the low frequencies below $50 \mathrm{~Hz}$. Through the previous analysis of ambient noise in Chapter 3, we could understand those low-frequency signal noise was mostly from tides, seismic noise ocean turbulence. In addition, some sound pulses were shown in the figure, they were from the constant back and forth resources on the hydrophones created by the waves. From data (a), there were unique signals at the 
frequencies of around $200 \mathrm{~Hz}$, which appeared to originate from the sound sources on shore like travel noise, because this hydrophone was very close to the land.

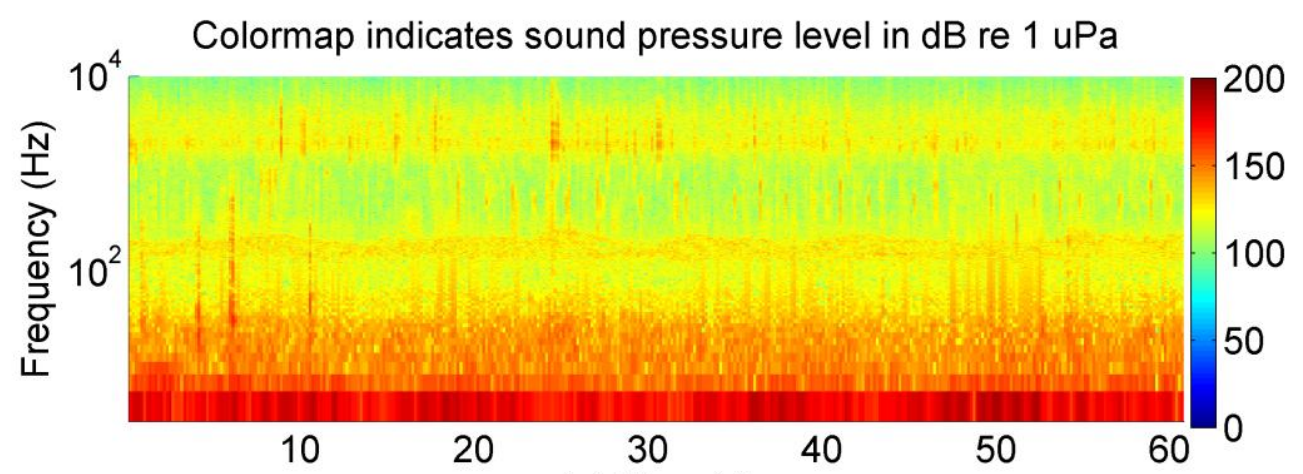

(a) Time (s)

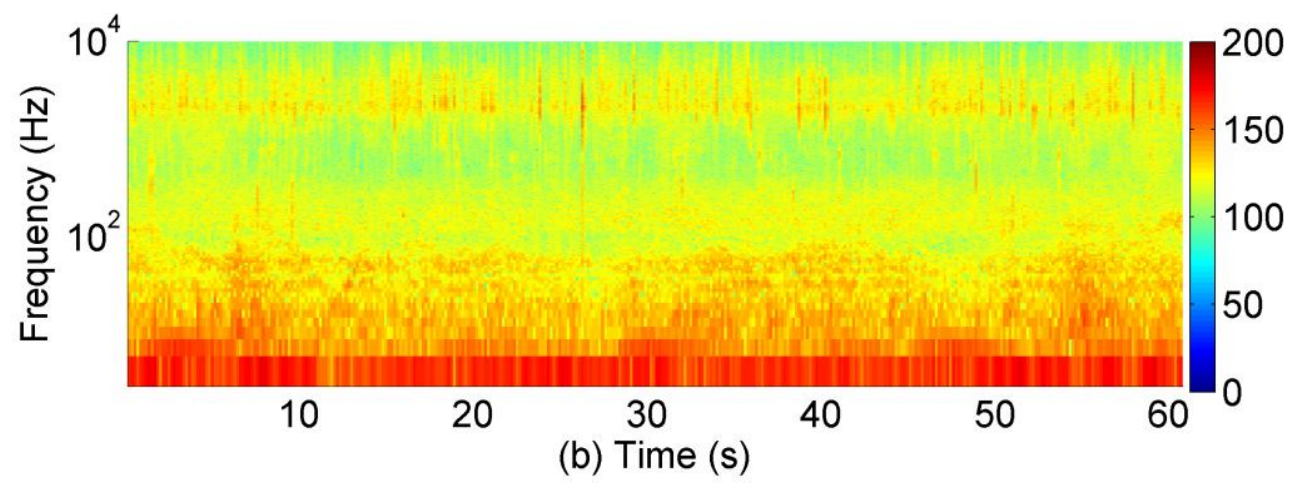

Figure 4.16. Ambient noise in field tests was recorded for 60 seconds. Data (a) is from the near hydrophone (\#1); Data (b) is from the far hydrophone (\#2).

Another sound effect in the field test is the enhancement of sound due to the walls in the port. When low frequency acoustic signals are radiated by the ROV, the sound level distribution along the port results to large deviations. This is due to the multiple reflection of sound at the rigid walls of the port, so this may cause level differences for acoustic measurement. Some of these deviations are associated with the standing waves, resonances or anti-resonances. In this matter, the method to understand the enhancement of sound is to analyze the behavior of low frequency sound in time-frequency domain. In [48], they analyzed the low frequency sound field enhancement system and implemented the simulation. In my experiment, I simplified this mathematical process, and chose the first acoustic peak value in time domain considered as ROV acoustic signal. 


\subsubsection{Acoustic Identification}

From Fig.4.17, ambient noise at low frequencies below $100 \mathrm{~Hz}$ was found very strong and would probably covered mechanical noise from the ROV, so it was hard to identify the signals in a low frequency range. Also, the high frequency above $3 \mathrm{kHz}$, the ambient noise was mostly from electronic thermal noise and bubble noise from breaking waves which could be ignored. Through the experiment, acoustic signatures in the frequency range from $100 \mathrm{~Hz}$ to $3 \mathrm{kHz}$ are shown in Fig.4.17. Field Test 4 was prepared to analyze ROV acoustic signatures because this test occurred at a time of lower ambient noise. The ROV was travelling from the adjacent hydrophone (\#1) toward the distant hydrophone \#2. Data (a) is recorded by Hydrophone (\#1) shows very evident mechanical noise from ROV and water flow between $200 \mathrm{~Hz}$ and $1 \mathrm{kHz}$ when the ROV was nearby. As the ROV moved away, the sounds generally decreased and then were not evident after 30 seconds. Similarly, for the hydrophone (\#2) in data (b), water flow noise appeared after 90 seconds, as the ROV approaching to the hydrophone (\#2). In this same period, consistent lines around 380-410 Hz and around 490-520 Hz remained in (a) and appeared in (b) as the ROV approached to the distant position. We could identify these signals as persistent motor noise from ROV for acoustic detection. 


\section{Test 4 Colormap indicates sound pressure level in $\mathrm{dB}$ re $1 \mathrm{uPa}$}

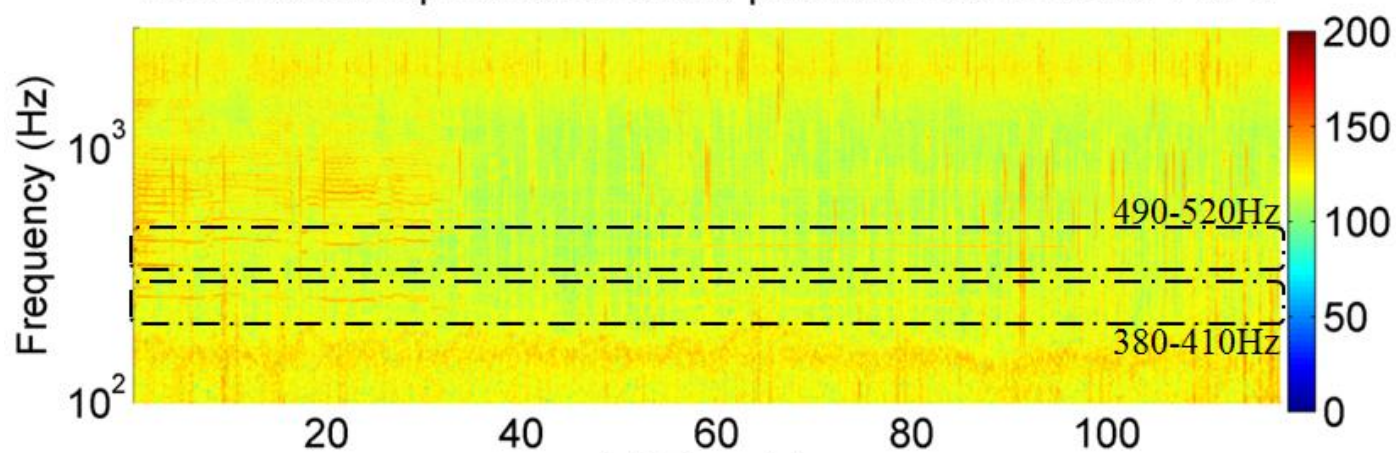

(a) Time (s)

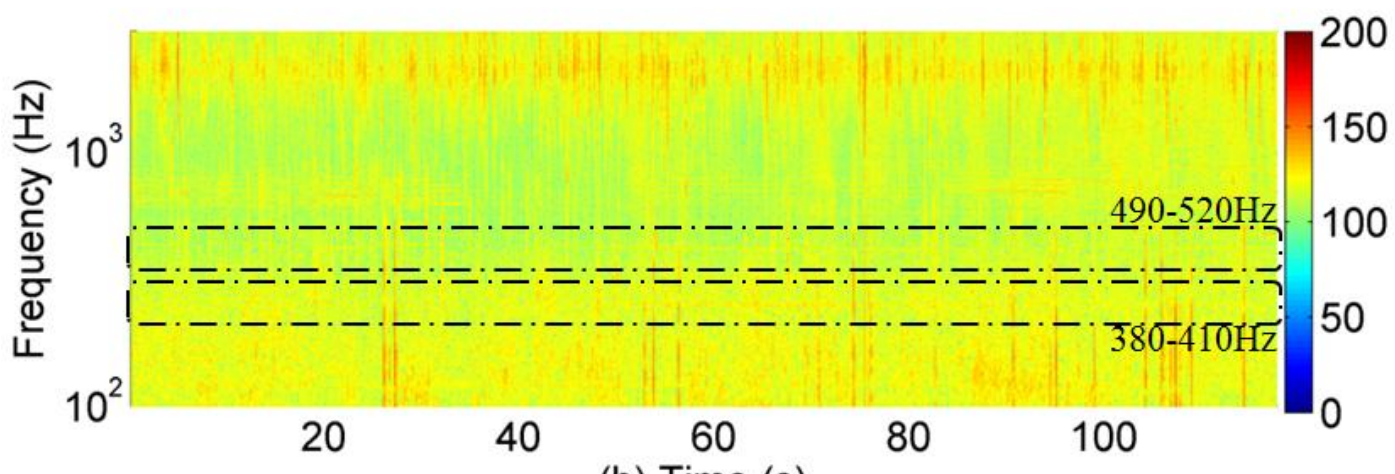

(b) Time (s)

Figure 4.17. ROV acoustic signature in Field Test No.4 was recorded for 120 seconds. Data (a) is from the adjacent hydrophone \#1, data (b) is from the distant hydrophone \#2

\subsubsection{Acoustic Detection Analysis}

The preliminary results shown in Figure 4.15 included four field tests, where the ROV positions were determined by a GPS on a surface float and its acoustic signals were recorded simultaneously by two hydrophones as it moved between them. The experiment could observe the sound amplitude level in different frequency ranges. Due to the high ambient noise, the acoustic signature below $100 \mathrm{~Hz}$ from ROV was hard to find. From Fig.4.27, the acoustic signature at $380-520 \mathrm{~Hz}$ could be the best bandwidth for passive detection.

Fig.4.18 plots the relationship for the average SPL of the ROV acoustic signature in the certain frequency range, as a function of the distances between the hydrophone (\#1) and ROV target. The color dots present four trial test results. The horizontal axis indicates the distance measured by GPS between the hydrophone and the ROV, the 
vertical axis indicates the limited SPL measured by hydrophone (\#1) at a corresponding time of 120 seconds during each run. The black horizontal line indicates the average level of measured ambient noise by approximately $116 \mathrm{~dB}$ re $1 \mathrm{uPa}$. From our four tests separated in the different time, the mean level of fluctuation is $\pm 1 \mathrm{~dB}$ re $1 \mathrm{uPa}$. Besides, after $30 \mathrm{~m}$ running operations, the measured signals would be disturbed and mixed by the equal-value ambient noise.

When the detectable SPL from ROV got lower and closer to a certain noise level, it would limit the detectable distances for underwater targets. Based on that, it was possible to estimate the distances by detectable acoustic signals and found out the real GPS positions. As a result, this experiment could predict the maximum and minimum distances upon the ambient noise of $116 \mathrm{~dB}$ re $1 \mathrm{uPa}$ were about $22 \mathrm{~m}$ and $15 \mathrm{~m}$ away from the hydrophone (\#1), which had a 7 m-range variation.

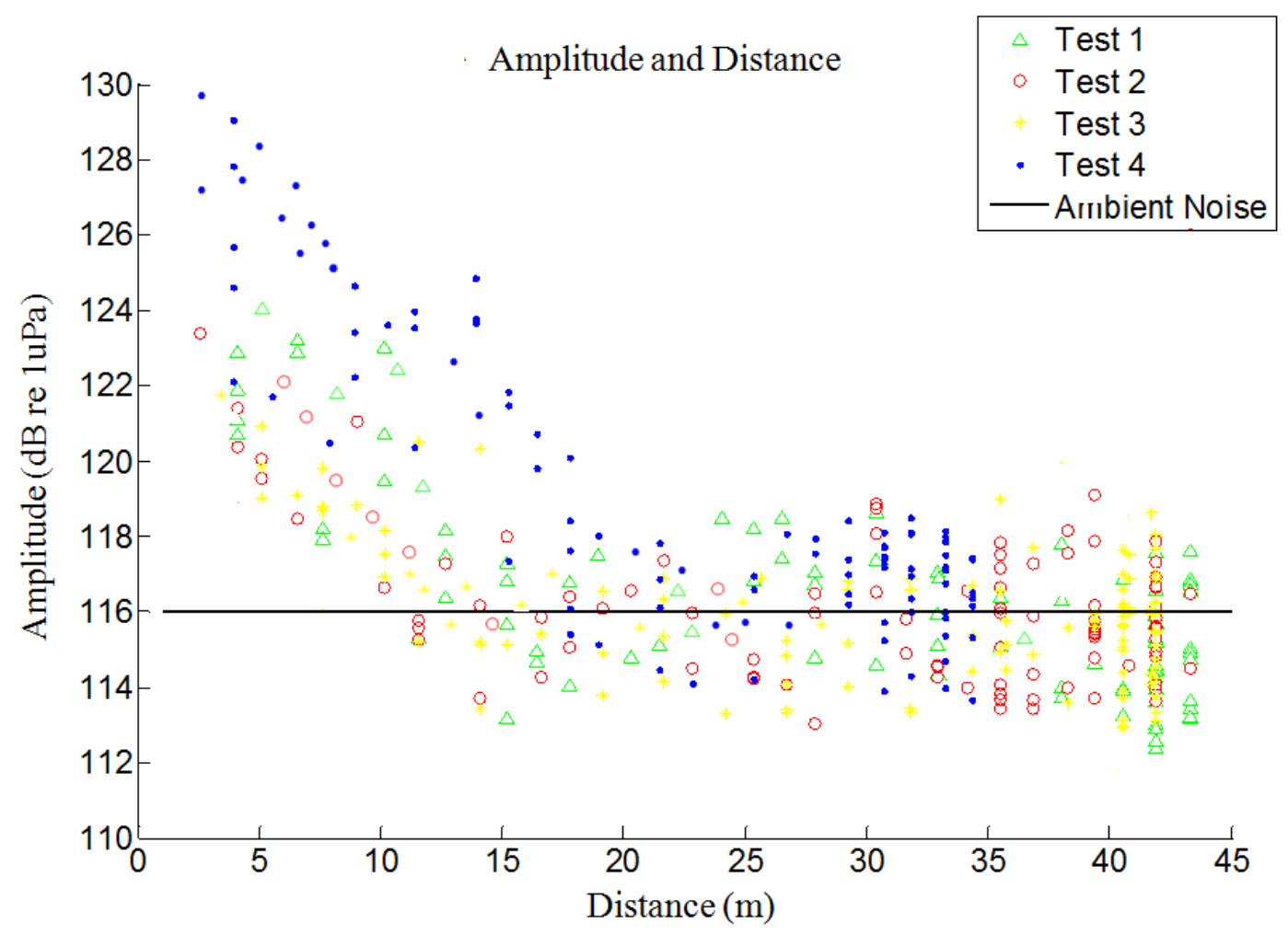

Figure 4.18. Experimental data in four trial runs. Shown is the relationship of the average SPL in the frequency ranges of 380-420 Hz and 490-520 Hz, and GPS measured distance. $\mathrm{X}$-axis shows the distance measured by GPS; Y-axis shows the band-limited SPL. 


\subsubsection{Conclusion}

This is the last section of the experimental analysis. The experiment succeeded to assess the feasibility of the passive acoustic detection in the shallow-water port environment with a large amount of ambient noise. Two previous tank tests gave the basic understanding of ROV acoustic signatures, which would help locate the detectable frequency ranges in 400-500 $\mathrm{Hz}$.

Be different from two previous tests, this field test had more detection space to detect the ROV motion and enough depth to place the hydrophone in the seawater environment. From the experiment, transmission loss of acoustics could be measured in seawater during the detectable distances of ROV. Also, this section presented the analysis of ambient noise, which was a complex and significant concern for passive acoustic detection.

GPS-surface float was used in this experiment to record the actual distance and compare the data with acoustic measurement results. From the experimental tests, we found that this passive acoustic method was reasonable and available to detect underwater targets and estimate the target distance. In all, we found the acoustic signals of $380-410 \mathrm{~Hz}$ and $490-520 \mathrm{~Hz}$ were the main components for passive detection. Based on SNR of this test, it was possible to detect the ROV distance with minimum $15 \mathrm{~m}$ and maximum $22 \mathrm{~m}$ away in large ambient noise environment. 


\section{CHAPTER 5}

\section{RESULTS AND DISCUSSION}

Based on the analysis of previous chapters, we developed the research with further improvement from simple to complex conditions and showed different experimental results in three typical environments [49], [50]. These tests were started at a laboratory test tank, then extended to the outdoor tank and finally to field test in the shallow-water environment. They clearly showed the characterization of acoustic signature from ROV mechanisms and the acoustic propagation in the water.

This chapter focuses on the comparison of three experimental results and analyzes acoustic signals in different frequency ranges. The main components for underwater detection of a small ROV are identified. In addition, this chapter will present the prediction results with measurement results, and deploy data precision analysis.

\subsection{Experimental Results}

This paper presents the results from three passive acoustic evaluation of the signature emitted from a small COTS ROV. These results are summarized in Fig. 5.1. In the frequency range of $0-50 \mathrm{~Hz}$, the strong signals were mostly from the water flow noise, so it was difficult to find signals from ROV mechanisms. In the frequencies between 70 $\mathrm{Hz}$ and $80 \mathrm{~Hz}$, the signals can be only found in data (a), because the large ambient noise in Fig. 5.1 (b) and (c) always affected the signals detection in those lower frequencies. Acoustic emission in the 100-200 Hz range in laboratory tank and outdoor tank could be detected, but not found in the field test, which suggested that the actual detection would 
rely on higher-frequency components of an ROV signature. Fig. 5.1 (b) illustrates that the high frequency band between $800 \mathrm{~Hz}$ and $2000 \mathrm{~Hz}$ was part of components from the running ROV, but most of the signals were caused by the signal reverberation in the tank. Therefore, from all the comparisons above, we conclude the components of the signature in the two spectral bands of $380-410 \mathrm{~Hz}$ and $490-520 \mathrm{~Hz}$ are the most promising for acoustic detection, and they can be detected in the typical of a shallow-water environment.

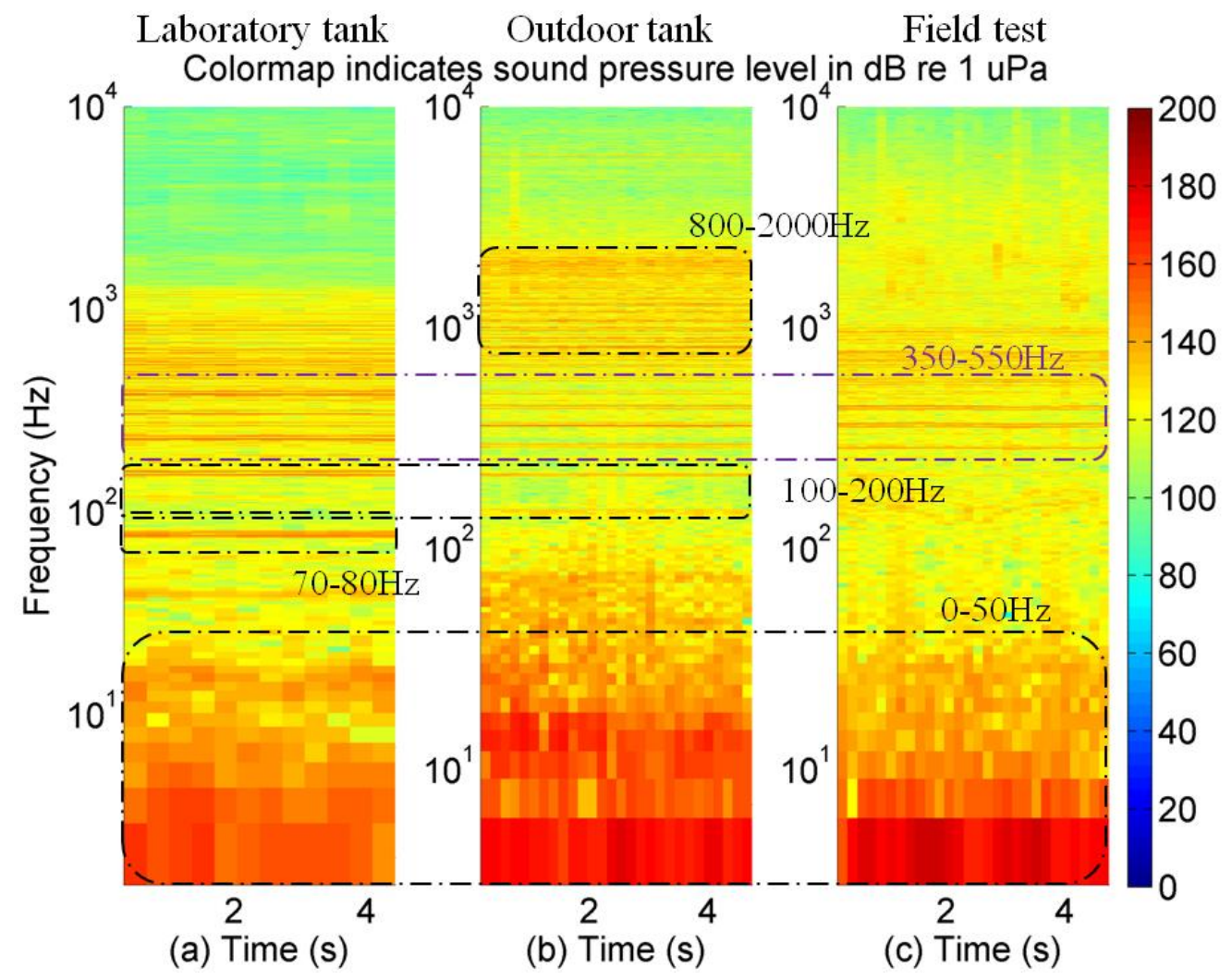

Figure 5.1. The comparison of different acoustic tests when ROV was running. Separately the data was from (a) Laboratory tank; (b) Outdoor tank; (c) Field test.

\subsection{Prediction and Measurement of Acoustic Signals}

Based on the laboratory and field tests, we simulated the acoustic signal propagation for the detectable distance to compare the measurement in the shallow-water environment. Fig.5.2 shows the comparison of signal predicted values and signal 
measured values in the sound level with frequency ranges of $380-410 \mathrm{~Hz}$ and $490-520 \mathrm{~Hz}$. Black line shows the maximum prediction for ROV acoustic is $137 \mathrm{~dB}$ re $1 \mathrm{uPa}$ and has the decreasing trend as the transmission loss. Similarly, blue dots indicate the average SPL recorded by each second when ROV was moving backward off the hydrophone position. When distances were greater than $22 \mathrm{~m}$, the acoustic signature level was below the ambient noise and mixed into the noise level. When the ROV was in the distant place, mutiple jump points were appeared, which were due to the ROV motors were reactivated in a far distance. The comparison in Fig. 5.2 certifies that the average measured levels in each distance matched predicted levels with a precision of $\pm 3 \mathrm{~dB}$ re $1 \mathrm{uPa}$ in sound amplitude level and $\pm 3 \mathrm{~m}$ in distance range, which is the result of observing the whole process of ROV motion and averaging the errors.

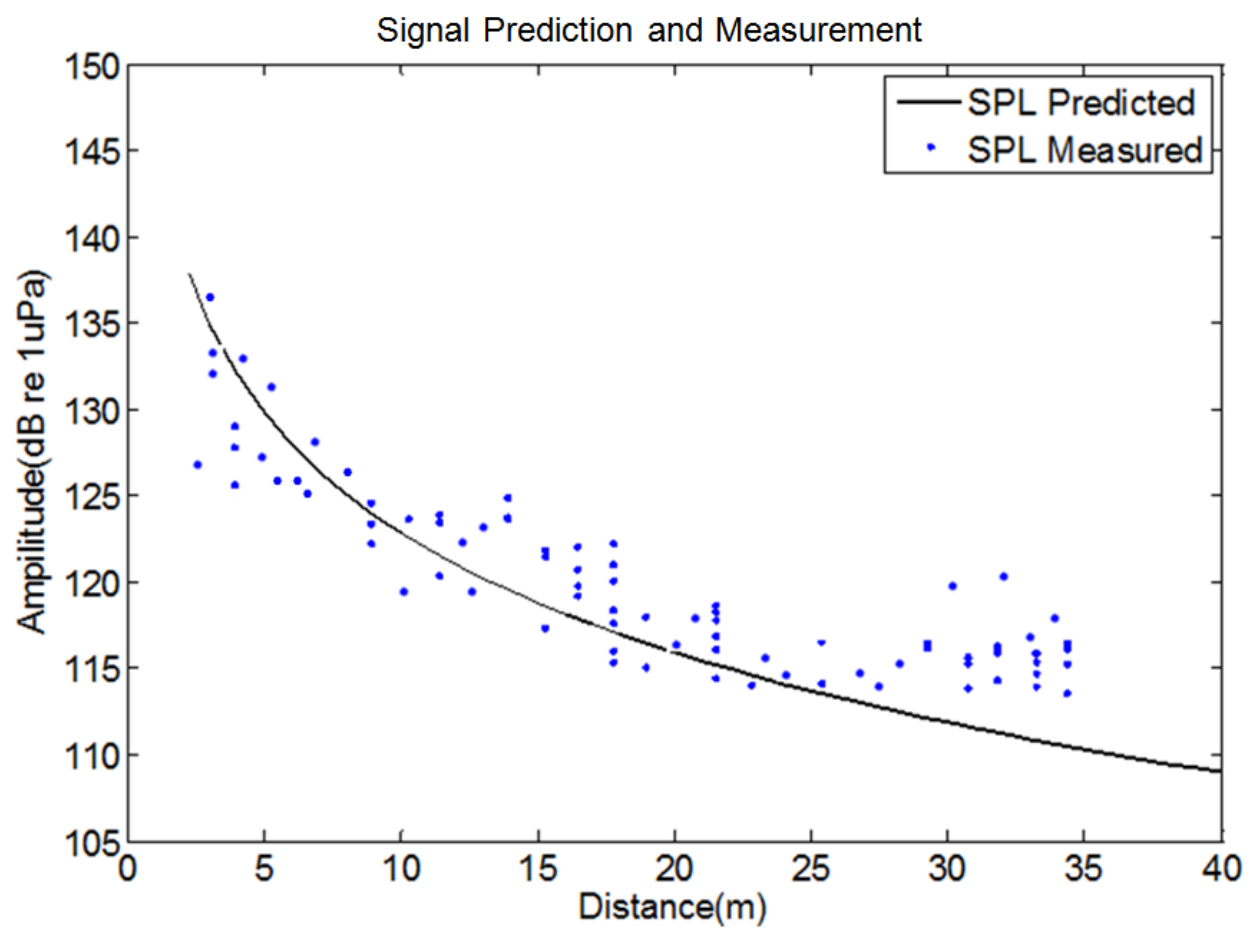

Figure 5.2. The comparison of acoustic signal prediction and measurement. The frequency ranges of acoustic signature are $380-410 \mathrm{~Hz}$ and $490-520 \mathrm{~Hz}$ 


\subsection{Conclusion}

This chapter addressed the comparison of experimental procedure for the ROV measurement in three typical conditions. It showed the acoustic signals in different frequency ranges and presented the results from the signal sources. While excluding other signals, we concluded that the signals with frequency ranges between $350 \mathrm{~Hz}$ and $550 \mathrm{~Hz}$ were the main components for passive acoustic detection. In addition, we compared the signal predicted levels with signal measured levels from ROV. The experiential results showed that the sound prediction value matched the actual measurement values with a precision evaluation at $\pm 3 \mathrm{~dB}$ re $1 \mathrm{uPa}$ in sound amplitude level and $\pm 3 \mathrm{~m}$ in distance.

This project demonstrated the passive acoustic method can be used to estimate the distance of underwater vehicle such as a small object ROV. 


\section{CHAPTER 6}

\section{CONCLUSION}

\subsection{Summary}

This paper started with a literature review of related academic research, summarized previous and current progress in underwater acoustic fields. From the detailed description in Chapter 1 and Chapter 2, we found that underwater acoustic was specialized and esoteric knowledge for further exploration. Numerous studies showed that acoustic detection was a promising and developing research topic of interests in the marine security. From Chapter 3, the experiment was turned to address the experimental approaches and designs for own projects, which included the reasonable electronic instruments, experimental platforms for collecting and analyzing the acoustic signals. Chapter 3 also presented the passive SONAR equation with the detailed explanation to each component of sound levels. Based on the understanding of acoustic detection methods, we addressed these models for further calculations and analysis on passive acoustic detection.

The main experimental processes and results were stated in Chapter 4. This chapter first presented the experimental characterization of the acoustic signature and flow fields of a maneuvering ROV conducted in a laboratory test tank. The detailed classification on mechanical noise of ROV has been pointed out. Acoustic analysis method was used to illustrate ROV thrusters. Then we simulated the sources of emission for detecting an ROV in three typical environments. Due to the sound propagation in lower frequencies produced by an underwater vehicle, this experiment has not taken into account the noises in the high frequency range of over $1 \mathrm{kHz}$. 
From the analysis of outdoor tank test and field test, water flow signals from the moving underwater vehicle were found by a relatively low contribution for typical ROV operations, because the sound pressure level of water flows could not be detected at a distant distance. Consequently, the flow-induced signals could not be used for underwater vehicle detection. From the experimental data, we found the acoustic signals due to propeller wash were also a minor component for reliable detection for the ROV threats.

Finally, the comparison results suggested the acoustic signatures from the electric motors were the most reliable and persistent signals for detecting such a small ROV. We found the electric motor signals were arrayed in different frequency ranges: around $80 \mathrm{~Hz}$, around $400 \mathrm{~Hz}$ and around $500 \mathrm{~Hz}$. The choices of different frequencies for detection were based on the specific applications. In the indoor laboratory environment, the ambient noise was relatively low to quantify acoustic signals in the frequencies around 80 Hz. However, in the outdoor field environment, the ambient noise was too stronger to cover the ROV acoustic signals in the low frequencies below $100 \mathrm{~Hz}$. In this case, it was necessary to find the acoustic signals of around $400 \mathrm{~Hz}$ and $500 \mathrm{~Hz}$ instead of further passive detection. In the prediction, the estimated detection distances in a shallow water and port environment were $36 \mathrm{~m}$ and $23 \mathrm{~m}$. In the actual measurement of the port environment, the detection distance found by GPS tracking was in the range of $15 \mathrm{~m}$ and $22 \mathrm{~m}$. It demonstrated that the prediction for detection matched the actual measurement. To conclude this project, we can use passive acoustic method to detect an underwater ROV. Based on detectable sound pressure levels in an open-noisy-ocean environment, the distance of underwater ROVs could be measured.

\subsection{Limitation of Approach}

During the maneuvers, the optimization of the experimental setup was a critical factor to consider. However, in the actual situation, there were many uncontrollable

environments and variable factions brought to the experiments in the tank and the field tests. Here are the restrictions from the project. 
In the field test, both naval and commercial port facilities were generally located in the shallow-water areas. At these depths, the outside environment had strong influences on the performance of all acoustic surveillance and detection systems. Moreover, the factors of background environments were always variable with the changes of location, shipping and industry densities, time of days and biological activities. In this case, all these conditions would make the experiments more complex to master.

Compared with the field test, the indoor test in the laboratory had relatively steady states. However, the limited space and freshwater in the tank, would also pose some adverse influences. The limited space in the small tank brought more sound reflection and refraction, which strengthened signal interferences and caused more trouble for acoustic detection. The freshwater in the indoor laboratory was another problem, because the low salinities and densities would affect the sound propagation and transmission loss, decrease the precision and accuracy of detection. Since we only measured the ROV sound source in the laboratory tank with the distance only $30 \mathrm{~cm}$, so in this part, we have not considered the transmission loss, however, the open sea environment in the simulation models has been considered. In addition, if further considering the sound absorption by tank materials, that would make the experiments more complex to analyze. So for such near field conditions like this experiment, measurement absorption by materials could always be negligible.

Based on the restrictions between laboratory tank test and the field test, another outdoor tank test with seawater was conducted. It could make up part of the limitation and build up the relationship from the previous two tests. However, this outdoor tank test was still hard to avoid the variable ambient noise and reverberation levels, so the restriction and limitation still remained in the outdoor tank test.

\subsection{Applications}

The significant application for underwater acoustics is for underwater detection, navigation and tracking. Unlike most radio signals which are quickly absorbed, sound 
signals could propagate in the underwater environment and easily collected by electronic devices. Thus, acoustic technology can be used to measure distances between a tracking target and the reference objects, triangulate the position of the targets with high accuracies. Based on that, passive acoustic methods can be used for U.S. naval patrols and Coastal Guard to detect against underwater threats.

Underwater acoustic detection is also possible to predict the mechanical motion in the industry, such as underwater building construction, offshore exploration and undersea creature research. In addition, that is reasonable to find similar applications in the commercial and industry, apart from the military applications.

\subsection{Future Work}

Based on current understanding of underwater acoustics, there still has quite a long way to improve experimental processes. Underwater acoustic detection would bring various future works for researchers. In my opinion, some aspects have certain possibilities to strengthen and optimize with respect to these fields, so the detailed descriptions are presented in the following.

1. Detail acoustic propagation for prediction. This project used simple mathematical models to estimate the sound pressure level, but in fact, the model should be more complex than that, especially for the transmission loss and Doppler shift effects. Also, the ROV mechanism signature should be not limited in the classification as we had, this signal like electromagnetic noise is not considered in this project analysis.

2. Characterize the wake completely. Three dimensional characteristics and outdoor PIV systems must be taken into account in the future test. Because both would be more helpful for researchers to understand the flow dynamics, measure instantaneous velocity and observe the movement of water flow with particles. But this is still a hard work to realize with the limitation of instruments. 
3. Setup multiple hydrophones. Single hydrophone always misses acoustic data and detects imprecise data during the collection. In order to improve accuracy and precision for underwater detection, multiple hydrophones can compensate for each other and be a better improvement to minimize signal losses.

4. Determine the precise underwater locations of hydrophones. Based on the maximum acoustic detection distances, multiple hydrophones should be set up in different places to cover the whole areas and avoid missing the signals from underwater targets or threats.

5. Further research on acoustic localization and navigation tracking. Sound is the only source of information in the underwater scenario, so the identification and classification of sound sources should be done on the basis of the observed acoustic wave characteristics. Moreover, with the support of more set-up hydrophones, we can use time-flight methods and sound pressure levels to find the distances between the hydrophones and underwater targets.

6. Develop and strengthen monitoring systems. Underwater acoustic detection has an extensive perspective for homeland security threats. The main underwater targets for threats detection are divers, unmanned vehicles and submarine. For those applications to protect the homeland security and defeat the security threats, the systems must enable precise positioning and accuracy navigation to the security area. 


\section{REFERENCE}

[1] Port Security: The National Center for Secure \& Resilient Maritime Commerce, available at: http://www.stevens.edu/csr/about/index.html.

[2] Center for Island, Maritime, and Extreme Environment Security, available at http://www.cimes.hawaii.edu/.

[3] Chen, X., Wang, R. and Tureli, U., "Passive Acoustic Detection of Divers Under Strong Interference", OCEANS 2006, 2006, 1 -6.

[4] Sorensen, E., Ou, H., Zurk, L. and Siderius, M., "Passive acoustic sensing for detection of small vessels", OCEANS 2010, 2010, 1 -8.

[5] Averbuch, A., Zheludev, V., Neittaanmäki, P., Wartiainen, P., Huoman, K. and Janson, K., "Acoustic detection and classification of river boats", Applied Acoustics, 2011, 72, 22 - 34.

[6] Glegg, S., Olivieri, M., Coulson, R. and Smith, S., “A passive sonar system based on an autonomous underwater vehicle", Oceanic Engineering, IEEE Journal of, 2001, 26, $700-710$.

[7] Lennartsson, R., Dalberg, E., Persson, L. and Petrovic, S., "Passive acoustic detection and classification of divers in harbor environments", OCEANS 2009, MTS/IEEE Biloxi Marine Technology for Our Future: Global and Local Challenges, 2009, 1 -7.

[8] Stolkin, R., et al., "Feature based passive acoustic detection of underwater threats", Photonics for Port and Harbor Security II, SPIE, 2006, 6204, 620408.

[9] Borowski, B., Sutin, A., Roh, H.-S. and Bunin, B., "Passive acoustic threat detection in estuarine environments", Optics and Photonics in Global Homeland Security IV, SPIE, 2008, 6945, 694513.

[10] Petrovic, S., Dalberg, E., Lennartsson, R. and Persson, L., “Analysis of underwater acoustic and electric noise in the port of Gothenburg", OCEANS 2008, 2008, 1 -5.

[11] Chen, X. and Tureli, U., "Passive Acoustic Detection of Divers Using Single Hydrophone Signals", Systems and Computers, 2006. ACSSC '06 Fortieth Asilomar Conference on, 2006, 554 -558.

[12] Hazelwood, R. and Robinson, S., "Underwater acoustic power measurements in reverberant fields", OCEANS 2007 - Europe, 2007, 1 -6. 
[13] Vaccaro, R., "The past, present, and the future of underwater acoustic signal processing”, Signal Processing Magazine, IEEE, 1998, 15, 21 -51.

[14] Stolkin, R. and Florescu, I., "Probabilistic analysis of a passive acoustic diver detection system for optimal sensor placement and extensions to localization and tracking”, OCEANS 2007, 2007, 1 -6.

[15] Stolkin, R., Radhakrishnan, S., Sutin, A. and Rountree, R., "Passive acoustic detection of modulated underwater sounds from biological and anthropogenic sources", Proceedings of OCEANS 2007, 2007, 1 -8.

[16] Herman M., "Sound in the sea, from ocean Acoustics to Acoustical Oceanography", Cambridge University Press, 2005.

[17] Urick, R. J., Principles of Underwater Sound, Third Edition, New York: McGrawHill, 1983.

[18] Cuschieri, J. and Frandsen, S., "Acoustic signature of an AUV”, Acoustical Society of America Journal of, 2003, vol. 114, iss. 4, 2333-2333.

[19] REMUS 100, HYDROID Inc, available at: http://www.hydroidinc.com/remus100. $\underline{\mathrm{html}}$.

[20] Calvo, O., Sousa, A., Bibiloni, J., Curti, H., Acosta, G. and Rozenfeld, A., "Lowcost Autonomous Underwater Vehicle for underwater Acoustic Inspections", Maritime research, Journal of, 2009, vol. 6, no. 2, 37-52.

[21] Jason II, Wood Hole Oceanography Institute available at: http://www.whoi.edu/ page.do?pid=8423.

[22] Lennartsson, R., Dalberg, E., Fristedt, T., Nolander, E. and Persson, L., "Electric detection of divers in harbor environments", OCEANS 2009, MTS/IEEE Biloxi - Marine Technology for Our Future: Global and Local Challenges, 2009, 1 -8.

[23] Weiss, R., "Whales' Deaths Linked to Navy's Sonar Tests", Washington Past, Dec. 31, 2011, 1-7. Reprinted online available at: http://www.qinetiq.com/homeproducts/cer berus.SupportingPar.21560.File.pdf.

[24] Sutin, A., Bunin, B., Sedunov, A., Sedunov, N., Tsionsky, M., Bruno, M., "Stevens Passive Acoustic System for Underwater Surveillance", Proceedings of Waterside Security Conference, 2010. 
[25] Sutin, A. and Bunin, B., "Acoustic research for port protection at the Stevens Maritime Security Laboratory", Underwater Acoustic Measurements: Technologies \& Results, 2009. UAM 2009. 3rd International Conference \& Exhibition, 2009.

[26] Bunin, B. J., Sutin, A. and Bruno, M. S., "Maritime security laboratory for maritime security research", Optics and Photonics in Global Homeland Security III, SPIE, 2007, $6540,65400 \mathrm{~S}$.

[27] Lennartsson, R., Robinson, J., Persson, L., Hinich, M. and McLaughlin, S., "Passive sonar signature estimation using bispectral techniques", Statistical Signal and Array Processing, 2000. Proceedings of the Tenth IEEE Workshop on, 2000, 281 -285.

[28] S. Stanic, C. K. Kirkendall, A. B. Tveten, and T. Barock, "Passive Swimmer Detection", NRL REVIEW 2004 [Online], available at: http://www.nrl.navy.mil /research/\%20nrl-review/2004/acoustics/stanic/.

[29] D. Carevic, "Detection and Tracking of Underwater Targets Using Directional Sensors", Proceedings of Intelligent Sensors, Sensor Networks and Information, 2007 3rd International Conference, 2007, pp. 143-148.

[30] A. Maguer, et al., "Receiving and transmitting acoustic systems for AUV/gliders", NURC-PR-2009-004, Proceedings of Underwater Acoustic Measurements: Technologies and Results, 2009 3rd International Conference and Exhibition, 2009, pp. 1-12.

[31] United Stated Coast Guard (G-OPC), "Environment Assessment of the Installation and Operation of an Integrated Anti-swimmer System”, San Pedro, California, May, 2005. Available at: http://www.uscg.mil/hq/cg4/cg47/docs/FinalIAS-SanPedro.pdf.

[32] Chandrasekhar, V., Seah, W. K., Choo, Y. S. and Ee, H. V., "Localization in underwater sensor networks: survey and challenges", Proceedings of the 1st ACM international workshop on Underwater networks, ACM, 2006, 33-40.

[33] Anti-terrorist diver detection system to be evaluated by US Navy, QinetiQ's Cerberus system for ship and port protection, May, 2010, available at: http://www.qinetiq.com/home/newsroom/news_releases_homepage/2004/2nd_quarter/cer berus.html.

[34] Morrissey, R., Ward, J., DiMarzio, N., Jarvis, S. and Moretti, D., "Passive acoustic detection and localization of sperm whales in the tongue of the ocean", Applied Acoustics, 2006, 67, 1091 - 1105. 
[35] Northrop Grumman Global Security, available at: http://www.northropgrummang lobalsecurity.com/.

[36] Brian Bingham, "An analytical framework for predicting the performance of autonomous underwater vehicle positioning," Proceedings of the Unmanned Untethered Submersible Technology Conference. August, 2009.

[37] SeaBotix LBV 150 (San Diego, CA), available at: http://www.seabotix.com/ products/lbv150-4.htm.

[38] Hydrophone Type 8103, available at: http://www.bksv.com/products/transducersc onditioning/acoustictransducers/hydrophones/8103.aspx.

[39] Aquarian Audio Products H1a Hydrophone (Anacortes, WA), available at: http://www.aquarianaudio.com/product.php?productid=2.

[40] Voltage Preamplifier EC 6081/VP 2000, available at: http://www.reson.com/wp content/uploads/2010/12/EC6081.pdf.

[41] IOtech USB-based Personal Daq/3000 Series, available at: http://www.mccdaq.com/ products/pdaq3s.htm.

[42] Adian, R. J., "Particle-imaging Techniques for Experimental Fluid Mechanics", Annual Review of Fluid Mechanics, 1991, 23, 261-304.

[43] Olsen, M. G. and Adrian, R. J., "Brownian motion and correlation in particle image velocimetry", Optics \& Laser Technology, 2000, 32, 621 - 627.

[44] Cho, S., Lee, C. W., La, H. S., Na, J. and Kang, D., "Observations of underwater sound: Wave breaking noise in the beach and cliff zone", Pacific Rim Underwater Acoustics Conference, 2007.

[45] Mitson, R. B., "Underwater noise of research vessels", Cooperative Research Report No. 209, 1995.

[46] Wang, Q., Yan, K. and Li, H., "Motor Noise Source Identification Based on Frequency Domain Analysis", Proceedings of the 2009 IEEE International Conference on Mechatronics and Automation, 2009, 2373-2377.

[47] Cochard, N., Lacoume, J., Arzelies, P. and Gabillet, Y., "Underwater acoustic noise measurement in test tanks", Oceanic Engineering, IEEE Journal of, 2000, 25, 516 -522. 
[48] Birkedal Nielsen, S. and Celestinos, A., "Low Frequency Sound Field Enhancement System for Rectangular Rooms using Multiple Low Frequency Loudspeakers", Journal of Audio Engineering Society convention 120, 2006, 6688.

[49] Cai, M., Sou, I. M., Layman, C., Bingham, B. and Allen, J., "Characterization of the acoustic signature of a small remotely operated vehicle for detection", Proceedings of OCEANS 2010, 2010, 1 -7.

[50] Cai, M. and Bingham, B., "Passive Acoustic Detection of a Small Remotely Operated Vehicle" (In press), Proceedings of OCEANS Santander 2011, 2011, 1-7. 


\section{LIST OF APPENDICES}

\section{A. Basic Code of Developed Applications}

\section{$\% \%$ Prediction in different noise environments}

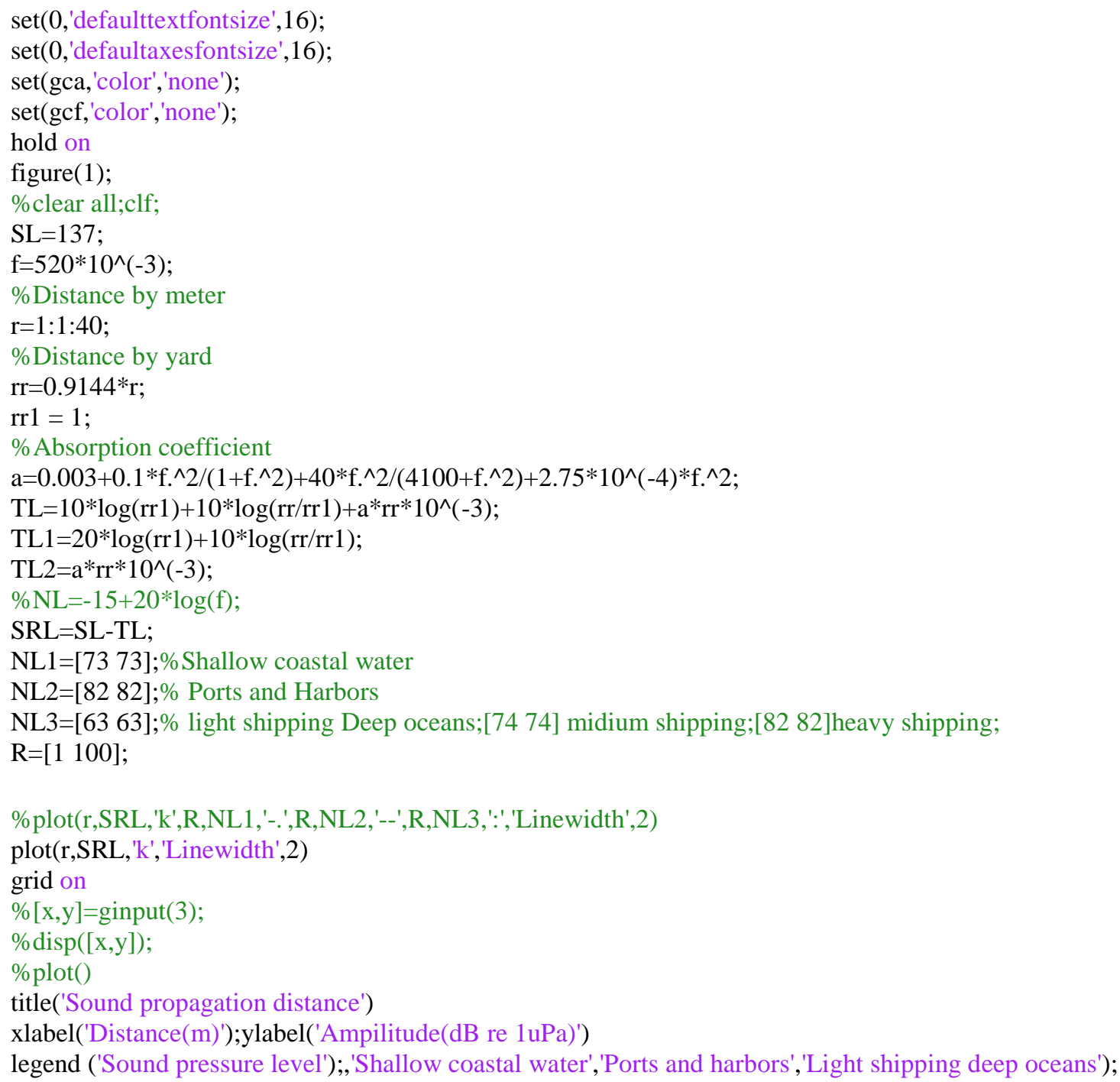

$\% \%$ GPS Distance and sound ampilitude level

$\operatorname{set}(0$, 'defaulttextfontsize',16);

$\operatorname{set}(0$, 'defaultaxesfontsize',16);

set(gca,'color','none');

set(gcf,'color','none');

set(gcf, 'renderer', 'painters');

$\%$ clf; 


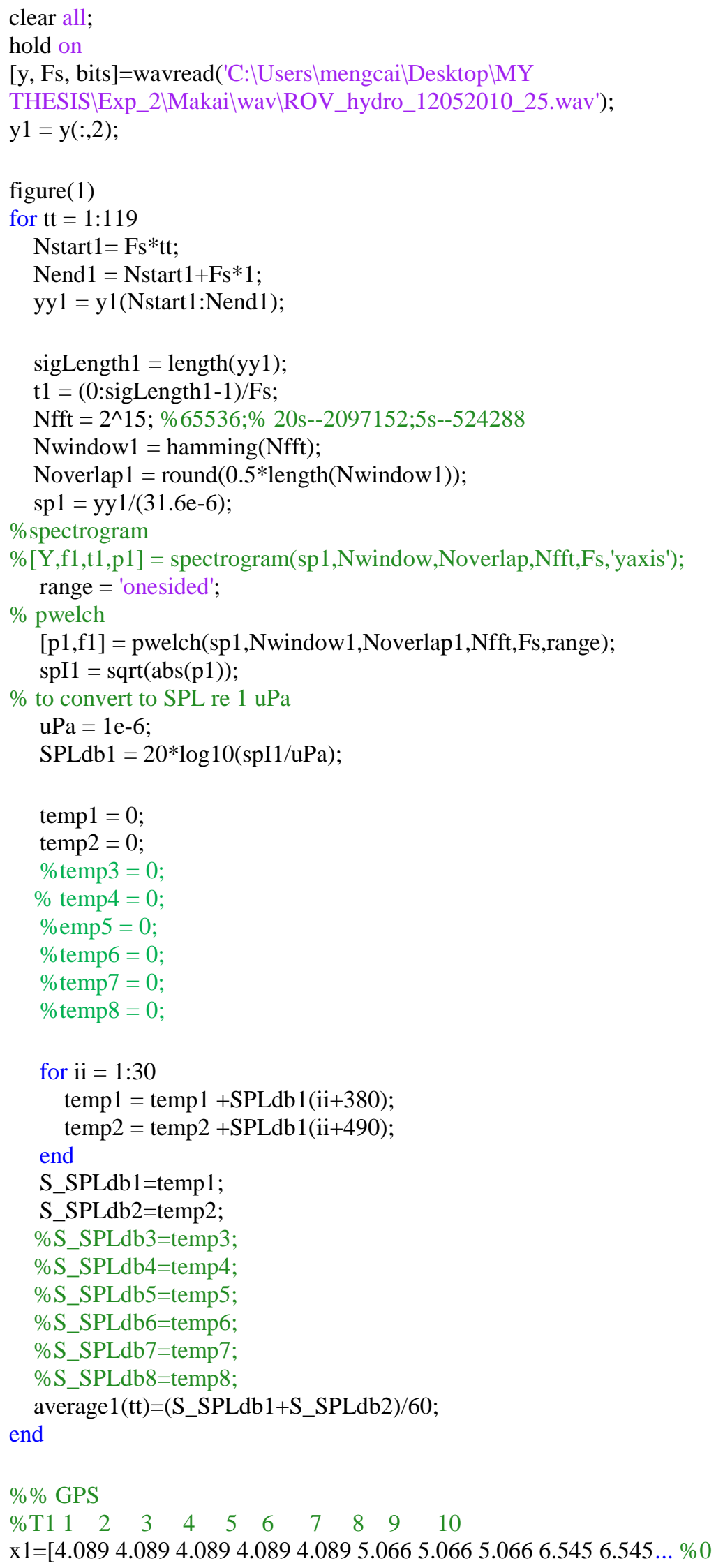


$7.5987 .5987 .5989 .0439 .04310 .1310 .1310 .1310 .1311 .56 \ldots \% 1$ $12.6612 .6612 .6615 .2015 .2015 .2015 .2016 .4216 .4217 .73 \ldots \% 2$ $17.7318 .9518 .9518 .9520 .2621 .4821 .4821 .4821 .4824 .01 \ldots \% 3$ $24.0124 .0125 .3325 .3326 .5326 .5327 .8627 .8627 .8629 .07 \ldots \% 4$ $30.3930 .3930 .3930 .3930 .3930 .3932 .9332 .9832 .9832 .98 \ldots \% 5$ $32.9332 .9332 .9335 .4635 .4635 .4637 .9937 .9937 .9937 .99 \ldots \% 6$ $37.9939 .3740 .5240 .5240 .5240 .5240 .5240 .5241 .9041 .90 \ldots \% 7$ $41.9041 .9041 .9041 .9041 .9041 .9041 .9041 .9041 .9041 .90 \ldots \% 8$ $41.9041 .9041 .9041 .9041 .9041 .9041 .9041 .9041 .9041 .90 \ldots \% 9$ $41.9041 .9043 .3143 .3143 .3143 .3143 .3143 .3143 .3143 .31 \ldots \% 10$ 43.3143 .3143 .3143 .3143 .3143 .3143 .3143 .3143 .3143 .31 ]; \%11

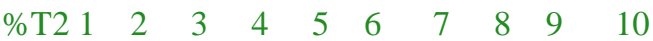

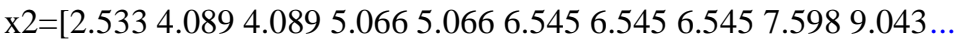
$9.0439 .04310 .1311 .5611 .5611 .5612 .6614 .0814 .0815 .20 \ldots$ $16.6016 .6017 .7317 .7319 .1319 .1320 .2620 .2621 .6621 .66 \ldots$ $22.8022 .8022 .8025 .3325 .3325 .3326 .7127 .8627 .8627 .86 \ldots$ $30.3930 .3930 .3930 .3930 .3931 .6031 .6031 .6032 .9332 .93 \ldots$ $32.9334 .1334 .1335 .4635 .4635 .4635 .4635 .4635 .4635 .46 \ldots$ $35.4635 .4635 .4635 .4635 .4635 .4635 .4635 .4636 .8436 .84 \ldots$ $36.8436 .8436 .8436 .8436 .8438 .2538 .2538 .2538 .2538 .25 \ldots$ $39.3739 .3739 .3739 .3739 .3739 .3739 .3739 .3739 .3739 .37 \ldots$ $39.3739 .3739 .3739 .3739 .3739 .3740 .7841 .9041 .9041 .90 \ldots$ $41.9041 .9041 .9041 .9041 .9041 .9041 .9041 .9041 .9041 .90 \ldots$ 41.9041 .9041 .9041 .9043 .3143 .3143 .3143 .3143 .3143 .31 ];

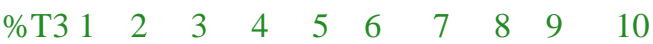

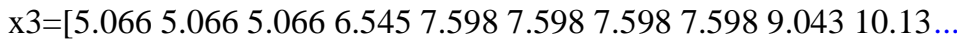
$10.1310 .1311 .5611 .5612 .6612 .6612 .6614 .0814 .0814 .08 \ldots$ $14.0815 .2016 .6016 .6019 .1319 .1319 .1321 .6621 .6621 .66 \ldots$ $21.6624 .1824 .1824 .1825 .6326 .7126 .7126 .7126 .7126 .71 \ldots$ $29.2429 .2429 .2429 .2431 .7731 .7731 .7731 .7734 .3134 .31 \ldots$ $34.3135 .7335 .7335 .7335 .7336 .8436 .8438 .2538 .2538 .25 \ldots$ $39.3739 .3739 .3740 .7840 .7840 .7840 .7840 .7840 .7841 .90 \ldots$ $41.9041 .9041 .9041 .9041 .9041 .9041 .9041 .9041 .9041 .90 \ldots$ $41.9041 .9041 .9041 .9041 .9041 .9041 .9041 .9040 .5240 .52 \ldots$ $40.5240 .5240 .5240 .5240 .5240 .5240 .5240 .5240 .5240 .52 \ldots$ $40.5241 .7241 .7241 .7241 .7241 .7240 .5240 .5240 .5240 .52 \ldots$ 40.5240 .5240 .5240 .5240 .5237 .9935 .4635 .4635 .46 35.46];

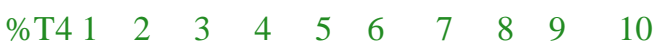

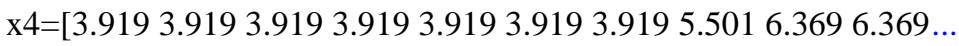
$6.3696 .3697 .8388 .8668 .8668 .86610 .2711 .3811 .3811 .38 \ldots$ $13.9013 .9013 .9015 .23 \quad 15.2315 .2316 .4216 .4216 .4216 .42 \ldots$ $17.7317 .7317 .7317 .7317 .73 \quad 17.7317 .7318 .9518 .9521 .48 \ldots$ $21.4821 .4821 .4821 .4821 .4822 .8024 .0125 .3325 .3325 .33 \ldots$ $25.3325 .3326 .7127 .8627 .8629 .2429 .2429 .2429 .2429 .24 \ldots$ $29.2429 .2429 .2429 .2429 .2429 .2430 .6830 .6830 .6830 .68 \ldots$ $30.6830 .6830 .6830 .6830 .6830 .6830 .6830 .6830 .6830 .68 \ldots$ $31.7731 .7731 .7731 .7731 .7731 .7731 .7731 .7733 .2033 .20 \ldots$ $33.2033 .2033 .2033 .2033 .2033 .2033 .2033 .2033 .2033 .20 \ldots$ $33.2033 .2033 .2033 .2033 .2033 .2033 .2034 .3134 .3134 .31 \ldots$ 34.31 34.31 34.31 34.31 34.31 34.31 34.31 34.31 34.31 34.31];

$\% \%$ 


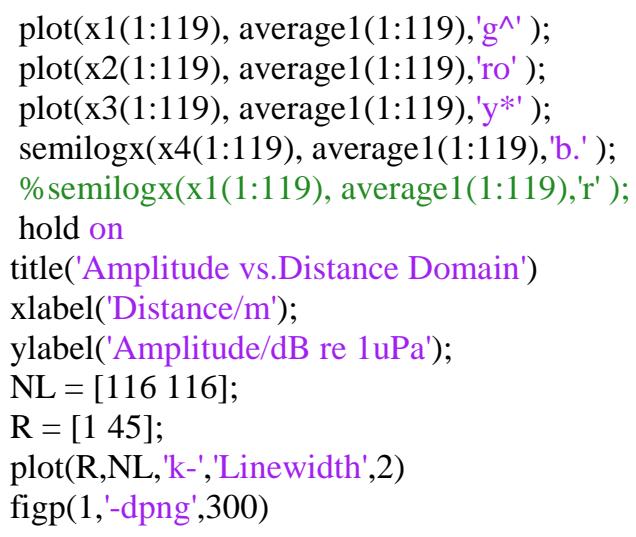

\section{B. Photography (Related setups)}

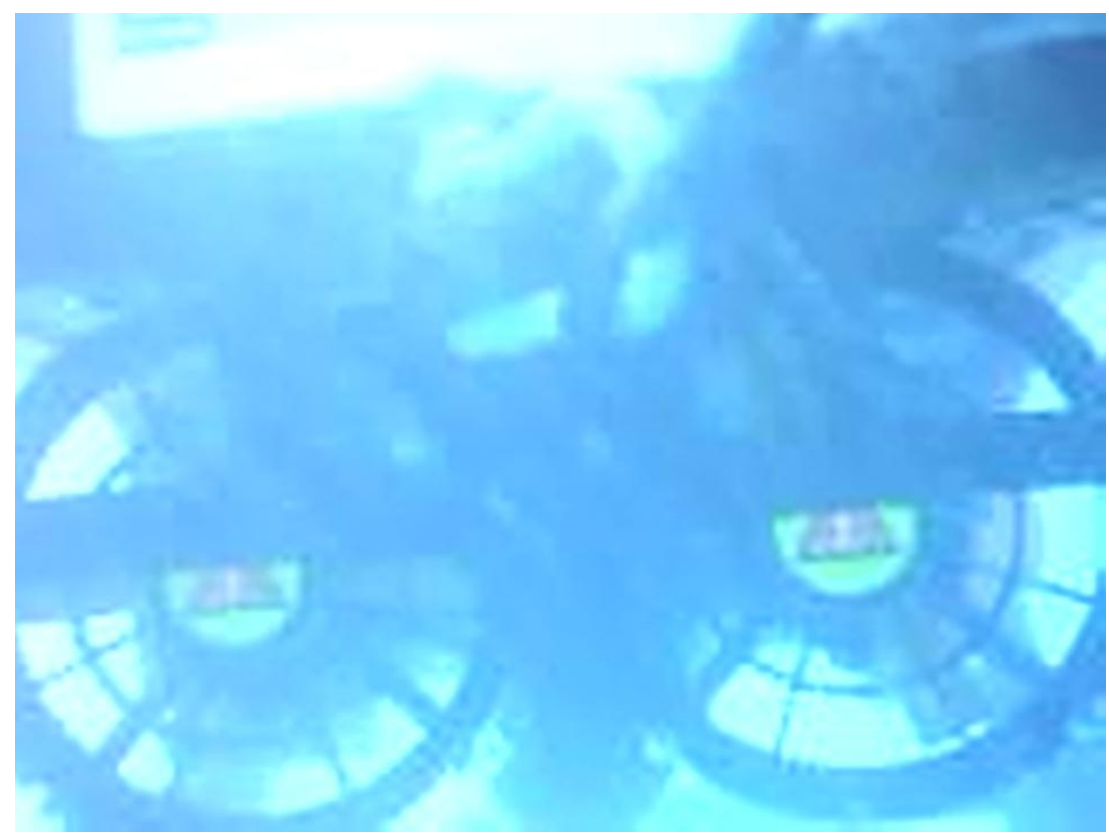

Figure B.1 ROV running with propellers when testing in the outdoor tank 


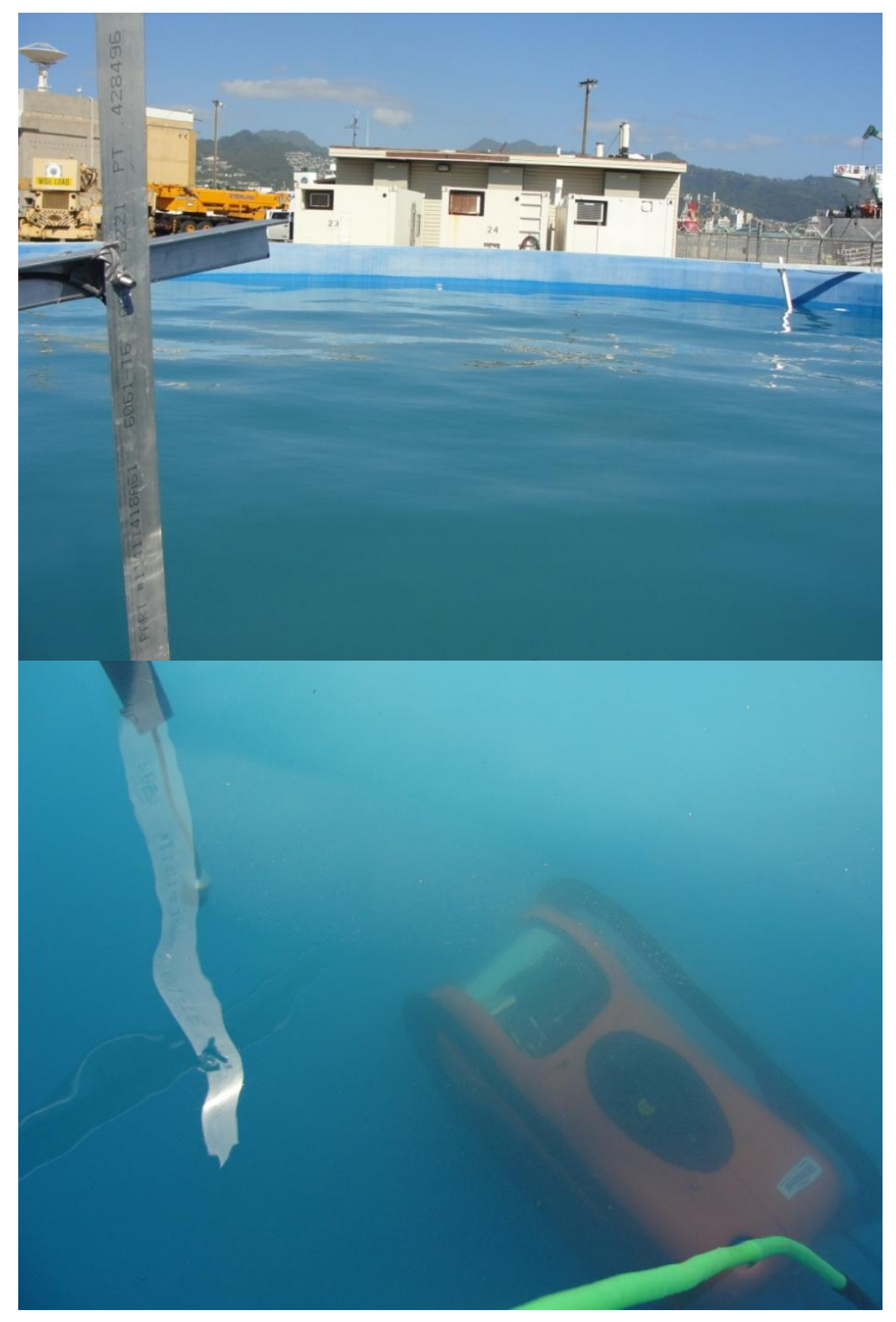

Figure B.2 The experimental setup in the outdoor tank imported by a two hydrophone tied to the post and a ROV. 


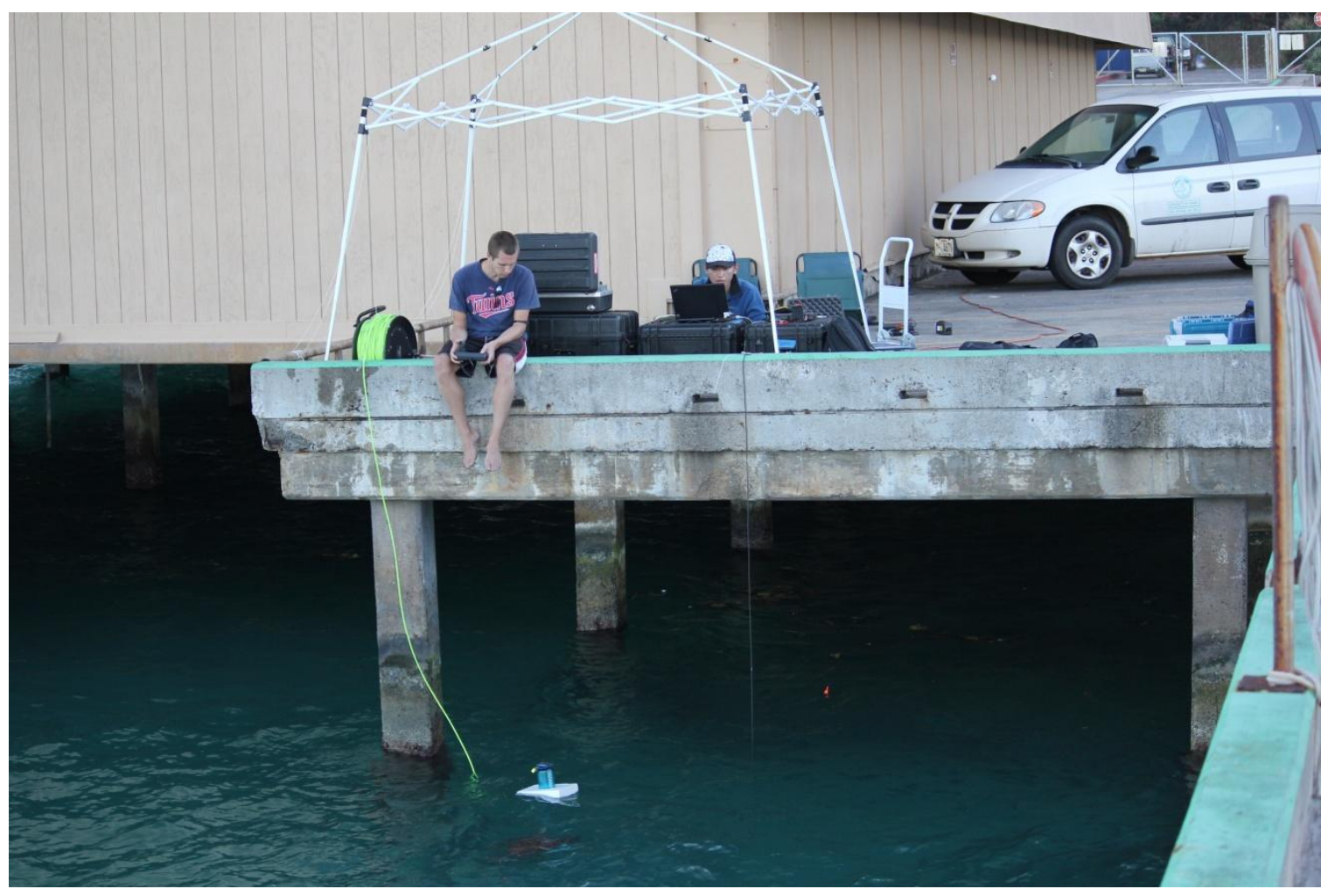

Figure B.3 The experimental process when testing at Makai pier, Hawaii. (Left is Nicholas Kraus, right is Meng Cai) 